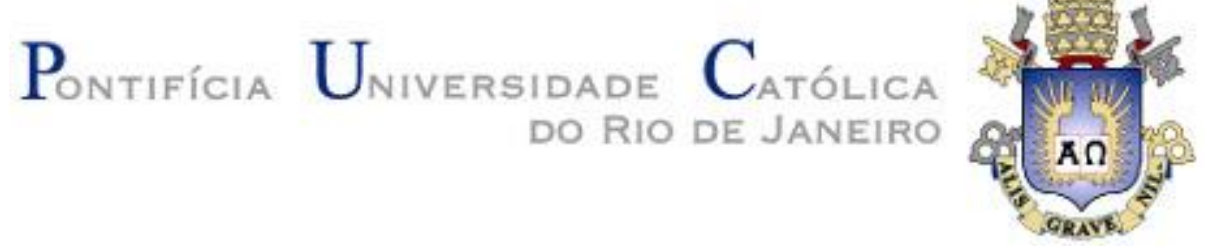

Omar Elías Horna Pinedo

Projeto e Qualificação de um Aparato para o

Estudo Experimental de Bolhas de Separação Laminar

Dissertação de Mestrado

Dissertação apresentada ao Programa de Pósgraduação em Engenharia Mecânica da PUC-Rio como requisito parcial para obtenção do grau de Mestre em Engenharia Mecânica.

Orientador: Prof. Igor Braga de Paula

Rio de Janeiro

Outubro de 2018 


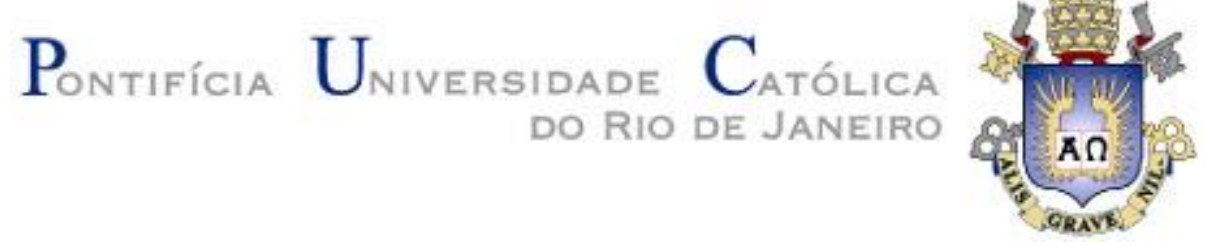

Omar Elías Horna Pinedo

\title{
Projeto e Qualificação de um Aparato para o Estudo Experimental de Bolhas de Separação Laminar
}

Dissertação apresentada como requisito parcial para obtenção do grau de Mestre pelo Programa de PósGraduação em Engenharia Mecânica do Centro Técnico Científico da PUC-Rio. Aprovada pela Comissão Examinadora abaixo assinada.

\author{
Prof. Igor Braga de Paula \\ Orientador \\ Departamento de Engenharia Mecânica - PUC-Rio
}

Prof. Luiz Fernando Alzuguir Azevedo

Departamento de Engenharia Mecânica - PUC-Rio

Prof. Daniel Rodríguez Álvarez

Escola de Engenharia - UFF

Prof. Márcio da Silveira Carvalho

Coordenador Setorial do Centro

Técnico Científico - PUC-Rio

Rio de Janeiro, 3 de outubro de 2018 
Todos os direitos reservados. É proibida a reprodução total ou parcial do trabalho sem autorização da universidade, do autor e do orientador.

\section{Omar Elias Horna Pinedo}

Graduou-se em Engenharia Mecânica pela Universidade Nacional de Trujillo, UNT, Perú (2013). Concluiu o curso de Mestrado em Engenharia Mecânica na Pontifícia Universidade Católica do Rio de Janeiro, PUC-Rio (2018). Atualmente faz Doutorado nessa mesma Universidade. Trabalha na área de Termociências, Linha de Pesquisa Engenharia de Fluidos orientado ao campo da Aerodinâmica.

Ficha Catalográfica

Horna Pinedo, Omar Elías

Projeto e qualificação de um aparato para o estudo experimental de bolhas de separação laminar / Omar Elías Horna Pinedo; orientador: Igor Braga de Paula. - 2018.

127 f. : il. color. ; $30 \mathrm{~cm}$

Dissertação (mestrado)-Pontifícia Universidade Católica do Rio de Janeiro, Departamento de Engenharia Mecânica, 2018.

Inclui bibliografia

1. Engenharia Mecânica - Teses. 2. Bolhas de separação laminar. 3. Instabilidade hidrodinâmica. 4. Velocimetría Laser Doppler. 5. Velocimetría por imagens de partículas. I. Paula, Igor Braga de. II. Pontifícia Universidade Católica do Rio de Janeiro. Departamento de Engenharia Mecânica. III. Título. 


\section{Agradecimentos}

Após terminar este projeto e parar por um momento para contemplar esta caminhada, só posso sentir satisfação e gratidão por tudo o que aprendi. Há várias pessoas que gostaria de agradecer, que me motivaram, me formaram e facilitaram o caminho para que possa ter está grande satisfação pessoal e a oportunidade de alcançar um grau significativo de formação acadêmica. Quero agradecer aos meus pais Andrés e Aurora, por ter me dado tudo o que lhes fosse possível dar apesar do que isso poderia ter significado para eles. A minhas irmãs pela alegria de ter compartilhado o mesmo lar e por seu apoio incondicional mesmo com a distância. A meu professor Guillermo Quevedo, por ter me mostrado o maravilhoso caminho da ciência e da literatura, por ter me resgatado e levado até elas, e por ter acreditado em mim. Ao professor Giovanni Zucchi, por ser esse referente acadêmico e fonte de inspiração, e por sua mensagem simples, mas poderosa: "não tenham medo". Quero agradecer ao meu orientador Prof. Igor Braga por ter me introduzido neste maravilhoso ramo da ciência e da engenharia que envolvem os fenômenos de instabilidade hidrodinâmica e transição de escoamentos separados, pelo desafio que representa e a oportunidade que significa, para redescobrir e decifrar alguns dos mecanismos íntimos que governam a dinâmica dos fluidos; pelo suporte e por não poupar esforços quando se trata de resolver algum problema que de momento encontrasse mais além dos meus conhecimentos. A Pedro Panisset, pelas inúmeras vezes que trabalhamos no laboratório resolvendo as dificuldades técnicas que foram apresentando-se ao longo do desenvolvimento deste trabalho, e por seu importante ajuda no processo de aquisição e post processamento dos dados. Quero agradecer ao pessoal técnico do Laboratório de Engenharia de Fluidos da PUC-Rio, Marcio e Alexandre por seu acurado trabalho na fabricação da bancada experimental. A Fabio Martins e Mike Valente, por sua contribuição no desenho da placa plana. Aos pesquisadores Leonardo Soares e Luciana Boher, que estão sempre dispostos a compartilhar a sua experiência. A Javier Aliaga, por sua inestimável colaboração ao longo dos diversos estágios deste trabalho. A Juan Jose, pela motivação e apoio inicial para concretizar este projeto acadêmico quando era apenas uma possibilidade. E aos novos amigos que conheci, que fizeram e ainda fazem minha estância mais agradável, grato por sua companhia e amizade: Martin Santacatterina, 
Monique Feitosa, Gisele Diaz, Rodrigo Navarro, Loren Alford, Suzane Pereira, Daniele Diaz, Gabriela Castro.

De uma maneira especial quero agradecer ao povo brasileiro, a todos aqueles que acreditam na educação como uma forma de mudar as pessoas e transformar o mundo.

O presente trabalho foi realizado com apoio da Coordenação de Aperfeiçoamento de Pessoal de Nível Superior - Brasil (CAPES) - Código de Financiamento 001 


\section{Resumo}

Horna Pinedo, Omar Elías; de Paula, Igor Braga. Projeto e Qualificação de um Aparato para o Estudo Experimental de Bolhas de Separação Laminar. Rio de janeiro, 2018. 127p. Dissertação de Mestrado Departamento de Engenharia Mecânica, Pontifícia Universidade Católica do Rio de Janeiro.

O presente trabalho consiste no projeto, construção e qualificação de um aparato para o estudo experimental de bolhas de separação laminar sobre uma placa plana. A previsão do comportamento das bolhas de separação é importante para o projeto de aeronaves, turbinas e geradores eólicos, pois o desprendimento dessas bolhas tem grande impacto na performance de aerofólios. A dinâmica das bolhas não é bem compreendida, além de ser difícil de ser capturada por simulações numéricas que utilizam modelagem da turbulência. Por isso, ensaios experimentais são muito utilizados para a calibração dos modelos utilizados em simulações de engenharia. Neste trabalho, foram criados equipamentos para simular experimentalmente bolhas de separação laminar sobre uma placa plana. Os dispositivos foram projetados para o canal de água do Laboratório de Engenharia de Fluidos da PUC-Rio. O gradiente de pressão necessário para induzir a separação da camada limite e consequente formação da bolha foi ajustado com uma parede falsa, de modo a criar um canal convergente-divergente com a placa plana. Foi projetado um mecanismo de sucção da camada limite na parede falsa para evitar a separação do escoamento nessa superfície. A localização e as vazões de cada ponto de sução foram determinadas com o auxílio de simulações numéricas. Também foi projetado e testado um sistema de sopro e sucção para a excitação de ondas de instabilidade do tipo Tollmien-Schlichting na camada limite da placa plana. O funcionamento de cada dispositivo foi avaliado através da medição da velocidade do escoamento. Para isso, foram empregadas técnicas de medição por velocimetría laser doppler e velocimetría por imagem de partículas. Os resultados obtidos validam o projeto e qualificam o aparato para o estudo de bolhas de separação laminar.

\section{Palavras-chave}

Bolhas de Separação Laminar; Instabilidade Hidrodinâmica; Velocimetría Laser Doppler; Velocimetría por Imagens de Partículas. 


\section{Abstract}

Horna Pinedo, Omar Elías; de Paula, Igor Braga (Advisor). Design and Qualification of an Apparatus for the Experimental Study of Laminar Separation Bubbles. Rio de Janeiro, 2018. 127p. Dissertação de Mestrado Departamento de Engenharia Mecânica, Pontifícia Universidade Católica do Rio de Janeiro.

The present work involves the design, construction and performance test of an apparatus for the investigation of laminar separation bubbles in a flat plate boundary layer. Laminar separation bubbles are relevant for many engineering applications and the dynamic of such bubbles has a strong impact on the performance of aircrafts and turbines. The separated boundary layer reattaches to the surface due to the laminar-turbulent transition in the bubble region. This dynamic process is highly challenging for flow simulation tools used for engineering purposes. Thus, there is a demand for experimental studies that can be used for calibration of models present in those simulation tools. To this end, an apparatus was designed and built for the water channel of the Laboratory of Fluid Engineering at PUC-Rio. The boundary layer separation on the flat plate was induced by imposing a constant adverse pressure gradient to the flow. To this end a false wall was built, in order to form a converging-diverging channel with the flat plate. Flow separation on the false wall was avoided using a suction mechanism that was designed to reduce locally the boundary layer thickness. Location of suction and suction flow rates were determined with aid of numerical simulations. In addition, it was designed and built a disturbance source to generate TollmienSchlichting waves in the boundary layer of the flat plate. This device was used to trigger the boundary layer transition in a controlled manner. All equipment were tested and their designs were validated against experimental measurements. Laser Doppler anemometry and Particle Image Velocimetry techniques were adopted for assessment of each equipment. Results validate the design and show that separation bubbles can be investigated in detail using this apparatus.

\section{Keywords}

Laminar Separation Bubbles; Hydrodynamic Instability; Laser Doppler Velocimetry; Particle Image Velocimetry. 


\section{Sumário}

1 Introdução 23

1.1. Motivação 23

1.2. Objetivos do trabalho 28

$\begin{array}{ll}\text { 1.3. Organização do trabalho } & 28\end{array}$

2 Revisão bibliográfica $\quad 29$

2.1. Camada limite 29

2.1.1. Camada limite sobre uma placa plana 30

2.1.2. Crescimento da camada limite 31

2.1.3. Influência do gradiente de pressão sobre a camada limite 33

2.1.4. Separação da camada limite 34

2.1.5. Critério de separação 34

2.1.6. Métodos de controle da separação da camada limite, ativos e passivos 35

2.1.6.1. Geradores de Vórtices: 36

2.1.6.2. Sucção da camada limite 37

2.1.6.3. Jato sintético controlado (Injeção e Sopro oscilatório) 39

2.2. Instabilidade Hidrodinâmica e Transição de Escoamentos

Separados 40

2.2.1. Receptividade de fluxos separados às perturbações externas 41

2.2.2. Instabilidade linear 43

2.3. Bolhas de Separação Laminar 48

2.3.1. Bolhas de separação laminar curta e longa 49

2.3.2. Estouro de uma Bolha de Separação laminar, "Bursting" 50

2.4. Abordagem proposta 51

3 Construção do aparato 52

3.1 Cálculos Preliminares 52

3.1.1. Cálculo dos pontos de sucção 53

3.1.2. Simulação Numérica 56 
3.1.2.1. Modelo SST transition

3.1.2.2. Teste de Malha 58

3.1.2.3. Resultados da Simulação 63

3.2. Placa plana 68

3.3. Imposição do gradiente de pressão $\quad 70$

3.4. Excitação artificial de ondas de instabilidade $\quad 71$

3.5. Montagem 74

4 Metodologia experimental $\quad 75$

4.1 Canal de água 75

4.2 Técnicas Experimentais $\quad 77$

4.2.1 Velocimetría a Laser Doppler 77

4.2.1.1 Aspectos gerais da técnica 78

4.2.1.2 Princípio de funcionamento 78

4.2.2 Velocimetría por Imagem de Partículas 82

4.2.2.1 Aspectos gerais da técnica 82

4.2.2.2 Princípio de funcionamento 83

4.3 Procedimento experimental 88

4.3.1 Aquisição de dados com a técnica LDV 88

4.3.2 Aquisição de dados com a técnica PIV 92

4.3.2.1 Fonte de iluminação 93

4.3.2.2 Câmera 93

4.3.2.3 Sincronizador $\quad 94$

4.3.2.4 Arranjo experimental para a medição das BSL 95

4.3.2.5 Medição das vazões de sucção 96

4.3.2.6 Partículas traçadoras 98

4.3.2.7 Calibração 99

5 Resultados 101

5.1 Verificação do Escoamento sobre a placa plana 101

5.2 Avaliação da Sucção e Sopro Oscilatório 106

5.3 Avaliação da sucção da camada limite 107

5.4 Avaliação da Bolha de Separação laminar 112

5.4.1 Validação do fenômeno 113 
6 Conclusões e recomendações

7 Referências bibliográficas 


\section{Lista de figuras}

Figura 1.1 Motor aeronáutico GE9X da GE Aviation, a turbina é mostrada em cor vermelho e está constituída por duas partes, o estágio da turbina de baixa pressão corresponde à parte maior.

Figura 1.2 Perda de pressão numa LPT, adaptado de Sharma (1998).

Figura 2.1 Representação esquemática da camada limite sobre um aerofólio. Adaptado de Pijush K. Kundu (2008).

Figura 2.2 Representação esquemática da espessura de deslocamento.

Figura 2.3 Representação esquemática da espessura de momentum.

Figura 2.4. Perfis de velocidade ao longo da camada limite com gradiente de pressão favorável e adverso. Adaptado de Pijush K. Kundu (2008).

Figura 2.5 Linhas de corrente e perfis de velocidade perto do ponto de separação " $S$ ", o ponto de inflexão é indicado por " $I$ ". A linha tracejada representa $u=0$. Adaptado de Pijush K. Kundu (2008).

Figura 2.6. Camada limite em um canal divergente (difusor) com fluxo externo $U(x)$ da equação (2.17). Adaptado de Schlichting, H. (1979).

Figura 2.7 Gerador de vórtices perto do bordo de ataque da asa de um avião Boeing 737-800. O sentido do fluxo e a posição das aletas estão indicadas pelas setas. Tomado de: http://www.boldmethod.com Figura 2.8 Perfis de velocidade desenvolvidos baixo um gradiente de pressão adverso. Em cor azul pode-se observar as mudanças no perfil após a sucção através da parede, retirado de T. Van der Hoeven (2013).

Figura 2.9 (a) Bocal divergente sem sucção da camada limite, (b) Bocal divergente com sucção da camada limite. Schlichting, H (1979).

Figura 2.10 Simulação de um Jato sintético injetado no interior da camada limite para o atraso do ponto de separação. Adaptado de: (http://num3sis.inria.fr/blog/synthetic-jet-simulations/)

Figura 2.11 Instabilidade e transição para turbulência em uma Bolha de Separação Laminar. Dovgal A. V. et al. (1994).

Figura 2.12 Geração acústica de ondas de instabilidade em um fluxo separado sobre um aerofólio. Onde, Cp: distribuição de pressão e uf': 
crescimento das perturbações excitadas. Retirado de Dovgal A. V. et al. (1994).

Figura 2.13 Curva de estabilidade neutra para ondas de

Tollmien-Schlichting bidimensionais (linha continua) e tridimensionais

(linha tracejada). Adaptado de, De Paula, I. B. (2006).

Figura 2.14 Esquema de uma Bolha de Separação Laminar, Horton (1969).

Figura 2.15 Distribuição de Cp sobre um aerofólio com uma bolha de separação laminar, Russel (1979).

Figura 3.1 Esquema do Aparato para o estudo das Bolhas de Separação laminar. Onde $\alpha$ é o ângulo de convergência e $\beta$ o ângulo de divergência.

Figura 3.2 Localização dos pontos de sucção ao longo da placa divergente 53 Figura 3.3 Queda de pressão ao longo da placa, considerando um fluxo ideal. 54 Figura 3.4 Déficit de pressão imposto para gerar a sucção do escoamento, Vsucção é a velocidade de sucção e $\rho g \Delta$ h é o déficit de pressão na coluna hidrostática.

Figura 3.5 Correlação entre $\mathrm{T}_{\mathrm{u}}$ e $\lambda_{\theta}$. Abu-Gannam e Shaw (1980)

Figura 3.6 (a) Vista frontal da malha, (b) refinamento da superfície superior

(c) refinamento da superfície inferior.

Figura 3.7 Condições de contorno sobre o domínio computacional

Figura 3.8 Distribuição da velocidade ao longo de uma linha horizontal no interior da bolha para diferentes configurações de malha. (A seguir, $\mathrm{x}=0$ encontra-se no extremo inferior esquerdo do domínio computacional)

Figura 3.9 Perfis de velocidade tomados a montante do ponto de separação, na posição $\mathrm{x}=400 \mathrm{~mm}$.

Figura 3.10 Quadro de linhas de corrente no interior da região formada pelas placas. O fluxo de entrada é laminar

Figura 3.11 Bolha de separação laminar sobre a superfície da placa plana

Figura 3.12 Quadro de linhas de corrente no interior da região formada pelas placas, para o caso sem sucção da camada limite.

Figura 3.13 Quadro de linhas de corrente no interior da região formada pelas placas, para um fluxo de entrada turbulento

Figura 3.14 Ampliação da região perto da parede, onde se verifica que a bolha não foi formada 
Figura 3.15 Influência da bolha de separação na distribuição da pressão 67

Figura 3.16 Desenho do conjunto da placa plana

Figura 3.17 Desenho do bordo de ataque, baseado em um perfil de dupla elipse

Figura 3.18 Posição da fenda sobre a placa plana 69

Figura 3.19 Desenho da placa convergente - divergente 71

Figura 3.20 (a) bomba de seringa, (b) peça encarregada de gerar o jato 72

Figura 3.21 Dinâmica da inserção de ondas de instabilidade 72

Figura 3.22 Localização do ponto de inserção de ondas de instabilidade 73 Figura 3.23 Arranjo experimental projetado para o estudo das bolhas de separação laminar

Figura 3.24 Aparato experimental fabricado e montado no canal de agua para o estudo das bolhas de separação laminar

Figura 4.1 Canal de água do laboratório de Engenharia de Fluidos da PUC-Rio.

Figura 4.2 Secção de testes do canal de água no laboratório de Engenharia de Fluidos da PUC-Rio.

Figura 4.3 Curva de calibração da velocidade na secção de testes do canal de agua

Figura 4.4 Esquema do padrão de franjas de interferência formado na interseção dos feixes incidentes. O espaçamento entre franjas é df. Retirado de http://www.tsi.com/

Figura 4.5 Parâmetros geométricos do volume de medição. Adaptado de http://www.tsi.com

Figura 4.6 Dispersão de luz por uma partícula passando através do volume de medição do LDV. Retirado de http://www.tsi.com/

Figura 4.7 Acondicionamento do sinal (a) aquisição de dados, (b) filtro passa banda, no domínio das frequências (c) reconversão ao domínio do tempo. Figura 4.8 Desenho esquemático de um sistema PIV Bidimensional de dois componentes. Adaptado de Raffel et al. (2007)

Figura 4.9 Parâmetros envolvidos no registro de imagens PIV. Adaptado de Raffel et al. (2007) 
Figura 4.10 Exemplo de resultado obtido por correlação cruzada.

Adaptado de Törnblom (2004)

Figura 4.11 Esquerda: Módulo PowerSight laser Velocimeter,

Direita: Módulo PowerSight Controller. $\quad 88$

Figura 4.12 Arranjo experimental para o sistema LDV 89

Figura 4.13 Intersecção dos feixes do laser e formação do volume

de medição dentro do canal de água. $\quad 90$

Figura 4.14 Inclinação do modulo PowerSight Laser Velocimeter

e região de medição com o sistema LDA

Figura 4.15 Trajetória que recorre o volume de medição no processo de aquisição dos dados.

Figura 4.16 Correção do perfil de velocidade $\quad 92$

Figura 4.17 Laser, LITRON da série LDY-300 93

Figura 4.18 Arranjo experimental para a medição das bolhas de separação

laminar implementado no laboratório de engenharia de fluidos da PUC-Rio. 95

Figura 4.19 Vista lateral da região de medição, e visualização do

caminho ótico localizado na parte inferior do canal de água.

Figura 4.20 Vista frontal da região de medição.

Figura 4.21 Curva de calibração do medidor de vazão tipo turbina

Figura 4.22 (a) sistema de monitoração das vazões de sucção,

(b) montagem do sistema de bombeio

Figura 4.23 (a) alvo de calibração, (b) ajuste do alvo de calibração no plano de iluminação.

Figura 5.1 Sistema de coordenadas

Figura 5.2 Correspondência entre os dados experimentais (LDV)

e o perfil de Blasius para perfis medidos em diferentes posições

longitudinais ao longo da placa.

Figura 5.3 Fator de forma $\mathrm{H}=\delta^{*} / \theta$ ao longo da placa plana

Figura 5.4 Perfis de velocidade média ao longo de uma secção transversal ao fluxo, para a posição $\mathrm{x}=600 \mathrm{~mm}$ desde o bordo de ataque

Figura 5.5 Evolução do fator de forma na camada limite submetida a sucção e sopro oscilatório 
Figura 5.6 Contorno do componente " $u$ " de velocidade para a região do vértice, Esquerda: sem sucção. Direita: Qsucção $=1708 \mathrm{~L} / \mathrm{h}$

Figura 5.7 Campo vetorial de velocidade para a região do vértice,

Esquerda: sem sucção. Direita: Qsucção $=1708 \mathrm{~L} / \mathrm{h}$

Figura 5.8 Linhas de corrente para a região do vértice, Esquerda:

sem sucção. Direita: Qsucção $=1708 \mathrm{~L} / \mathrm{h}$

Figura 5.9 Contorno de vorticidade e campo de velocidade para a Janela 1,

Esquerda: sem sucção. Direita: Qsucção $=1708 \mathrm{~L} / \mathrm{h}$

Figura 5.10 Flutuação da velocidade, componente u' para a região do

vértice, Esquerda: sem sucção. Direita: Qsucção = 1708L $/ \mathrm{h}$

Figura 5.11 Flutuação da velocidade, componente v' para a região

do vértice, Esquerda: sem sucção. Direita: Qsucção $=1708 \mathrm{~L} / \mathrm{h}$

Figura 5.12 Regiões de medição para a verificação da sucção da camada

limite.

Figura 5.13 Linhas de corrente para a região de medição 2.

Qsucção $=835 \mathrm{~L} / \mathrm{h}$

Figura 5.14 Linhas de corrente para a região de medição 3.

Qsucção $=833 \mathrm{~L} / \mathrm{h}$

Figura 5.15 Linhas de corrente para a região de medição 4.

Qsucção $=400 \mathrm{~L} / \mathrm{h}$

Figura 5.16 Linhas de corrente para a região de medição 5.

Qsucção $=217 \mathrm{~L} / \mathrm{h}$

Figura 5.17 Comparação de resultados, imagens acima em verde:

Visualização de uma BSL no canal de água da PUC-Rio. Imagem em preto e branco: Visualização de fumaça de uma BSL sobre um aerofólio

Eppler 387. Retirado de Braun, S. \& Kluwick, A. (2005)

Figura 5.18 Reconstrução dos campos de velocidade média aquisitados

Figura 5.19 Contorno de velocidade média na bolha de separação laminar

Figura 5.20 Imagem ampliada do contorno de velocidade média da

bolha de separação laminar. Os três pontos marcados indicam as

regiões onde serão extraídos dados para um analise espectral.

Figura 5.21 Perfis da componente de velocidade média U, em diferentes posições ao longo da bolha. 
Figura 5.22 Derivada primeira (a) e segunda (b) do perfil de velocidade média U, em diferentes posições ao longo da bolha. 118

Figura 5.23 PSD das flutuações da velocidade em diferentes estações. $\quad 119$

Figura 5.24 Distribuição de energia para diferentes modos 119

Figura 5.25 Modos POD do escoamento na região de recolamento da bolha 120 


\section{Lista de tabelas}

Tabela 3.1 Posições dos pontos de sucção, e vazão de sucção,

$\operatorname{para} \beta=12^{\circ}$

Tabela 3.2 Parâmetros envolvidos na verificação do refinamento

longitudinal

Tabela 3.3 Parâmetros envolvidos na verificação do refinamento normal à parede

Tabela 3.4 Parâmetros da malha selecionada

63

Tabela 3.5 verificação da sucção para $\beta=7^{\circ}$

64

Tabela 3.6 Verificação da sucção para diferentes ângulos de divergência mantendo a vazão constante

Tabela 3.7 Características gerais da topologia da bolha para diferentes ângulos de divergência.

Tabela 4.1 parâmetros do sincronizador

Tabela 4.2 parâmetros envolvidos no cálculo da massa de partículas

99 


\section{Lista de Símbolos e Abreviaturas}

\begin{tabular}{|c|c|c|}
\hline & $\mathrm{K}$ & Ângulo do feixe do laser incidente \\
\hline & $\overline{\mathrm{a}}$ & Vetor aceleração do fluido \\
\hline & $\mathrm{u}$ & Componente da velocidade na direção $\mathrm{x}$ \\
\hline & $\mathrm{v}$ & Componente da velocidade na direção y \\
\hline & $\mathrm{C}_{\mathrm{p}}$ & Coeficiente de pressão \\
\hline & $\lambda_{\theta}$ & Coeficiente de gradiente de pressão de Thwaites \\
\hline & $\mathrm{S}$ & Comprimento da separação dos feixes do laser \\
\hline & $\mathrm{f}$ & Comprimento focal \\
\hline & $\lambda$ & Comprimento de longitude de onda \\
\hline & $\mathrm{Q}_{\text {sucção }}$ & Caudal de sucção \\
\hline & $\mathrm{D}_{\mathrm{e}^{-2}}$ & Diâmetro do feixe do laser \\
\hline ఏু & $d_{e^{-2}}$ & Diâmetro do feixe focalizado \\
\hline$\stackrel{2}{\varrho}$ & $\mathrm{z}_{0}$ & Distância da lente ao plano da imagem \\
\hline 茫 & $\mathrm{Z}_{0}$ & Distância da lente ao plano iluminado em foco \\
\hline 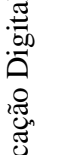 & $\Delta \overline{\mathrm{X}}$ & $\begin{array}{l}\text { Deslocamento das partículas em unidades de } \\
\text { comprimento }\end{array}$ \\
\hline : & $\rho$ & Densidade do fluido \\
\hline. & $\rho_{\mathrm{p}}$ & Densidade das partículas \\
\hline Јُ & $d_{p}$ & Diâmetro das partículas \\
\hline & $\Delta \mathrm{h}$ & Descenso no nível da agua, \\
\hline & $\delta$ & Espessura da camada limite \\
\hline & $\delta_{99}$ & Espessura da camada limite, quando $u=0.99 U_{\infty}$ \\
\hline & $\delta^{*}$ & Espessura de deslocamento \\
\hline & $\theta$ & Espessura de momentum \\
\hline & $\Delta_{\mathrm{z}}$ & Espessura do plano de iluminação \\
\hline & $\mathrm{d}_{\mathrm{f}}$ & $\begin{array}{l}\text { Espaçamento entre franjas dentro do volume de } \\
\text { medição }\end{array}$ \\
\hline & $P_{\theta t}$ & Fonte da equação de transporte de $\operatorname{Re}_{\theta t}$ \\
\hline & $f_{D}$ & Frequência Doppler \\
\hline & $\beta$ & Frequência da oscilação \\
\hline
\end{tabular}




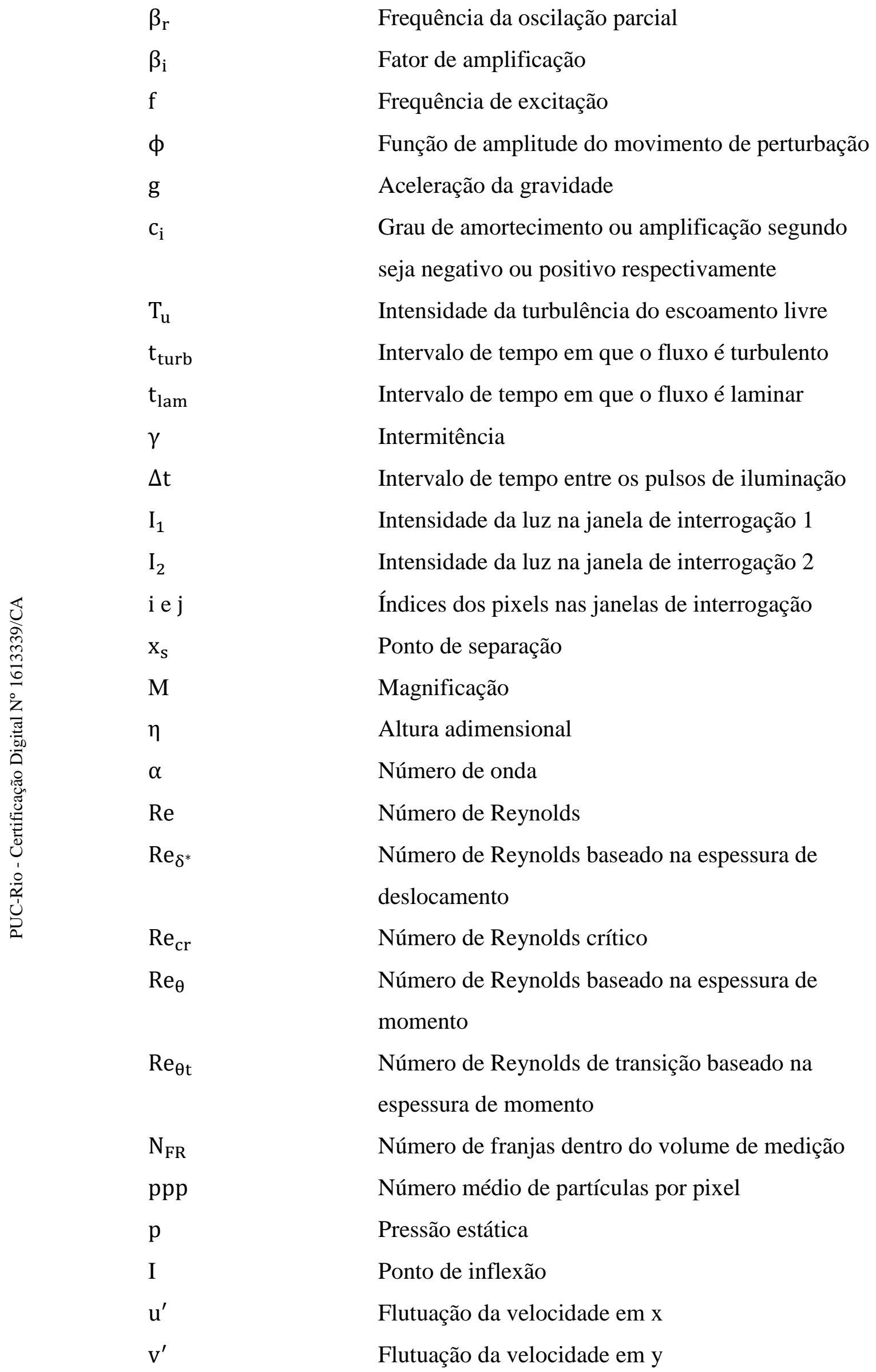




\begin{tabular}{|c|c|}
\hline $\mathrm{w}^{\prime}$ & Flutuação da velocidade em z \\
\hline $\mathrm{p}^{\prime}$ & Flutuação da pressão \\
\hline$\Delta \mathrm{P}$ & Queda de pressão \\
\hline c & Velocidade de grupo \\
\hline$t_{p}$ & Tempo de resposta da partícula \\
\hline$\Delta_{\text {pixel }}$ & Tamanho de um pixel em milímetros \\
\hline $\mathrm{U}_{\infty}$ & Velocidade da corrente livre \\
\hline$v$ & Viscosidade cinemática do fluido \\
\hline $\mathrm{c}_{\mathrm{r}}$ & $\begin{array}{l}\text { Velocidade de fase ou velocidade de propagação } \\
\text { das ondas na direção x }\end{array}$ \\
\hline $\mathrm{V}_{\text {sucção }}$ & Velocidade de sucção \\
\hline $\mathrm{Vol}_{\mathrm{m}}$ & Volume do volume de medição \\
\hline $\mathrm{U}_{\mathrm{p}}$ & Velocidade da partícula \\
\hline $\mathrm{V}_{\text {sol }}$ & $\begin{array}{l}\text { Volume da solução onde as partículas serão } \\
\text { semeadas }\end{array}$ \\
\hline AJS & Atuador de Jato Sintético \\
\hline BSL & Bolha de separação laminar \\
\hline GV & Gerador de Vórtices \\
\hline LPT & Turbina de baixa pressão \\
\hline LDV & Velocimetria Laser Doppler \\
\hline PMTs & Tubos fotomultiplicadores \\
\hline PIV & Velocimetria por imagens de partículas \\
\hline PDM & Processador Digital Multibit \\
\hline SST & Shear Stress Transport \\
\hline $\mathrm{TS}$ & Tollmien-Schlichting \\
\hline PSD & Power Spectral Density \\
\hline POD & Proper Ortogonal Descomposition \\
\hline
\end{tabular}


"O caos é uma ordem por decifrar"

Jose Saramago 


\section{Introdução}

\section{1. Motivação}

Este trabalho consiste na construção e qualificação de um aparato para o estudo experimental das bolhas de separação laminar. $\mathrm{O}$ fenômeno ocorre quando a camada limite laminar se separa e sofre um processo de transição para turbulento reconectando-se mais a jusante do ponto de separação formando assim uma região de recirculação fechada conhecida como bolha de separação laminar (BSL). As BSL podem ser encontradas em diversas aplicações de engenharia, tais como em asas de aeronaves e drones, pás de turbinas, geradores eólicos, dentre outras. De acordo com Carmichael (1981), Lissaman (1983), Sandham (2008), o estudo das BSL é de grande importância no desenvolvimento da tecnologia aeronáutica já que podem afetar significativamente o desempenho das superfícies de sustentação, introduzindo um aumento no arrastro, no ruído aeroacústico e na vibração da estrutura.

A crescente demanda global do transporte aéreo é um desafio para a indústria aeronáutica. Previsões feitas por Airbus (2013) mostraram que a demanda por aeronaves vai aumentar na medida em que as grandes cidades continuem se desenvolvendo, sobretudo nos países com economias emergentes. De acordo com aquele trabalho, atualmente as 42 maiores cidades do mundo lidam com mais de 100000 passageiros de longo curso por dia. Estima-se que para o 2032 haverá 90 megacidades e a demanda de aeronaves estará acima de 29000 novas unidades. Além disso, espera-se que dois terços da população dos países com economias emergentes fará uma viagem por ano em 2032. A viabilidade econômica e a sobrevivência futura de um fabricante de aeronaves dependem da melhora no desempenho aerodinâmico e na diminuição do consumo de combustível. Nesse contexto o desenho de motores a jato mais eficientes é de particular interesse. Recentemente tem se notado esforços para melhorar o desempenho das turbinas de baixa pressão (LPT do termo Low Pressure Turbine) que são uma componente 
chave do motor a jato (Airbus, 2013). A figura 1.1 mostra em cor vermelho a estagio da turbina de baixa pressão dum motor aeronáutico.

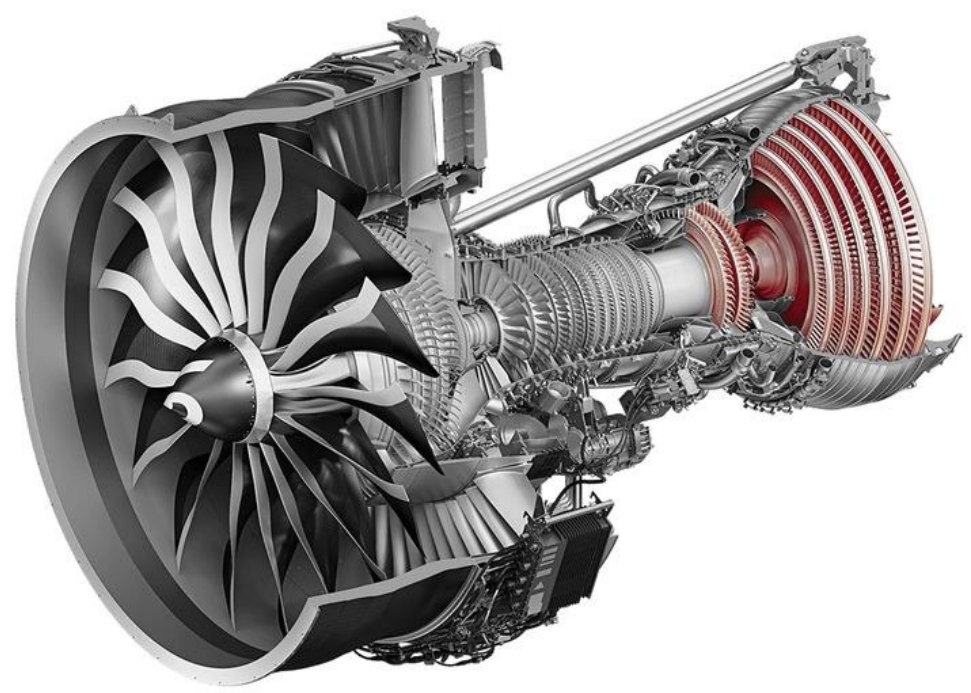

Figura 1.1 Motor aeronáutico GE9X da GE Aviation, a turbina é mostrada em cor vermelho e está constituída por duas partes, o estágio da turbina de baixa pressão corresponde à parte maior.

Sharma (1998) indicou que numa LPT o coeficiente de perda de pressão total aumenta em cerca de $300 \%$ para números de Reynolds baseado no comprimento da corda abaixo de 95000 em comparação com os números de Reynolds mais elevados, como mostrado na Figura 1.2. A elevada perda de pressão total em baixos números de Reynolds é associada com a separação da camada limite laminar sobre a parte traseira das pás da turbina no lado de sucção. Esses resultados são similares aos encontrados por Hormouziadis (1989). Nesse último trabalho foi sugerido que para condições de decolagem os números de Reynolds típicos nas pás das turbinas são mais elevados do que nas condições de cruzeiro onde os valores podem ser baixos devido à redução de potência e a baixa densidade do ar. Logo, nas condições de cruzeiro o escoamento nas pás é mais propenso à separação.

De acordo com Wakelam et al. (2013), para um aumento de eficiência dos aerofólios, é desejável um projeto que consiga estender a região de escoamento laminar sobre esse aerofólio, pois sabe-se que escoamentos turbulentos exibem arrasto viscoso significativamente maior do que os laminares. Logo, para se obter uma maior região de escoamento laminar é necessário deslocar a transição do escoamento, em direção ao bordo de fuga. De acordo com Wakelam et al. (2013), uma forma comum de buscar esse efeito é deslocar a região de desaceleração do 
escoamento em direção ao bordo de fuga. A ideia é que o fluxo se mantenha laminar por uma maior extensão. No entanto, nessa condição o escoamento é ainda mais propenso a separação.

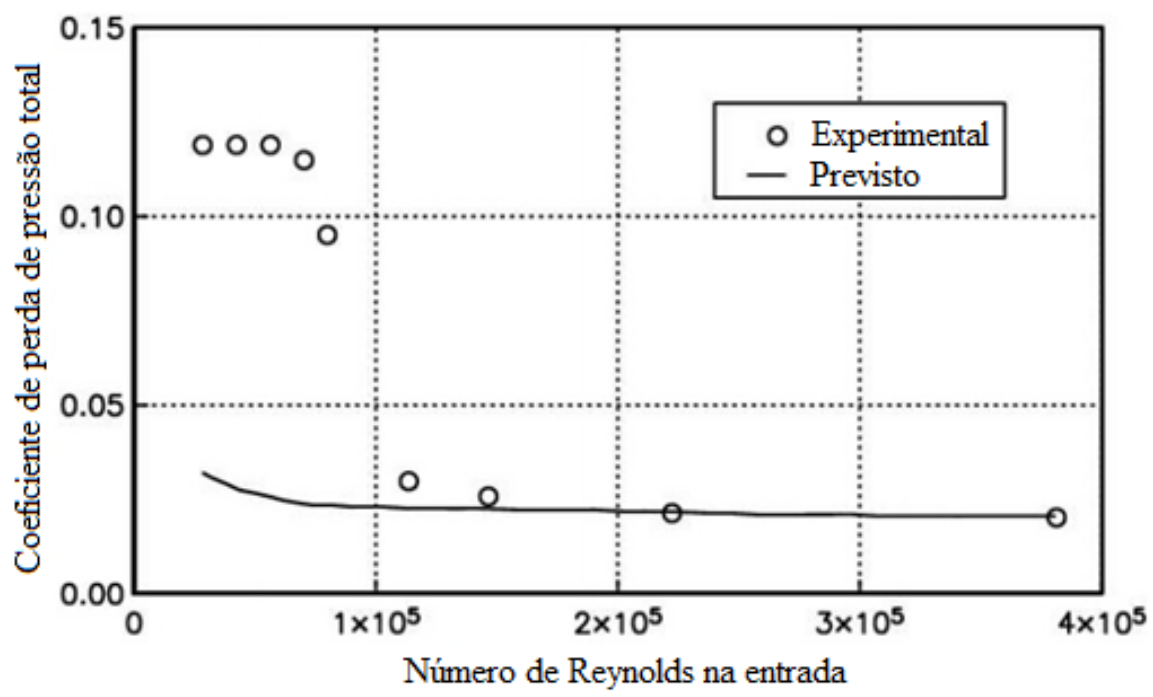

Figura 1.2 Perda de pressão numa LPT, adaptado de Sharma (1998).

Curtis et al. (1997) indicaram que as LPT podem representar até 30\% do peso total do motor e conter até 1900 pás individuais, levando em conta o peso de cada pá (que usualmente é de fundição) é claro que uma diminuição do número de pás pode fornecer uma considerável redução de custos tanto para o fabricante quanto para o cliente. De acordo com Martinstetter et al. (2010), progressos significativos foram feitos nas últimas décadas apontando para uma redução do número de pás das LPT através do desenho de pás de alta sustentação. O desafio desses projetos é alcançar alto desempenho em baixos números de Reynolds associado com as condições de voo de cruzeiro.

Técnicas de controle passivo e controle ativo foram investigadas em diversos trabalhos para tentar suprimir a separação do fluxo e melhorar o desempenho das turbinas em baixos números de Reynolds. O trabalho de Volino (2003) usou uma técnica de controle passivo com rugosidades de secção transversal retangular estendidas ao longo da direção transversal de um aerofólio (spanwise) para controlar a transição e reconexão da camada limite. Naquele trabalho foram considerados números de Reynolds baseados na corda na faixa de $2.5 \mathrm{E}+4$ até $3 \mathrm{E}+5$ e uma intensidade turbulenta da corrente livre na faixa de $0.5 \%$ até $8.5 \%$. Essas rugosidades, de fato, conseguiram suprimir a separação do fluxo em números de Reynolds baixos, mas, no entanto, ocasionaram uma alta perda de eficiência em 
elevados números de Reynolds. As desvantagens apresentadas por Volino (2003) são comuns a métodos passivos de controle de separação. De acordo com Gad-elHak (2000) o uso de técnicas de controle ativo tais como geradores de plasma e jatos sintéticos por exemplo, não possuem essa desvantagem, pois podem ser ligados somente na faixa de operação necessária. Jatos sintéticos têm sido estudados no controle da separação da camada limite tendo a vantagem de fornecer a inserção de quantidade de movimento com uma taxa liquida de fluxo de massa igual a zero. Entretanto, a aplicação dessa técnica no caso de turbinas é difícil por motivos de construção. O mesmo se aplica para o caso de geradores de plasma.

Diversos trabalhos na literatura mostram que de fato, os métodos ativos são capazes de controlar a separação da camada limite (Mittal et al., 2001). No entanto, o ganho líquido reportado com o uso dessas técnicas de acordo com Martinstetter et al. (2010), tem sido de até 50\%. Isso se deve em parte a baixa eficiência dos dispositivos na geração de perturbações que induzem a turbulência do escoamento. O desenvolvimento de tecnologias de controle da camada limite sobre superfícies de sustentação é limitado pela falta de compreensão da física subjacente dos mecanismos de instabilidade He, W. (2017). Estudos feitos por Malkiel \& Mayle (1996) e Lou \& Hourmouziadis (2000), dentre outros, sugerem que em algumas situações uma instabilidade invíscida bidimensional se origina na camada de cisalhamento separada via o mecanismo de Kelvin Helmholtz. Nesse caso, estruturas vorticais são geradas na camada cisalhante promovendo a transição da camada limite. Se considerarmos a interação do escoamento com instabilidades já existentes no escoamento, a física do problema se torna ainda mais complexa. Além disso, no trabalho de Rodriguez et. al. (2013) foi sugerido que mecanismos de instabilidade global podem se tornar dominantes em casos com escoamento reverso menor que $7 \%$ da velocidade do fluxo livre. Todos esses mecanismos desestabilizadores dificultam a compreensão e previsão do comportamento dinâmico das BSL. Uma boa compreensão física desses mecanismos é essencial para o projeto mais eficiente de perfis aerodinâmicos e de mecanismos de controle da separação. Essa compreensão requer um conhecimento detalhado da topologia do escoamento sob diferentes condições, do comportamento transitório da camada cisalhante separada e da sua evolução.

Neste trabalho foi fabricado um aparato experimental para permitir a geração das BSL visando contribuir para a compreensão da sua formação e evolução. Para 
isto, foi desenhada uma placa plana sobre a qual se desenvolve uma camada limite submetida a um gradiente de pressão adverso. O gradiente foi imposto externamente através de uma placa plana com um ângulo de divergência na direção do escoamento provocando a separação da camada limite e a formação da bolha sobre a superfície da placa plana. Para permitir o estudo da resposta da camada cisalhante separada a perturbações externas, foi projetado um gerador de perturbações baseado em um mecanismo de movimento alternativo que permite realizar o processo de injeção-sucção de um jato artificial localizado a montante da bolha. Para garantir a formação da bolha somente sobre a superfície da placa plana, teve-se que implementar um sistema de sucção da camada limite na placa divergente. A técnica de medição de velocimetría por efeito Doppler foi empregada para caracterizar o desenvolvimento da camada limite sobre a placa plana sem gradiente de pressão. Também foi empregada a técnica de visualização de fluxo através da injeção de corante para examinar as características gerais da topologia da bolha. Campos de velocidade foram medidos para avaliar o funcionamento dos mecanismos projetados no âmbito deste trabalho e para caracterizar a bolha de separação.

Este trabalho visa contribuir para a implementação de uma nova linha de pesquisa experimental no Laboratório de Engenharia de Fluidos da PUC-Rio orientada ao estudo da Instabilidade Hidrodinâmica no campo da Aerodinâmica. Neste trabalho, atuou-se desde o estágio de desenho da bancada experimental até os primeiros testes de qualificação e caracterização do fluxo. $\mathrm{O}$ autor desta dissertação espera que este trabalho seja o primeiro tijolo na construção de uma escada que nos leva cada vez mais perto da compreensão do fenômeno. 


\section{2.}

\section{Objetivos do trabalho}

O objetivo geral deste trabalho é contribuir para a compreensão dos mecanismos responsáveis da formação e desenvolvimento das bolhas de separação laminar. Os objetivos específicos são:

- Construir um aparato para a formação das bolhas de separação laminar.

- Construir um mecanismo para a excitação de ondas de instabilidade.

- Caracterizar o escoamento sobre a placa plana.

- Verificar a transição do escoamento submetido a ondas de instabilidade artificiais.

- Validar o projeto do mecanismo de sução da camada limite na placa divergente.

- Caracterizar a topologia da bolha de separação formada sobre a placa plana.

\section{3.}

\section{Organização do trabalho}

A organização deste documento segue a sequência descrita neste parágrafo. Primeiro é feita uma revisão sobre os conceitos fundamentais relacionados ao trabalho. Essa revisão aborda conceitos úteis ao projeto do aparato experimental e a motivação para o estudo de bolhas de separação. No capítulo 3, apresenta-se os cálculos preliminares e o detalhamento da construção do aparato. Já no capítulo 4 descreve-se a metodologia utilizada no projeto da bancada experimental. Os resultados obtidos são apresentados no capítulo 5. Nesse capítulo são mostrados os testes de qualificação do aparato e algumas medidas do escoamento separado. O capítulo 6 resume-se os resultados alcançados e faz-se sugestões para estudos futuros. Finalmente o capitulo 7 mostra a bibliografia empregada. 


\section{2 Revisão bibliográfica}

Neste capítulo é apresentada uma revisão dos conceitos e definições fundamentais envolvidos na formação e evolução das bolhas de separação laminar, com o intuito de fornecer uma visão geral do fenômeno e dos principais parâmetros que o influenciam. Os conceitos descritos neste capítulo servem como base para o projeto da bancada experimental.

\section{1.}

\section{Camada limite}

Em 1904 Ludwing Prandtl revolucionou o estudo da aerodinâmica e em geral da dinâmica dos fluidos com a introdução do conceito da camada limite. Ele demostrou como a viscosidade se faz decisiva próximo a superfícies, mesmo para escoamentos com elevados números de Reynolds. Prandtl fez distinção entre duas regiões do fluxo embora não seja possível delimita-las com absoluta precisão. Uma região consiste em uma camada muito fina que fica em contato imediato com o corpo, e outra região externa a essa camada. Na região da camada fina ele observou que as forças viscosas causam um gradiente de velocidade desde a velocidade nula junto à parede até a velocidade plena a uma certa distância do corpo. Na região externa a essa camada os efeitos da viscosidade têm menor relevância. Na Figura 2.1 mostra-se uma representação esquemática da camada limite sobre um aerofólio, onde $L$ é o comprimento da corda, $U_{\infty}$ é a velocidade da corrente livre e $\delta$ é a espessura da camada limite.

Partindo da equação de Navier-Stokes, Prandtl chegou ás equações da camada limite laminar, utilizando a premissa de que a espessura da camada é muito pequena em relação ao comprimento da placa e que consequentemente variações ao longo da direção do escoamento tendem a ser bem menores que variações na direção normal a superfície. 


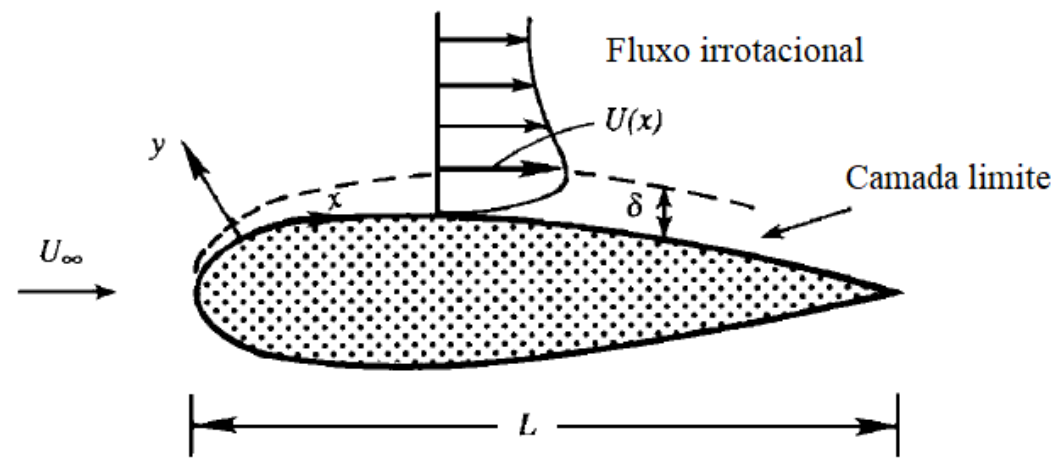

Figura 2.1 Representação esquemática da camada limite sobre um aerofólio. Adaptado de Pijush K. Kundu (2008).

Para o caso estacionário, bidimensional, considerando $u$ e $\mathrm{v}$ como as componentes da velocidade nas direções $x$ e $y$ respetivamente, sendo $\rho$ a densidade do fluido, $v$ a viscosidade cinemática, $p$ a pressão e $U(x)$ a velocidade do fluxo fora da camada limite para uma dada posição $x$, as simplificações do problema levam as seguintes relações de conservação:

$$
\begin{gathered}
u \frac{\partial u}{\partial x}+\mathrm{v} \frac{\partial u}{\partial y}=-\frac{1}{\rho} \frac{d p}{d x}+v \frac{\partial^{2} u}{\partial y^{2}} \\
\frac{\partial u}{\partial x}+\frac{\partial \mathrm{v}}{\partial y}=0
\end{gathered}
$$

Com as condições de contorno:

$$
y=0: u=0, \mathrm{v}=0 ; y \rightarrow \infty: u=U(x)
$$

e uma relação para o fluxo externo:

$$
U \frac{d U}{d x}=-\frac{1}{\rho} \frac{d p}{d x}
$$

\subsection{1.}

\section{Camada limite sobre uma placa plana}

Considerando um fluxo plano de um fluido com pequena viscosidade sobre uma placa plana para o qual a velocidade $U_{\infty}$ é constante e paralela ao eixo $x$, a variação de pressão $d p / d x$ é nula. Nesse caso, as equações da camada limite tomam a seguinte forma.

$$
u \frac{\partial u}{\partial x}+v \frac{\partial u}{\partial y}=v \frac{\partial^{2} u}{\partial y^{2}}
$$




$$
\frac{\partial u}{\partial x}+\frac{\partial \mathrm{v}}{\partial y}=0
$$

Com as condições de contorno:

$$
y=0: u=0, \mathrm{v}=0 ; y \rightarrow \infty: u=\mathrm{U}_{\infty}
$$

Esse conjunto de equações foi analisado por Blasius (ver Schlichting 1979), utilizando-se relações de similaridade. Assim, Blasius reduziu o problema a uma equação diferencial ordinária. Para isso foi necessário utilizar a função corrente e introduzir um adimensional de altura $\eta=\sqrt{\frac{U_{\infty}}{v x} y}$.

\subsection{2.}

\section{Crescimento da camada limite}

Vamos definir os parâmetros mais importantes para a caracterização dos perfis dentro da camada limite. Conforme sugerido por Blasius (ver Schlichting, 1979), a espessura da camada limite $\delta_{99}$ é definida como a posição onde $u=$ $0,99 U_{\infty}$. Segundo a solução de Blasius para uma placa plana com ângulo de ataque zero, sem gradiente de pressão, tem-se:

$$
\delta_{99}=5.0 \sqrt{\frac{v x}{U_{\infty}}}
$$

Uma medida fisicamente significativa para a camada limite é a espessura de deslocamento $\delta^{*}$ definida como a distância que a parede teria que ser deslocada para fora num fluxo potencial de modo a satisfazer a conservação de massa do escoamento sobre a superfície, assim então:

$$
\delta^{*}=\int_{0}^{\infty}\left(1-\frac{u}{U_{\infty}}\right) d y
$$
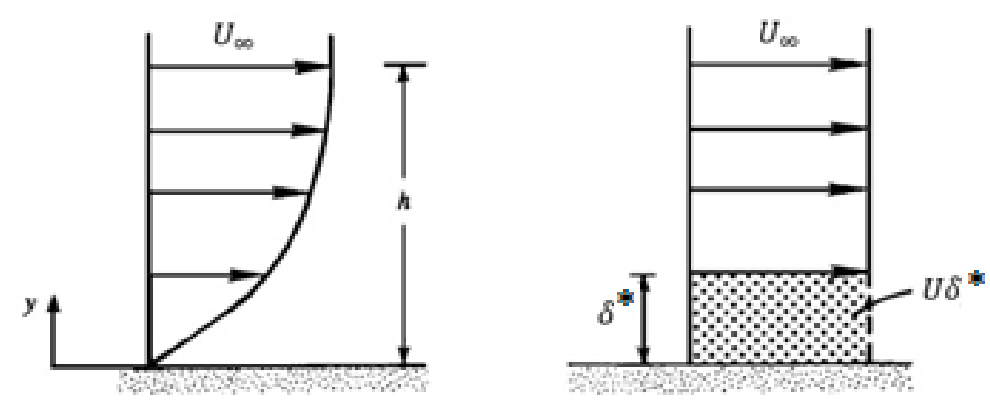

Figura 2.2 Representação esquemática da espessura de deslocamento. 
A figura 2.2 mostra um esquema deste parâmetro. Para o caso da placa plana com ângulo de ataque zero, sem gradiente de pressão, temos:

$$
\delta^{*}=1.7208 \sqrt{\frac{v x}{U_{\infty}}}
$$

A espessura de momentum $\theta$ define-se como a perda de fluxo de quantidade de movimento devido a presença da camada limite, e é determinado pela seguinte equação:

$$
\theta=\int_{0}^{\infty} \frac{u}{U_{\infty}}\left(1-\frac{u}{U_{\infty}}\right) d y
$$

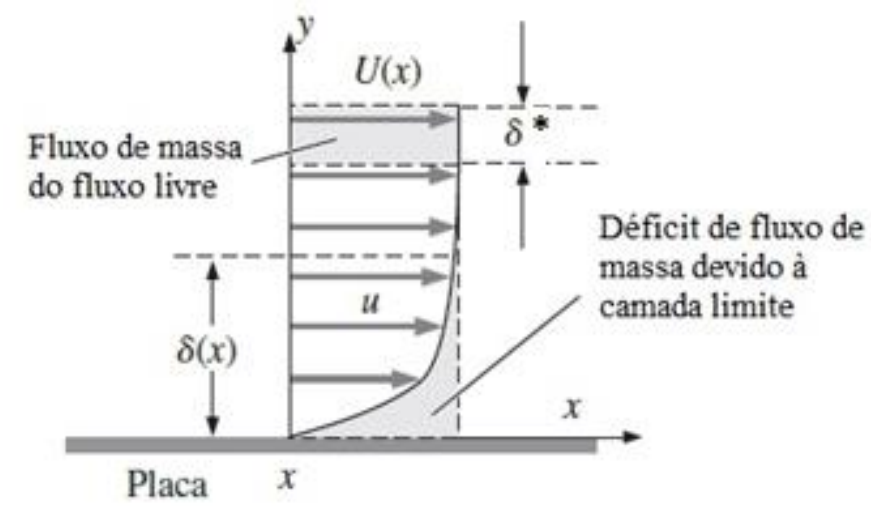

Figura 2.3 Representação esquemática da espessura de momentum.

A figura 2.3 mostra um esquema deste parâmetro. Para o caso da placa plana com ângulo de ataque zero, sem gradiente de pressão, temos:

$$
\theta=0,664 \sqrt{\frac{v x}{U_{\infty}}}
$$

Algumas relações úteis entre $\delta_{99}, \delta^{*}$, e $\theta$ são:

$$
\delta^{*}=0,34 \delta_{99}, \theta=0,13 \delta_{99}
$$

Apesar das equações 2.10 e 2.12 estarem definidas somente para camadas limites sobre placas planas sem gradiente de pressão, os conceitos de espessura de deslocamento e de momentum são utilizados para caracterizar camadas limites sujeitas a gradientes de pressão. No entanto nesses casos são utilizadas as equações integrais 2.9 e 2.11. Essas mesmas equações são válidas tanto para a região laminar, transitória e turbulenta. 


\subsection{3.}

\section{Influência do gradiente de pressão sobre a camada limite}

Se considerarmos um corpo curvo como mostrado na Figura 2.4. Na região central as linhas de corrente do fluxo externo convergem, resultando num aumento da velocidade $U(x)$ e consequentemente uma diminuição de pressão. De acordo com a equação 2.4, isso equivale a um gradiente de pressão favorável $(d p / d x<0$, onde $x$ é a coordenada ao longo da superfície do corpo). A jusante as linhas de corrente divergem, resultando uma diminuição de $U(x)$ e consequentemente um aumento da pressão, isto é, um gradiente de pressão adverso $d p / d x>0$. Na região de gradiente adverso a espessura da camada limite aumenta rapidamente, isto pode ser inferido integrando-se a equação da continuidade (eq. 2.2), de modo a obter:

$$
\mathrm{v}(\mathrm{y})=-\int_{0}^{y} \frac{\partial u}{\partial x} d y
$$

Em comparação com uma placa plana sem gradiente de pressão a desaceleração do fluxo externo causa um aumento da espessura da camada limite não apenas por difusão viscosa, mas também por advecção. $\mathrm{O}$ crescimento rápido da espessura da camada limite e a mudança na forma do perfil de velocidades associada a esse crescimento influenciam sua separação.

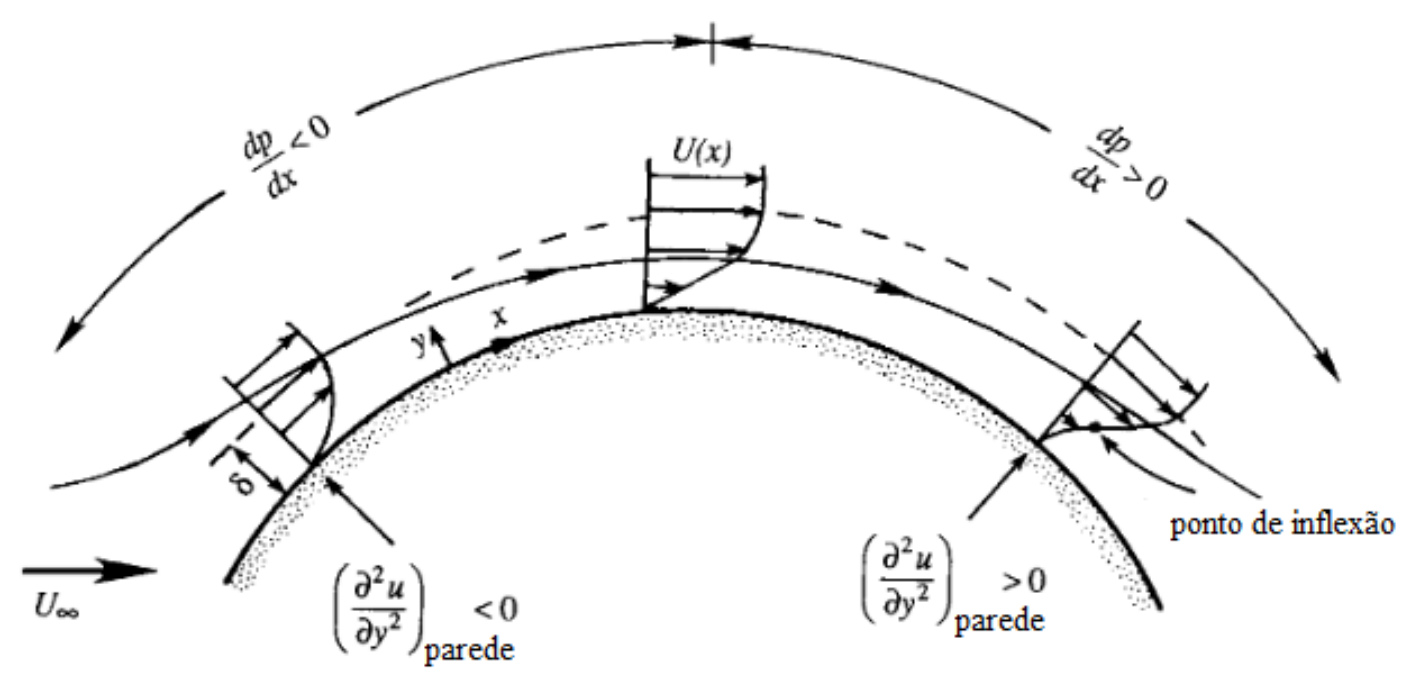

Figura 2.4. Perfis de velocidade ao longo da camada limite com gradiente de pressão favorável e adverso. Adaptado de Pijush K. Kundu (2008). 


\subsection{4.}

\section{Separação da camada limite}

Em uma camada limite submetida a um gradiente de pressão adverso pode ocorrer a formação de escoamento reverso nas camadas mais próximas à superfície as quais possuem menor quantidade de movimento. Isto é, o escoamento flui no sentido oposto à corrente principal, conforme ilustrado na Figura 2.5. Onde a linha tracejada corresponde a região de velocidade nula que limita a região de fluxo reverso. O ponto de separação " $S$ " mostrado na Figura 2.5, é definido como o limite entre o fluxo direto e reverso na camada mais próxima da parede, onde o esforço cisalhante na parede desaparece, portanto:

$$
\left(\frac{\partial u}{\partial y}\right)_{y=0}=0
$$

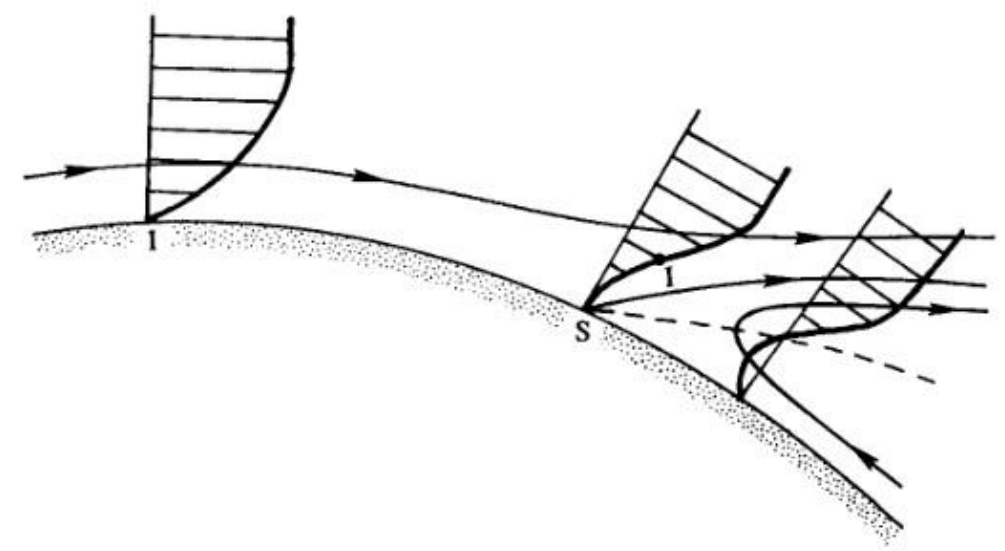

Figura 2.5 Linhas de corrente e perfis de velocidade perto do ponto de separação " $S$ ", o ponto de inflexão é indicado por " $I$ ". A linha tracejada representa $u=0$. Adaptado de Pijush K. Kundu (2008).

\subsection{5.}

\section{Critério de separação}

Existem na literatura diversos critérios para tentar prever as condições e o local em que a separação do escoamento pode ocorrer. Neste trabalho buscou-se utilizar um desses métodos para auxiliar no projeto do aparato experimental. Sendo assim, resolveu-se incluir uma breve descrição do método utilizado. No trabalho de Stratford (1957) foi proposto um critério para determinar o ponto de separação da camada limite diretamente a partir distribuição de velocidade $U(x)$. Stratford 
considerou um fluxo externo com velocidade constante $U_{0}$ desde $x_{0}$ até $x_{f}$. A partir de $x_{f}$ o fluxo é desacelerado, isto é, $d U / d x<0$. Com isso, Stratford propôs o seguinte critério para estimar o ponto $\left(x_{S}\right)$ onde ocorre a separação:

$$
\left[1-\left(\frac{U(x)}{U_{0}}\right)^{2}\right]^{\frac{1}{2}}\left(x_{s}-x_{f}\right) \frac{d}{d x}\left[\left(\frac{U(x)}{U_{0}}\right)^{2}\right]=-0.102
$$

Para valores conhecidos de $U(x), U_{0}$, e $x_{f}$, esta equação determina o ponto de separação $x_{s}$. Em um canal divergente o fluxo é retardado, se considerarmos o fluxo externo como uma fonte de fluido como mostrado na Figura 2.6, segundo a teoria do fluxo potencial a distribuição de velocidades estaria dada por:

$$
U(x)=\frac{U_{0}}{1+\frac{x}{l}}
$$

onde $l$ é um parâmetro geométrico. Para este caso, de acordo com Stratford a posição do ponto de separação estaria dado por: $x_{s} / l=0.16$

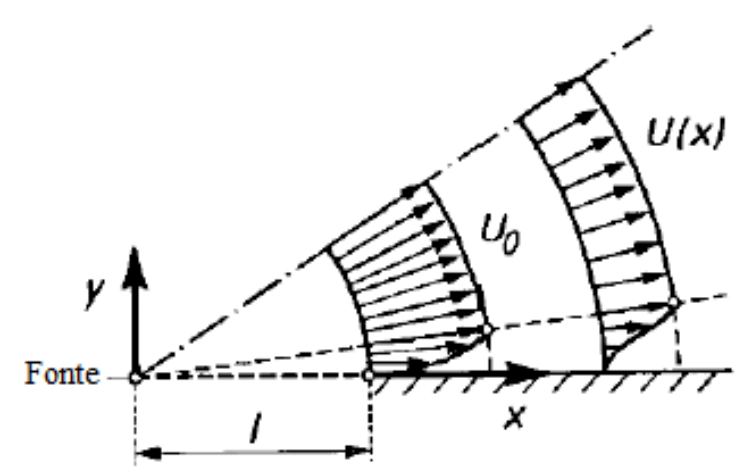

Figura 2.6. Camada limite em um canal divergente (difusor) com fluxo externo $U(x)$ da equação (2.17). Adaptado de Schlichting, H. (1979).

\subsection{6.}

\section{Métodos de controle da separação da camada limite, ativos e} passivos

Dentro do desenvolvimento da tecnologia aeronáutica os métodos de controle da separação são um importante campo de estudo. Esses métodos têm por objetivo aumentar a força de sustentação e diminuir a força de arraste, melhorando assim o desempenho de superfícies de sustentação aerodinâmica tais como aerofólios, pás de turbinas, asas de aviões, etc. Os métodos de controle são comumente classificados em passivos e ativos, sendo os métodos de controle passivos aqueles 
em que nenhuma energia precisa ser adicionada ao sistema, já os ativos requerem energia externa Gad el Hak (2000). Alguns métodos, tais como, geradores de vórtices, riblets, rugosidades, sopro e sucção constante, são considerados de controle passivo. Por outro lado, o aquecimento da parede, jatos sintéticos, atuadores de plasma, sopro e sucção oscilatório, são considerados métodos de controle ativo. Neste trabalho faz-se uma breve descrição de alguns desses mecanismos.

\subsubsection{1.}

\section{Geradores de Vórtices:}

O Gerador de Vórtices (GV) é um dispositivo de controle de fluxo passivo. Estruturalmente falando são aletas pequenas de geometria retangular ou triangular localizadas perto do bordo de ataque e cuja altura é similar à altura da camada limite, geralmente estão inclinados em relação ao fluxo de entrada e estão dispostos em pares num arranjo no sentido da envergadura da asa, como mostrado na

\section{Figura 2.7}

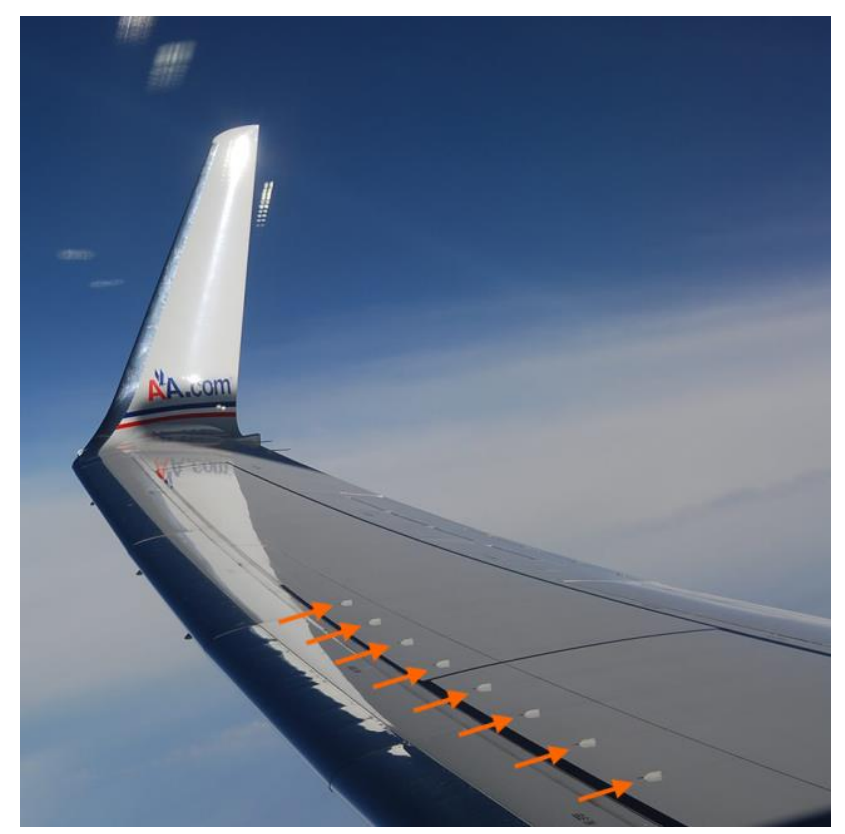

Figura 2.7 Gerador de vórtices perto do bordo de ataque da asa de um avião Boeing 737-800. O sentido do fluxo e a posição das aletas estão indicadas pelas setas. Tomado de: http://www.boldmethod.com/learn-to-fly/aerodynamics/vortexgenerators/

O GV modifica o movimento do fluxo perto da parede trazendo energia da região do fluxo externo até o interior da camada limite que agora é rica em energia e altamente turbulenta, portanto, muito mais resistente à separação. O GV é 
frequentemente utilizado em pás de turbinas eólicas e em asas de aviões com o objetivo de prevenir a separação da camada limite. Tem a vantagem de poder ser adicionados após a turbina ou a asa seja produzida, quando os resultados obtidos não são os esperados, Fernandez G. et al. (2013). Por outro lado, pesquisas em baixos número de Reynolds para o controle das bolhas de separação laminar mostraram que GV's podem reduzir significativamente o arrastro, Kero et al. (1993), Lin et al. (1994). No entanto, a desvantagem deste método é que atinge seu desempenho ótimo somente na faixa de números de Reynolds para o qual o dispositivo foi projetado. Fora dessa faixa ótima a perda de eficiência pode induzir um aumento no arrasto total do sistema.

\subsubsection{2.}

\section{Sucção da camada limite}

É um método de controle que foi sugerido por Prandtl como um dos meios de prevenir ou retardar a separação da camada limite. O método consiste em sugar através de furos, rasgos ou seções porosas a parte da camada limite mais próxima à parede que está viajando a menor velocidade, como resultado o perfil de velocidade exibe maior quantidade de movimento próximo à parede e, portanto, torna-se menos susceptível a separação. A Figura 2.8 mostra um desenho esquemático das mudanças no perfil de velocidade após ser sugado através da superfície.

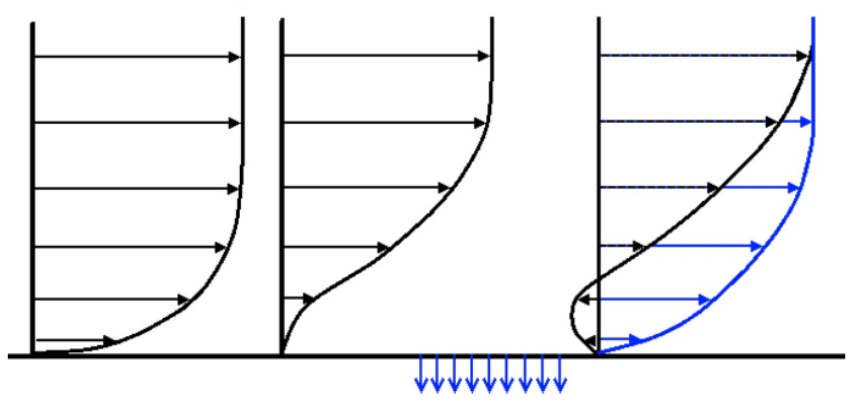

Figura 2.8 Perfis de velocidade desenvolvidos baixo um gradiente de pressão adverso. Em cor azul pode-se observar as mudanças no perfil após a sucção através da parede, retirado de T. Van der Hoeven (2013).

Neste trabalho será estudado um fluxo através de uma região de geometria convergente-divergente. A Figura 2.9 mostra a influência da sucção em um bocal com uma geometria desse tipo. Na Figura 2.9a o fluxo acelera na região convergente, consequentemente a pressão cai e atinge a sua máxima velocidade na 
constrição. Na região divergente, o escoamento desacelera ocasionando um gradiente de pressão adverso que a jusante da restrição causa a separação da camada limite nas duas superfícies. Nota-se na figura 2.9a que a separação na parte superior e na inferior exibem diferenças, apesar da geometria ser aparente simétrica. Isso pode ocorrer devido à instabilidade do escoamento e ao acoplamento das flutuações de pressão entre as regiões separadas. Nessa situação, as estruturas de separação não são independentes. Na Figura 2.9b a camada limite é sugada através das paredes da secção divergente e a separação é interrompida, nessa condição o fluxo preenche totalmente a secção divergente sem regiões de recirculação.

A sucção pode ser utilizada também como um meio para retardar o processo de transição do escoamento através da redução da espessura da camada limite.

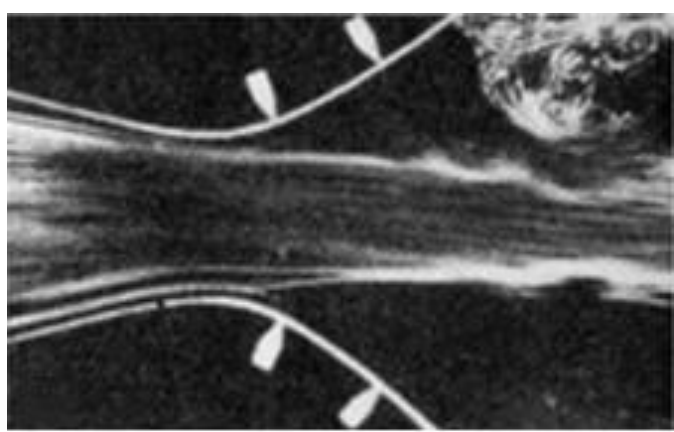

(a)

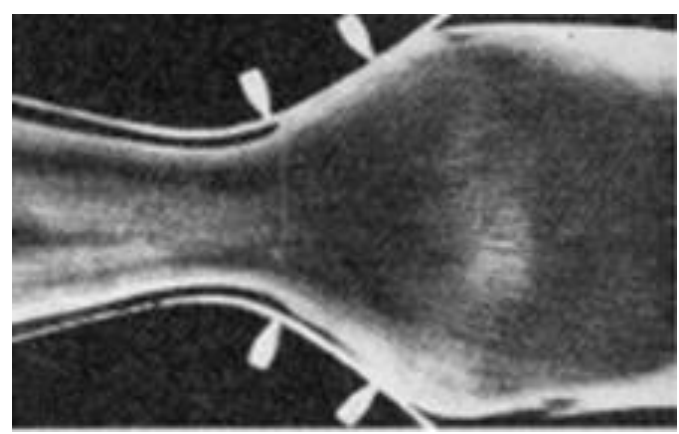

(b)

Figura 2.9 (a) Bocal divergente sem sucção da camada limite, (b) Bocal divergente com sucção da camada limite. Schlichting, H. (1979).

De acordo com Joslin (1998), uma questão de importância pratica para uso da técnica de sucção da camada limite é a determinação da vazão de sucção mínima necessária para a camada limite permaneça colada à superfície. Um excesso de sucção pode aumentar o consumo de energia do sistema e alterar o escoamento longe da parede. Sendo assim, a sucção deve ser suficientemente pequena para afetar somente as camadas de fluido mais próximas à parede e garantir que os efeitos de sumidouro sobre o fluxo potencial são desprezíveis.

No presente trabalho, foi prevista a sucção da camada limite na placa divergente para evitar o acoplamento da separação nessa superfície com a bolha formada sobre a placa plana. A metodologia utilizada para a definição das vazões de sucção é detalhada no capítulo 3 . 


\subsubsection{3. Jato sintético controlado (Injeção e Sopro oscilatório)}

O Atuador de Jato Sintético (AJS) é bastante utilizado no controle ativo da separação McCormick (2000). A técnica consiste num dispositivo que gera um jato através de um orifício ou ranhura devido à oscilação de um diafragma ou pistão. Usualmente o elemento oscilante tem acionamento do tipo eletromagnético ou piezoelétrico. Exemplos disto podem ser encontrados nos trabalhos de Schaeffler and Jenkins (2006), Milanovic and Zaman, (2005) e Smith and Glezer (2005). Uma característica importante dos AJS é que utilizam o próprio fluido do sistema e como operam mediante um processo oscilatório de injeção e sucção estes dispositivos conseguem aumentar a quantidade de movimento do escoamento próximo a superfície sem qualquer adição de massa liquida ao escoamento. Por isso, também são conhecidos como atuadores de fluxo de massa liquida zero. Alguns estudos demostraram a efetividade do AJS no controle da separação sobre aerofólios, como os estudos realizados por McCormick (2000), Amitay et al. (2001) e Tuck and Soria (2004), em particular Stalnov et al. (2009) fizeram estudos experimentais usando um AJS sobre um aerofólio IAI pr8-ES tipicamente utilizado em pás de turbinas de vento, e conseguiram demostrar seu desempenho ótimo numa faixa de números de Reynolds maior que o GV, isto inclui os baixos números de Reynolds em que se foca este trabalho.

Para obter uma ideia visual mais clara deste método a Figura 2.10 ilustra a simulação da injeção de um jato sintético dentro da camada limite desenvolvida sobre uma superfície plana com o objetivo de atrasar o ponto de separação. O fenômeno do atraso do ponto de separação consiste em que o jato atua como um excitador de ondas de instabilidade que podem atingir a região do fluxo instável e desencadear o processo de transição da camada limite que finalmente torna-se turbulenta e com isto as partículas de fluido perto da parede ficam mais energizadas, isto é, com maior quantidade de movimento, portanto, são mais difíceis de separar. 


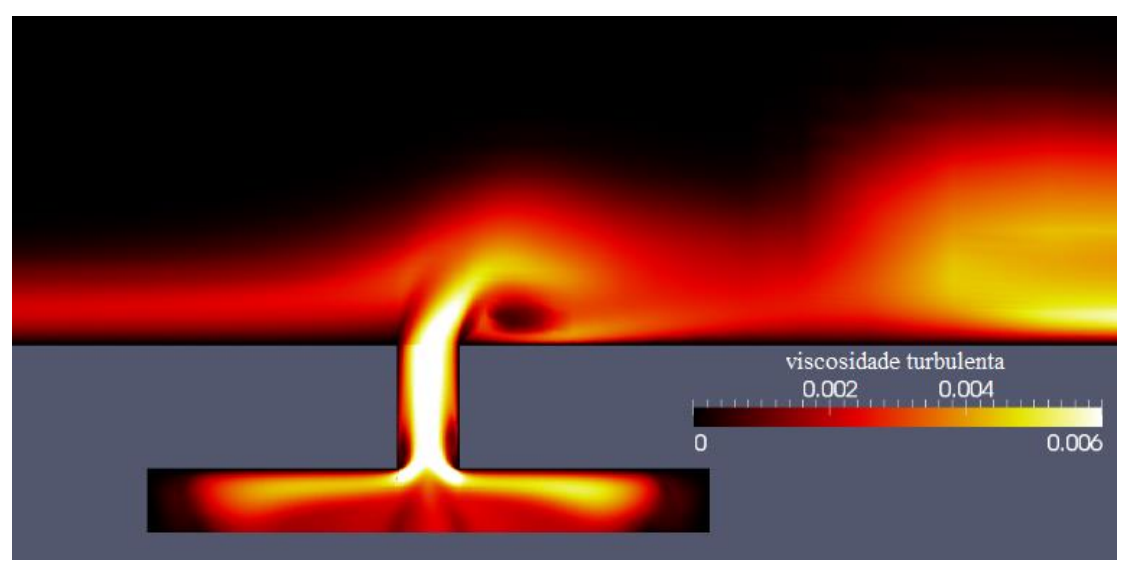

Figura 2.10 Simulação de um Jato sintético injetado no interior da camada limite para o atraso do ponto de separação. Adaptado de:

(http://num3sis.inria.fr/blog/synthetic-jet-simulations/)

Utilizando-se os conceitos de jatos oscilatórios, projetou-se um sistema de injeção-sucção periódica para excitar ondas de instabilidade na camada limite. O objetivo inicial é induzir a transição da camada limite sobre a placa plana. O dispositivo poderá ser utilizado em trabalhos futuros. O projeto desse dispositivo é detalhado no capítulo 3 .

\section{2.}

Instabilidade Hidrodinâmica e Transição de Escoamentos Separados

A Instabilidade hidrodinâmica está definida em termos do comportamento do fluxo quando perturbações externas são aplicadas sobre ele. Caso o escoamento retorne a sua condição inicial este define-se como estável. Se as perturbações aplicadas crescem levando o escoamento a um outro regime o mesmo é classificado como instável. Existe ainda a possibilidade de um escoamento ser estável a perturbações menores que um limiar. No caso de camadas limite a instabilidade das perturbações usualmente conduz a transição do escoamento laminar para turbulento. De acordo com Schlichting, H. (1979) a separação do escoamento altera a instabilidade da camada limite.

Uma caraterística importante dos escoamentos separados é que eles se tornam instáveis mesmo em números de Reynolds relativamente baixos. Como resultado, é comum associar instabilidades e/ou transição para turbulência com as regiões de 
escoamento separado Dovgal. et al. (1994). A Figura 2.11 ilustra os estágios de uma camada limite separada e como ocorre o seu recolamento.

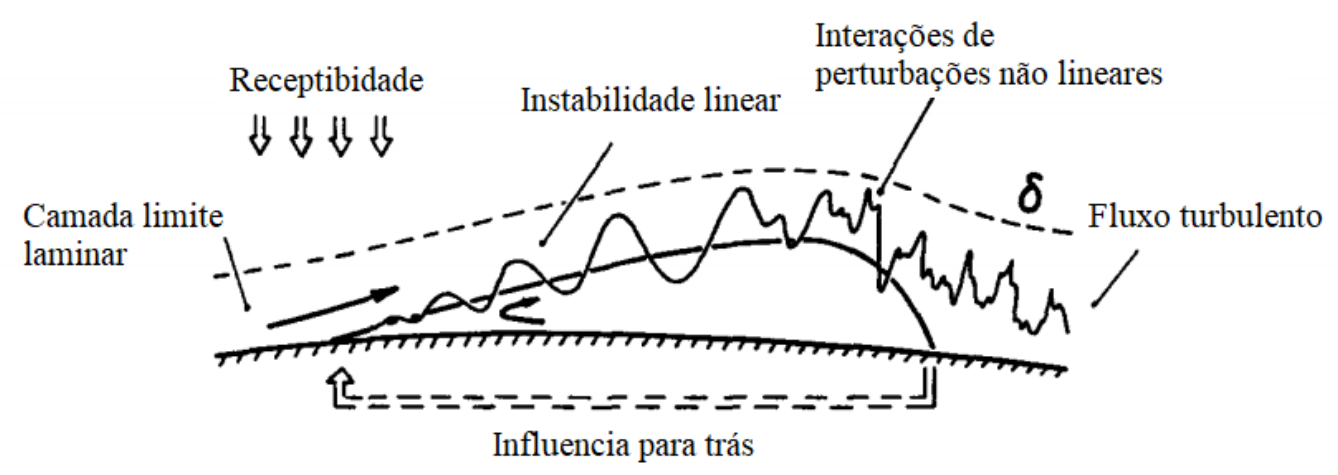

Figura 2.11 Instabilidade e transição para turbulência em uma Bolha de Separação Laminar. Dovgal A. V. et al. (1994).

De acordo com Dovgal. et al. (1994), pode-se dividir o fenômeno da transição em bolhas nos seguintes estágios: Receptividade, instabilidade linear com crescimento exponencial de perturbações, e o estágio de interações não lineares como mostrado na figura 2.11 baseada em observações experimentais. De acordo com Rodriguez et al. (2013), um mecanismo adicional que também é relevante é a auto alimentação das perturbações, resultante de uma instabilidade global que ocorre em correntes de recirculação baixa (menor que 7\%), nessas condições mecanismos de instabilidade global podem se tornar dominantes. Em oposição, regimes com intensidade de escoamento reverso (maior que $7 \%$ ) tendem a exibir transição a partir do crescimento de perturbações de pequena amplitude originárias tanto da camada limite como do escoamento livre. Nesse último caso, as perturbações do escoamento livre podem ser inseridas na camada limite através de mecanismos de receptividade. Alguns exemplos de estudos deste tipo de receptividade podem ser encontrados nos trabalhos de Arena A. \& Mueller T. (1980), Brendel M. \& Mueller T. (1988).

\subsection{1.}

\section{Receptividade de fluxos separados às perturbações externas}

De acordo com Morkovin et al. (1969), a receptividade é o processo de inserção de perturbações externas na camada limite. Essas perturbações externas podem ser originadas da turbulência do fluxo externo, de fontes de som localizadas fora do corpo ou na superfície da parede, de variações de temperatura, de 
vorticidade, de vibrações da superfície, dentre outras. A receptividade determina as condições iniciais das perturbações. Usualmente as perturbações geradas através da receptividade são muito pequenas podendo ser observadas só depois de sua amplificação devido algum mecanismo de instabilidade.

A dependência entre a amplitude das ondas de instabilidade na camada limite, os parâmetros do escoamento e a intensidade das fontes de perturbação, é difícil de ser estimada em uma correlação geral que sirva para diferentes mecanismos de receptividade Dovgal A. V. et al. (1994). Assim sendo, boa parte dos trabalhos de receptividade busca relacionar a amplitude de perturbações externas com as perturbações geradas na camada limite para escoamentos ou condições específicas. No trabalho de Dovgal A. V. \& Kozlov V. V. (1983) por exemplo, foi realizado um estudo experimental usando excitação acústica externa sobre uma bolha de separação laminar formada em um fluxo com gradiente de pressão adverso. Aqueles autores observaram que ao gerar ondas acústicas com uma apropriada frequência foi possível observar a amplificação das perturbações vorticais na bolha de separação. Uma análise mais detalhada revelou que as perturbações que causam a transição do fluxo separado foram geradas a montante do ponto de separação, especificamente no começo do gradiente de pressão adverso. No ponto de separação não foi observada grande geração de perturbações. Dovgal e coautores concluíram que a receptividade em bolhas de separação é maior a montante do ponto de separação. A Figura 2.12 mostra um esquema das observações daquele trabalho.

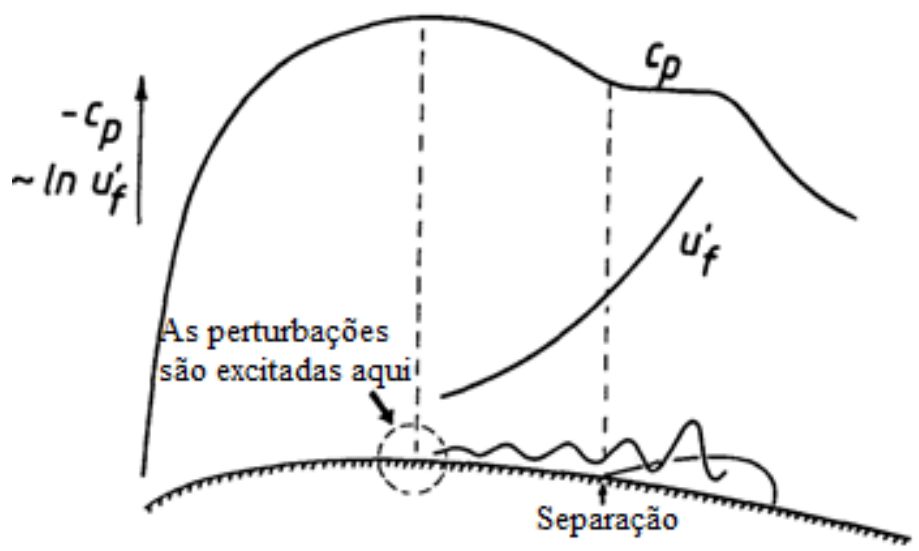

Figura 2.12 Geração acústica de ondas de instabilidade em um fluxo separado sobre um aerofólio. Onde, $C_{p}$ : distribuição de pressão e $u_{f}^{\prime}$ : crescimento das perturbações excitadas. Retirado de Dovgal A. V. et al. (1994). 
Atualmente, sabe-se que a geração de perturbações que conduzem a mudança de regime pode ocorrer tanto a montante, a jusante ou no local da separação. No trabalho de Rodriguez et.al. (2013) por exemplo, foi analisado o crescimento de perturbações com velocidade de propagação muito baixa. Essas perturbações podem crescer ao longo do tempo uma vez que não são convectados pelo escoamento, podendo causar instabilidade global. De acordo com Rodriguez et.al. (2013), esse cenário é esperado em casos com velocidades de recirculação menores que $7 \%$ da velocidade do fluxo livre. A bancada que está sendo projetada permite o ajuste do gradiente de pressão adverso e, consequentemente, diferentes regimes podem vir ser estudados no futuro. Inicialmente, pretende-se investigar casos com interação entre as bolhas e as ondas de instabilidade excitadas a montante da separação.

\subsection{2.}

\section{Instabilidade linear}

Seguindo a Figura 2.11 o seguinte estágio da transição é a instabilidade linear, que corresponde à propagação e amplificação na direção do escoamento das perturbações na camada limite que foram inseridas no estágio de receptividade.

A equação que descreve o comportamento do fluxo neste estágio é a equação de Orr-Sommerfeld, que é obtida através da linearização das equações de NavierStokes.

A teoria de estabilidade de fluxos laminares descompõe o escoamento em um fluxo base estacionário e um movimento de perturbação sobreposto. O fluxo base pode ser descrito pelas componentes cartesianas da velocidade $U, V, W$, e a pressão $P$. Enquanto que o movimento de perturbação variável no tempo por $u^{\prime}, v^{\prime}, w^{\prime}$ e a pressão $p^{\prime}$. Sendo assim, o escoamento pode ser decomposto na forma:

$$
\begin{gathered}
u=U+u^{\prime} ; v=V+v^{\prime} ; w=W+w^{\prime} \\
p=P+p^{\prime}
\end{gathered}
$$

Adicionalmente o fluxo base é considerado localmente paralelo e bidimensional, neste caso $U$ depende só de $y$, isto é, $U=U(y)$. As equações para o fluxo base ficam: 


$$
U=U(y) ; \quad V=W=0 ; \quad P=P(x, y)
$$

E para o movimento de perturbação:

$$
u^{\prime}(x, y, t) ; v^{\prime}(x, y, t) ; p^{\prime}(x, y, t)
$$

Assim, as componentes do escoamento podem ser decompostas como:

$$
u=U+u^{\prime} ; \quad v=v^{\prime} ; w=0 ; p=P+p^{\prime}
$$

Neste analises o movimento de perturbação é considerado pequeno, em outras palavras, as flutuações da velocidade da perturbação são pequenas, todos os termos quadráticos são desprezíveis em relação aos termos lineares. Logo, substituindo as equações 2.22 nas equações de Navier-Stokes para fluidos bidimensionais estacionários incompressíveis, e desprezando os termos quadráticos obtemos:

$$
\begin{gathered}
\frac{\partial u^{\prime}}{\partial t}+U \frac{\partial u^{\prime}}{\partial x}+v^{\prime} \frac{d U}{d y}+\frac{1}{\rho} \frac{\partial P}{\partial x}+\frac{1}{\rho} \frac{\partial p^{\prime}}{\partial x}=v\left(\frac{d^{2} U}{d y^{2}}+\nabla^{2} u^{\prime}\right) \\
\frac{\partial v^{\prime}}{\partial t}+U \frac{\partial v^{\prime}}{\partial x}+\frac{1}{\rho} \frac{\partial P}{\partial y}+\frac{1}{\rho} \frac{\partial p^{\prime}}{\partial y}=v\left(\nabla^{2} v^{\prime}\right) \\
\frac{\partial u^{\prime}}{\partial x}+\frac{\partial v^{\prime}}{\partial y}=0
\end{gathered}
$$

Levando em conta a hipótese que o escoamento base satisfaz as equações de NavierStokes, as equações anteriores se reduzem a:

$$
\begin{gathered}
\frac{\partial u^{\prime}}{\partial t}+U \frac{\partial u^{\prime}}{\partial x}+v^{\prime} \frac{d U}{d y}+\frac{1}{\rho} \frac{\partial p^{\prime}}{\partial x}=v\left(\nabla^{2} u^{\prime}\right) \\
\frac{\partial v^{\prime}}{\partial t}+U \frac{\partial v^{\prime}}{\partial x}+\frac{1}{\rho} \frac{\partial p^{\prime}}{\partial y}=v\left(\nabla^{2} v^{\prime}\right) \\
\frac{\partial u^{\prime}}{\partial x}+\frac{\partial v^{\prime}}{\partial y}=0
\end{gathered}
$$


Desta forma se obtém um conjunto de equações para as componentes do movimento de perturbação $u^{\prime}, v^{\prime}, p^{\prime} \operatorname{com} u^{\prime}$ e $v^{\prime}$ nulas na superfície e a uma grande distância da parede.

Voltando a ideia inicial, ao escoamento base que se move na direção $x$ com velocidade $U(y)$, se superpõe um movimento de perturbação composto por distintas oscilações parciais, cada oscilação é uma onda que se propaga na direção $x$. A função de corrente que representa uma oscilação parcial do movimento de perturbação é dada pela equação:

$$
\varphi(x, y, t)=\phi(y) e^{i(\alpha x-\beta t)}
$$

Um movimento plano de perturbação como este pode ser expandido em uma série de Fourier onde cada termo representa uma oscilação parcial. Na equação 2.29, $\alpha$ é o número de onda e a quantidade $\lambda=2 \pi / \alpha$ é o comprimento de onda da perturbação, $\beta$ é complexa e pode ser expressada da seguinte forma:

$$
\beta=\beta_{r}+i \beta_{i}
$$

$\beta_{r}$ é a frequência da oscilação parcial, $\beta_{i}$ é o fator de amplificação, determina a amplificação ou amortecimento da oscilação, se $\beta_{i}<0$ a oscilação é amortecida e o fluxo de fundo é laminar e estável, ao invés, se $\beta_{i}>0$ a oscilação é amplificada e o fluxo de fundo é instável. Além disto, é conveniente introduzir a quantidade:

$$
c=\frac{\beta}{\alpha}=c_{r}+i c_{i}
$$

onde $c_{r}$ é a velocidade de fase, ou seja, a velocidade de propagação das ondas na direção $x, c_{i}$ determina o grau de amortecimento ou amplificação segundo seja negativo ou positivo respectivamente. A velocidade do fluxo base depende só de $y$, a função de amplitude $\phi$ do movimento de perturbação foi suposta também dependente só de $y$. Assim, a partir da equação 2.29 pode-se obter os componentes da velocidade de perturbação, que ficam da seguinte forma:

$$
u^{\prime}=\frac{\partial \varphi}{\partial y}=\phi(y)^{\prime} e^{i(\alpha x-\beta t)}
$$




$$
v^{\prime}=-\frac{\partial \varphi}{\partial x}=-i \phi(y)^{\prime} e^{i(\alpha x-\beta t)}
$$

Introduzindo esses resultados nas equações 2.26 e 2.27 obtém-se:

$$
(U-c)\left(\phi^{\prime \prime}-\alpha^{2} \phi\right)-U^{\prime \prime} \phi=-\frac{i}{\alpha R_{e}}\left(\phi^{\prime \prime \prime \prime}-2 \alpha^{2} \phi^{\prime \prime}+\alpha^{4} \phi\right)
$$

A equação diferencial de perturbação, conhecida como equação de OrrSommerfeld, que é uma EDO de quarta ordem para a amplitude $\phi(y)$, onde $R e$ é o número de Reynolds e os termos do lado esquerdo vêm dos termos de inercia, enquanto que, os termos da direita vêm dos termos viscosos das equações de movimento. As condições de contorno para uma corrente na camada limite são de anulação das componentes da velocidade de perturbação na parede e a uma grande distância dela, ou seja, condições de contorno homogêneas, portanto, a equação passa a ser um problema de autovalor, onde a solução é obtida para valores particulares de $R e, \alpha$, assumindo que o número de Reynolds da corrente base e o comprimento de onda da perturbação são conhecidos, a equação de OrrSommerfeld fornece uma autofunção $\phi(y)$ e um autovalor complexo $c=c_{r}+i c_{i}$. As autofunções e autovalores obtidos da solução da equação de Orr-Sommerfeld são conhecidos como ondas de Tollmien-Schlichting.

Anteriormente vimos a influência do sinal de $c_{i}$ na amplificação ou amortecimento das perturbações, entretanto, o caso com $c_{i}=0$ corresponde a perturbações neutrais, isto permite separar em uma gráfico de $R e, \alpha$ a região estável da região instável. Assim, a curva formada por $c_{i}=0$ é denominada curva de estabilidade neutra. A Figura 2.13 mostra as curvas de estabilidade neutra para uma onda bidimensional e tridimensional, onde, $R_{\delta^{*}}$ é o Reynolds baseado na espessura de deslocamento, $R e_{c r}$ é o Reynolds crítico e $f$ é a frequência de excitação em Hz.

Da teoria da estabilidade se deriva a existência de dois tipos de instabilidades bidimensionais, a chamada instabilidade invíscida, que se desenvolve quando existe um ponto de inflexão em um perfil de velocidades, e a instabilidade viscosa, 
relacionada com a amplificação das ondas de Tollmien-Schlichting em camadas limite.

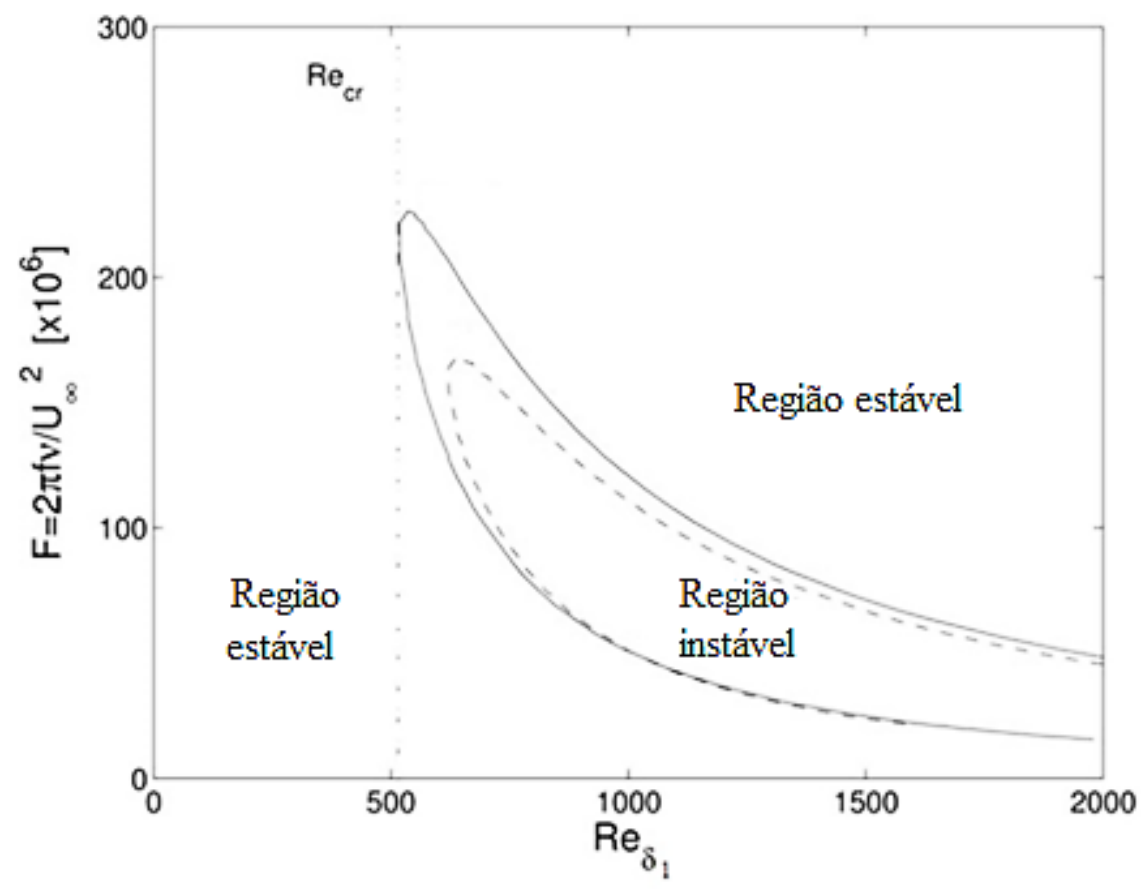

Figura 2.13 Curva de estabilidade neutra para ondas de Tollmien-Schlichting bidimensionais (linha continua) e tridimensionais (linha tracejada). Adaptado de, De Paula, I. B. (2006).

Para o caso tridimensional uma análise similar foi realizada por Squire (1933). Squire mostrou que a instabilidade linear de uma onda tridimensional pode ser mapeada em uma onda bidimensional em um número de Reynolds mais baixo. Isso sugere que em algumas situações as ondas bidimensionais são as mais instáveis. Uma revisão abrangente sobre os métodos de solução do problema de instabilidade em camadas limite bi e tridimensionais pode ser encontrado nos trabalhos de Mack (1985), Reed \& Saric (1989).

O trabalho pioneiro de Schubauer \& Skramstad (1947) avaliou a influência do gradiente de pressão na taxa de crescimento de ondas Tollmien-Schlichting. Eles encontraram que gradientes de pressão favoráveis tem uma influência estabilizante, em contraposição, gradientes de pressão adverso tem influência desestabilizadora. Isso era previsto de acordo com solução do problema de Orr-Sommerfeld para perfis de camadas limite $U(y)$ de regiões com gradiente de pressão. 


\section{3.}

\section{Bolhas de Separação Laminar}

A maior atenção no estudo de bolhas de separação laminar foi dirigida a seus efeitos sobre aerofólios devido a sua influência na diminuição da sustentação e o incremento do arrasto de pressão. De acordo com Brown e Stewart (1969) as bolhas de separação laminar ocorrem tipicamente na faixa de números de Reynolds baseado na corda de $5 \times 10^{5}$ até $3 \times 10^{6}$, dependendo da geometria do aerofólio, nível de turbulência do fluxo livre, ângulo de ataque, dentre outros.

As BSL se formam quando a camada limite laminar se separa antes de atingir a transição para turbulência. De acordo com Horton, (1969) e Brown e Stewart (1969) o fluxo laminar separado é altamente instável. Assim, depois do ponto de separação há um aumento na transferência de energia do escoamento base para as ondas de instabilidade, uma vez que as perturbações crescem o suficiente para que o fluxo se torne turbulento ocorre um aumento da transferência de momentum através das diferentes regiões da camada cisalhante. Isso gera um aumento da quantidade de movimento próximo a parede e promove o recolamento da bolha.

Este processo leva à reconexão do fluxo e consequentemente à geração de uma região fechada de baixo fluxo de momentum conhecido como bolha de separação laminar. A Figura 2.14 ilustra o esquema clássico da BSL.

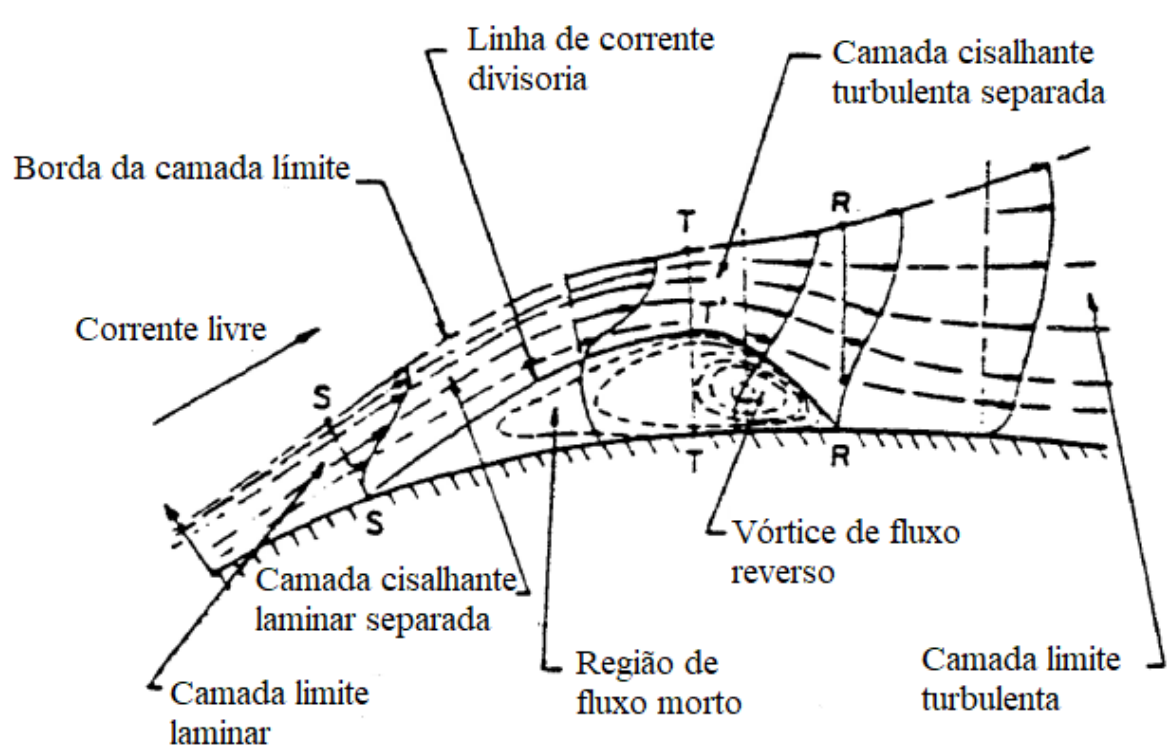

Figura 2.14 Esquema de uma Bolha de Separação Laminar, Horton (1969). 


\subsection{1. Bolhas de separação laminar curta e longa}

O comprimento da bolha é definido como a distância desde o ponto de separação até o ponto de reconexão. Em um aerofólio o comprimento de uma bolha curta tipicamente é menor que o $15 \%$ do comprimento da corda. Devido a que a camada cisalhante separada sofre transição a uma distância curta comparada com o comprimento característico do aerofólio.

Por outro lado, as características da bolha longa são similares as da bolha curta, no entanto, a transição ocorre muito mais tarde e o ponto de reconexão encontra-se perto do bordo de fuga. A bolha longa cobre uma maior porção da superfície de sustentação e causa um efeito global sobre a distribuição de pressão na superfície do aerofólio, Tani (1964). Seus efeitos sobre a performance de um aerofólio são significativos, isto é, bolhas longas reduzem a sustentação e incrementam o arrastro, enquanto que bolhas curtas tem um efeito local e tipicamente afetam pouco a performance desses aerofólios.

Na Figura 2.15, extraída do trabalho de Russell (1979) o ponto de partida do platô na curva de pressão, indicado por " $S$ ", determina a posição onde a camada limite laminar se separa da superfície superior do aerofólio. A terminação da região plana na curva de pressão indicado por o ponto “ $T$ ” pode ser utilizado para localizar os estágios finais do processo de transição. A região onde o escoamento já é turbulento e se recola a superfície é indicada pela letra $\mathrm{R}$. 


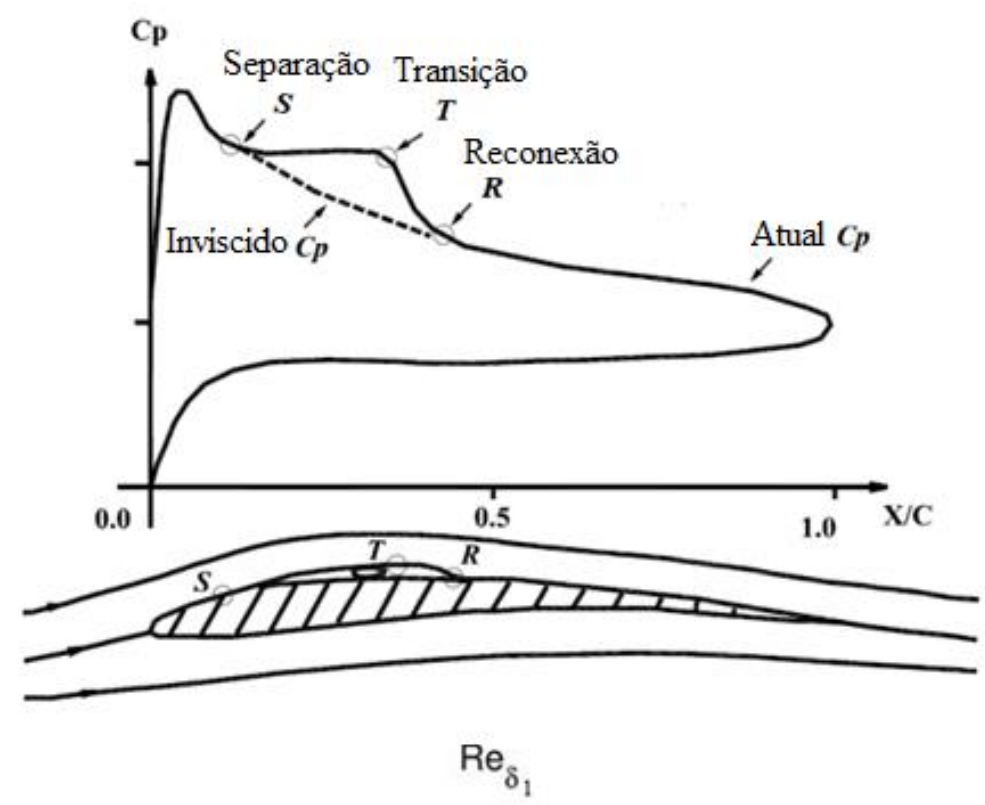

Figura 2.15 Distribuição de $C_{p}$ sobre um aerofólio com uma bolha de separação laminar, Russel (1979).

Também é possível observar que a distribuição de pressão na parede dentro da bolha de separação laminar é quase constante e aproximadamente igual à pressão no ponto de separação.

\subsection{2.}

\section{Estouro de uma Bolha de Separação laminar, "Bursting"}

O estouro de uma bolha de separação resultada em uma perda súbita de sustentação e um incremento dramático do arrasto, que causa uma abrupta entrada em estol. É desejável prever esse comportamento. Desde a visão de um modelo de bolha estacionaria o estouro da bolha pode ser visto como o colapso momentâneo ou definitivo do processo de reconexão da camada cisalhante turbulenta separada (Horton, 1969). De acordo com Gaster (1969) e Horton (1969), no caso da formação da bolha longa o colapso pode ser momentâneo, periódico ou permanente. No caso de acontecer um colapso permanente se diz que o aerofólio entrou na condição de estol. As mudanças de um comportamento instável para um estável pode ser a origem do estouro da bolha, segundo Pauley et al. (1990). No entanto, não existe um acordo geral em isto. De acordo Baragona et.al. (2003), não é claro se o colapso das bolhas é devido a mudanças nas características do escoamento base na bolha ou se devido a alguma instabilidade global, ligada a mudanças no escoamento externo. 
O trabalho de Serna et al. (2015), mostra um esforço recente na busca por um critério que permita estimar as condições de ocorrência de estouro de uma bolha longa. No entanto, os resultados do modelo ainda precisam ser avaliados para diferentes condições. O modelo proposto por Serna et al. (2015) é uma extensão do critério proposto por Gaster (1969). Apesar de diversos trabalhos tratarem deste tópico, ainda não se chegou a um consenso sobre o processo físico relacionado ao estouro da bolha. Sendo assim, os modelos propostos na literatura, são frequentemente baseados em correlações empíricas. Julga-se que uma melhor compreensão do fenômeno pode auxiliar na criação de modelos mais acurados. O estudo deste fenômeno é uma das grandes motivações para empreender este trabalho.

\section{4.}

\section{Abordagem proposta}

Neste trabalho espera-se construir e implementar uma bancada que permita gerar as bolhas de separação laminar e submete-la a perturbações artificiais. A geração das bolhas será realizada a partir da imposição de um gradiente de pressão adverso, tal como acontece em pás de turbinas de baixa pressão ou em assas que operam em baixos números de Reynolds. O aparato experimental será implementado num canal de agua que fornece a facilidade de trabalhar com velocidades pequenas e com equipamentos que não precisam uma resolução temporal muito elevada. 


\section{3 \\ Construção do aparato}

Neste capitulo são apresentados os procedimentos adotados no projeto do aparato experimental. O capítulo detalha as metodologias utilizadas para definir alguns parâmetros relevantes ao projeto, como por exemplo os locais de sucção da camada limite na placa divergente, as vazões de sucção, dentre outros. No final, são apresentados os desenhos dos componentes do aparato experimental

\section{1}

\section{Cálculos Preliminares}

Neste trabalho projetou-se uma bancada para simular o comportamento do escoamento ao longo de aerofólios, onde tipicamente existe uma região de aceleração do escoamento seguida de uma região de desaceleração e consequentemente com gradiente de pressão adverso.

Para simular essa distribuição de pressão em uma geometria mais simples que um aerofólio, foi projetado um conduto de paredes planas com uma constrição, conforme ilustrado na Figura 3.1. A base é formada por uma placa plana sobre a qual é desenvolvida a camada limite. As paredes superiores são formadas por duas placas inclinadas de modo a formar um canal convergente-divergente.

Região de Testes do Canal de Agua

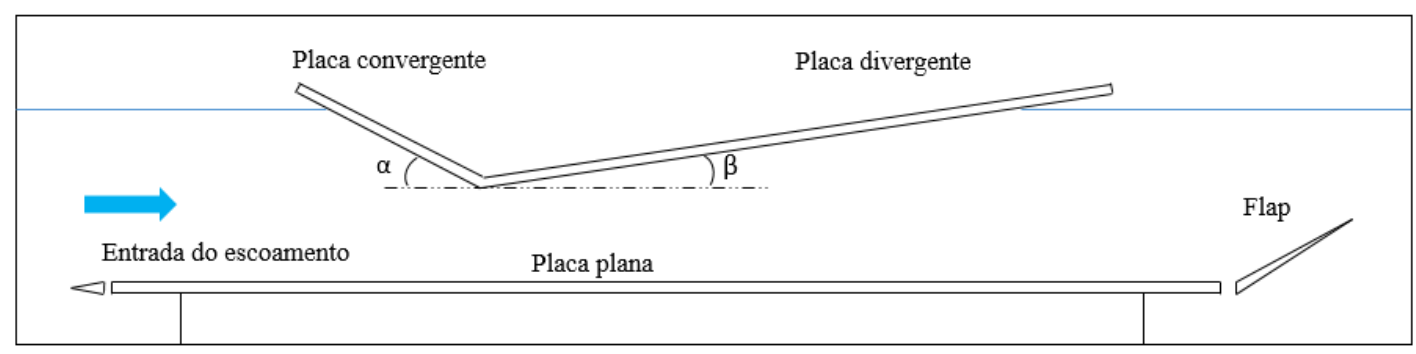

Figura 3.1 Esquema do Aparato para o estudo das Bolhas de Separação laminar. Onde $\boldsymbol{\alpha}$ é o ângulo de convergência e $\beta$ o ângulo de divergência.

Quando o fluxo atravessa a região divergente a camada limite se separa tanto na superfície da placa divergente como na placa plana. Conforme visto na revisão 
bibliográfica, nesse caso o problema é diferente daquele de bolhas de separação sobre superfícies livres e a dinâmica do escoamento depende do confinamento. Para evitar o problema do acoplamento entre o escoamento na placa divergente e na placa plana, foi projetado um sistema de sucção através ranhuras sobre a placa divergente. O projeto desse aparato é detalhado nas seguintes seções.

\subsection{1.}

\section{Cálculo dos pontos de sucção}

Um dos parâmetros críticos no projeto do sistema de sucção é a localização dos pontos de sucção. Para auxiliar na escolha dessas posições utilizou-se o critério de separação proposto por Stratford (1957), que foi descrito no capítulo 2. Com base nesse critério determinou-se um primeiro ponto de separação da camada limite sobre a superfície divergente e buscou-se colocar um ponto de sucção um pouco a montante daquele ponto para evitar o desprendimento. No entanto, uma vez feita a sucção, a camada limite seguira se desenvolvendo mais a jusante e encontraremos um novo ponto de separação para o qual corresponde um novo ponto de sucção e assim por diante, até cobrir o comprimento total da superfície.

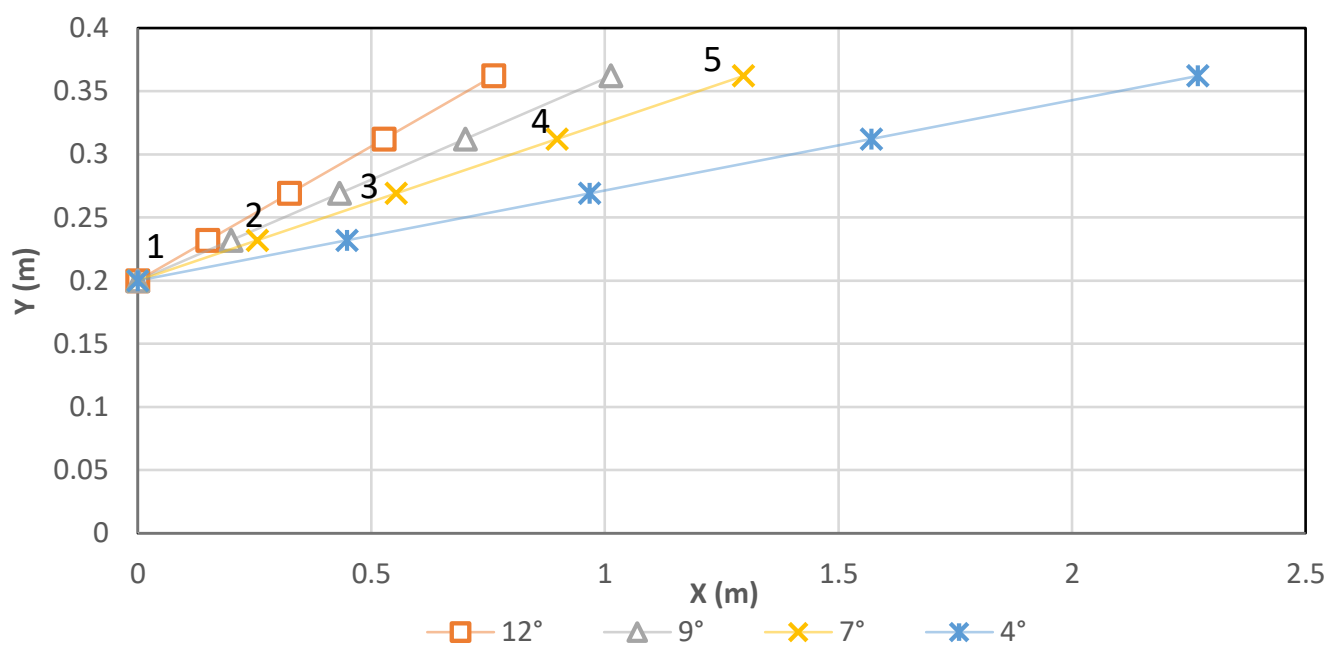

Figura 3.2 Localização dos pontos de sucção ao longo da placa divergente

A figura 3.2 mostra as posições dos pontos de sucção sobre a placa divergente para diferentes valores de $\beta$. Cada símbolo marcador representa um ponto de separação. Para o caso de $\beta=7^{\circ}$ foi utilizada uma numeração para identificar os pontos, que se mostra acima dos marcadores 
Analisando a dinâmica do escoamento no interior do conduto encontramos que valores de $\beta$ maiores que $12^{\circ}$ são pouco práticos para o estudo de bolhas, por causa do forte gradiente adverso, que dificulta o recolamento da bolha. No outro extremo, ângulos menores a $4^{\circ}$ também não são interessantes, pois o fraco gradiente adverso favorece a transição do escoamento sem a ocorrência de separação. Sendo assim, no projeto do aparato restringiu-se a faixa de ângulos de divergência $(\beta)$ entre $4^{\circ}$ e $12^{\circ}$. Com isso, foi possível estimar os pontos de sucção com base na condição mais crítica. A tabela 3.1 mostra os valores calculados para o caso de $\beta=$ $12^{\circ}$.

Outro parâmetro importante é a vazão de sucção. Uma estimativa inicial foi calculada a partir da diferença entre a pressão estática do escoamento que flui através do canal criado pelas placas e a pressão atmosférica. Se consideramos o escoamento de um fluxo potencial, sem perda de carga, encontramos que:

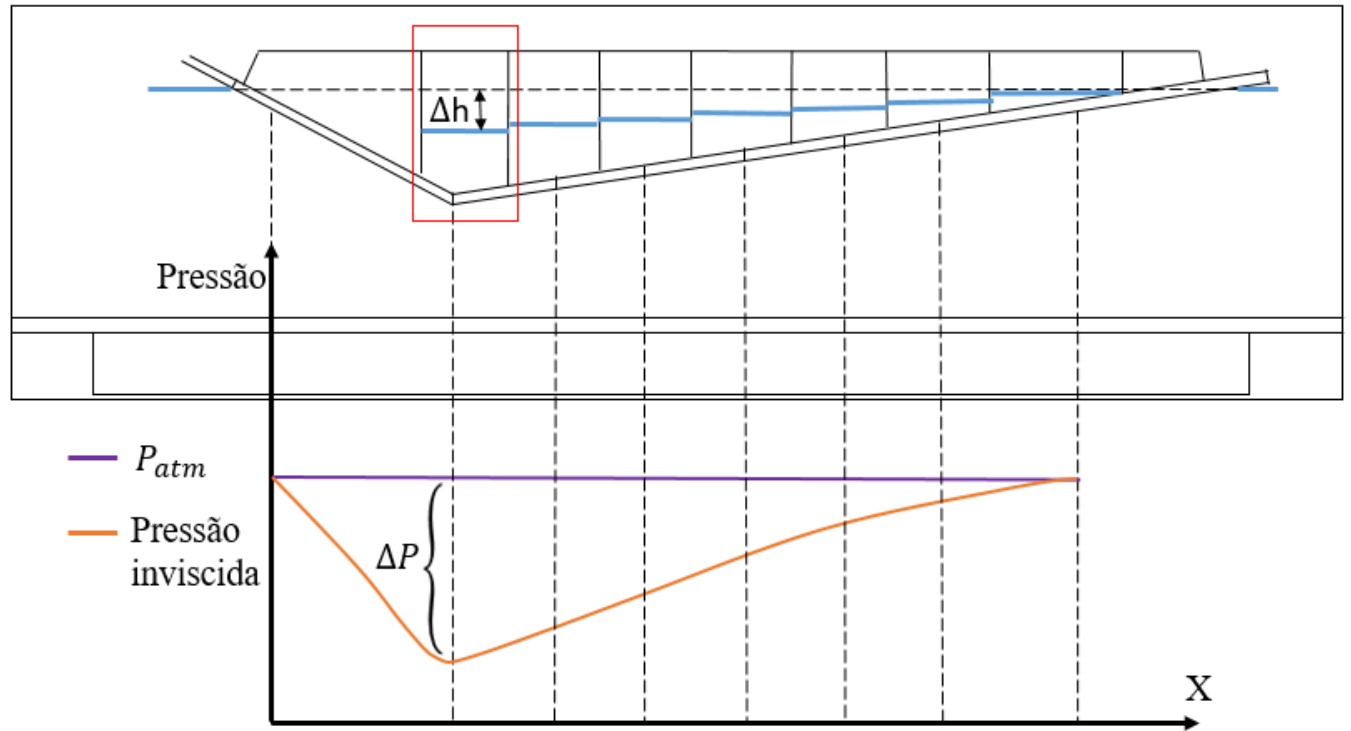

Figura 3.3 Queda de pressão ao longo da placa, considerando um fluxo ideal.

Quando o escoamento flui pela região convergente acelera e atinge a sua velocidade máxima na região da contração e consequentemente a sua pressão mínima, em seguida o fluxo continua atravessando o canal e desacelera na região divergente provocando o incremento da pressão. Este processo de aceleração e desaceleração provoca uma diferencia entre a pressão estática do escoamento e a pressão atmosférica sobre toda a superfície, em particular sobre cada ponto de sucção na superfície divergente. Esta superfície é dividida em secções e delimitada através de placas de modo a obter regiões com pressões relativamente similares. 
Em condições de regime permanente em cada secção encontraríamos um descenso no nível da água que chamamos $\Delta h$, este valor permanece constante e é proporcional à queda de pressão $\Delta P$ local. Como mostrado na figura 3.3. Nesta condição o fluido no interior das secções permanece em repouso, mas podemos quebrar esse equilíbrio impondo um déficit de pressão, isto pode ser realizado extraindo um volume equivalente a um descenso do nível da água igual a $\Delta h$, ou seja, provocando um déficit $\Delta P=\rho g \Delta h$. Com este valor, se quebra o equilíbrio e a pressão da coluna hidrostática é menor que a pressão estática do escoamento no interior do canal, portanto, se gera um fluxo ascendente que tenta compensar esse desequilíbrio com uma velocidade igual a $V_{\text {sucção }}=\sqrt{(2(\Delta P) / \rho)}$ ou $V_{\text {sucção }}=$ $\sqrt{2 g \Delta h}$. A figura 3.4 ilustra os parâmetros envolvidos nesta estimativa.

Levando em conta as dimensões do rasgo de sucção no sentido transversal da placa divergente, com "L" e "W" de comprimento e largura, podemos encontrar a vazão de sucção imposta $\dot{Q}=V_{\text {sucção }} L W$. Este procedimento pode-se repetir para cada ponto de sucção.

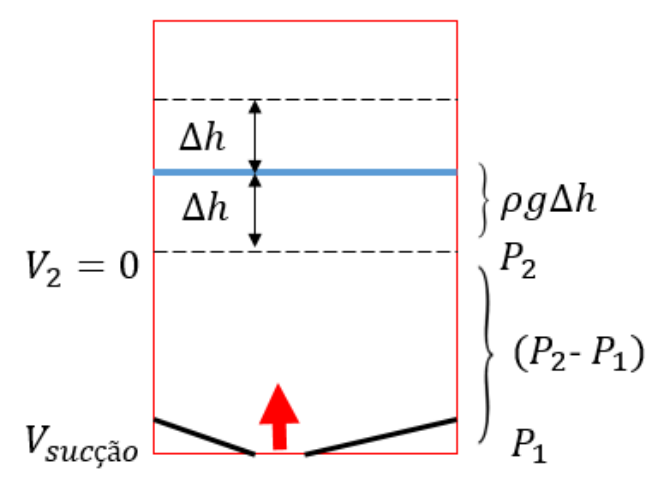

Figura 3.4 Déficit de pressão imposto para gerar a sucção do escoamento, $V_{\text {sucção }}$ é a velocidade de sucção e $\rho g \Delta h$ é o déficit de pressão na coluna hidrostática.

A tabela 3.1 mostra a localização dos pontos de sucção e as vazões de sucção estimadas. 
Tabela 3.1 Posições dos pontos de sucção, e vazão de sucção, para $\beta=12^{\circ}$

\begin{tabular}{|l|c|c|c|c|c|}
\cline { 2 - 6 } \multicolumn{1}{c|}{} & \multicolumn{5}{c|}{ Pontos de Sucção } \\
\cline { 2 - 6 } \multicolumn{1}{c|}{} & 1 & 2 & 3 & 4 & 5 \\
\hline $\mathrm{X}(\mathrm{m})$ & 0 & 0,150 & 0,325 & 0,527 & 0,762 \\
\hline $\mathrm{V}(\mathrm{m} / \mathrm{s})$ & 0,3 & 0,259 & 0,223 & 0,192 & 0,166 \\
\hline$\Delta P(\mathrm{~Pa})$ & $-33,8$ & $-22,2$ & $-13,6$ & $-7,2$ & $-2,5$ \\
\hline$|\Delta P|(\mathrm{mm} . c . a)$ & 3,4 & 2,3 & 1,4 & 0,7 & 0,3 \\
\hline $\mathrm{Q}(\mathrm{L} / \mathrm{h})$ & 3805 & 1044 & 720 & 448 & 224 \\
\hline$V_{\text {sucção }}(\mathrm{m} / \mathrm{s})$ & 0,425 & 0,115 & 0,081 & 0,050 & 0,025 \\
\hline
\end{tabular}

Além das cinco posições de sucção mostradas na tabela 3.1 foi necessário considerar mais duas posições na região da placa divergente que fica no ar, para garantir a sucção da camada limite quando a placa trabalha em ângulos pequenos, essas posições e vazões foram calculadas seguindo a mesma metodologia.

\subsection{2.}

\section{Simulação Numérica}

Simular a formação e evolução das BSL ainda segue sendo um grande desafio devido à complexidade dos processos envolvidos. Em simulações numéricas onde o fluxo de entrada é considerado totalmente turbulento a separação laminar não ocorre, nesse caso pode ocorrer uma separação turbulenta se o gradiente adverso for grande o suficientemente. Além disso, sabe-se da revisão bibliográfica que a dinâmica da bolha depende fortemente das perturbações existentes na camada limite a montante da separação e de ruídos externos. Logo, um grande desafio na simulação do problema é a obtenção de previsões acuradas da dinâmica do escoamento. Na literatura alguns trabalhos buscaram desenvolver correlações para auxiliar na simulação do problema. Abu-Gannam e Shaw (1980) propuseram uma relação entre o número de Reynolds local baseado na espessura de deslocamento, a intensidade turbulenta do escoamento livre e a transição do escoamento. Um dos resultados daquele trabalho é ilustrado na Figura 3.5. De acordo com aquela metodologia, se o $R e_{\theta}$ local for maior que o $R e_{\theta t}$ (Reynolds de transição, experimental), deve-se considerar o escoamento como sendo turbulento.

$\mathrm{Na}$ ferramenta numérica utilizada neste trabalho (FLUENT), existe a possibilidade de se utilizar um modelo semelhante (SST Transition), onde o escoamento turbulento é considerado a partir de condições fornecidas por correlações experimentais. A ideia é análoga à de Abu-Gannam e Shaw (1980). 
Apesar da escolha do modelo de turbulência e do ajuste dos parâmetros desse modelo serem críticos para a simulação de bolhas, neste estudo não se pretende comparar os resultados das bolhas simuladas com os experimentos. O objetivo aqui é simplesmente avaliar se nas condições do experimento a sucção da camada limite é de fato capaz de evitar a separação, e se caso o escoamento seja turbulento antes da contração ainda há a formação da bolha de separação.

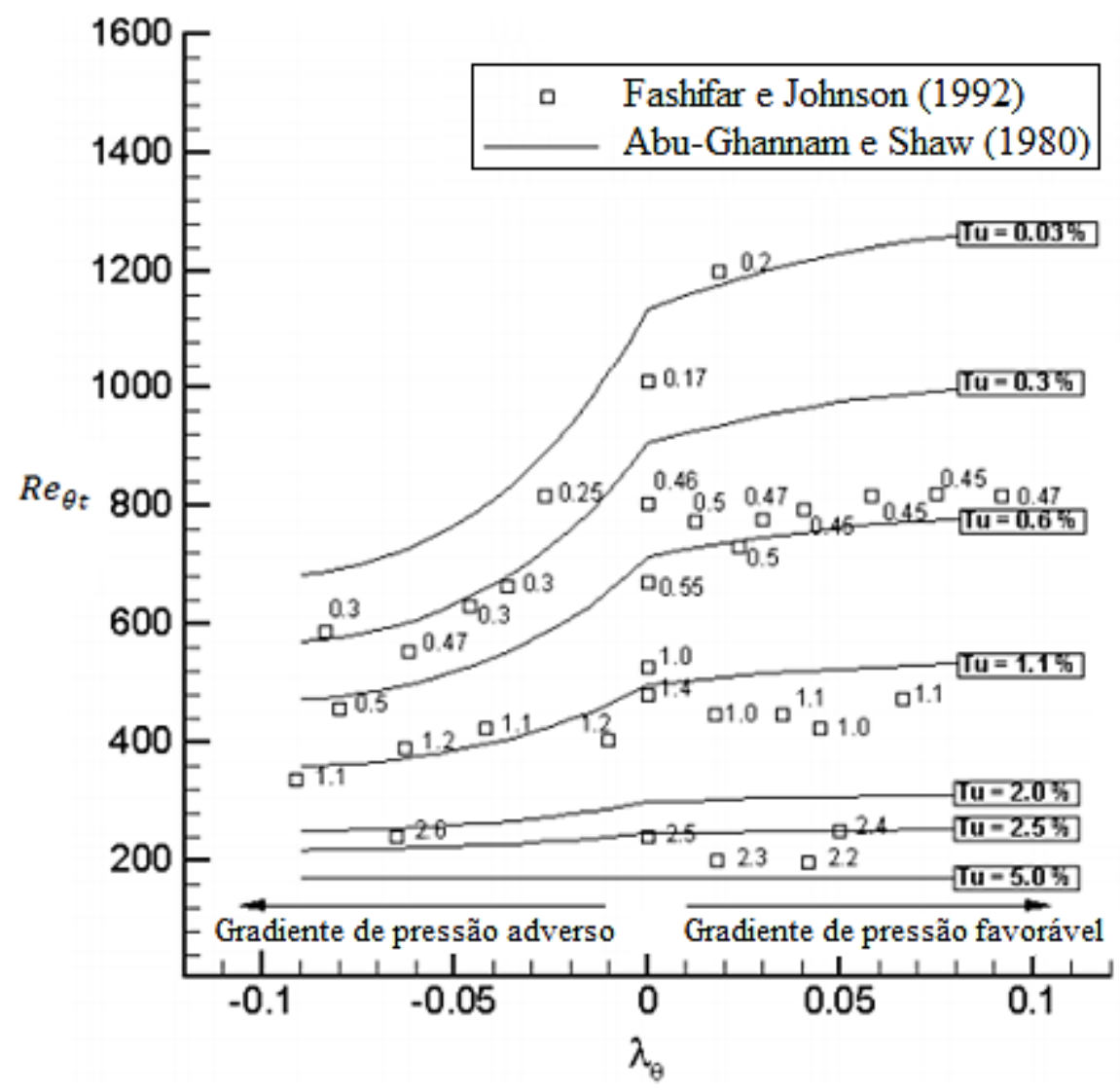

Figura 3.5 Correlação entre $T_{u}$ e $\lambda_{\theta}$. Abu-Gannam e Shaw (1980)

\subsubsection{1.}

\section{Modelo SST transition}

O modelo "SST Transition", utilizado no software FLUENT, é baseado no acoplamento das equações de transporte do modelo "k- $\omega$ SST" com outras duas equações de transporte, uma para a intermitência e outra para o critério de início da transição em termos do número de Reynolds baseado na espessura de momento. Este modelo foi extensivamente validado para uma ampla gama de fluxos de transição, Menter et al. (2004), Langtry et al. (2004). 
Em termos gerais o modelo de transição está baseado no fator de intermitência, definido como o intervalo de tempo em que o fluxo é turbulento dividido entre o intervalo de tempo total. Como mostrado na equação 3.1

$$
\gamma=\frac{t_{t u r b}}{t_{l a m}+t_{\text {turb }}}
$$

onde, para $\gamma=0$ o fluxo é Laminar; para $\gamma=1$ o fluxo é turbulento; e para $0<\gamma<1$ o fluxo é transicional. O objetivo é a equação de transporte para $\gamma$ usando correlações experimentais e formulação local.

A equação de transporte requerida para transportar informação sobre $R e_{\theta t}$ na camada limite é:

$$
\frac{\partial\left(\rho \widetilde{R e}_{\theta t}\right)}{\partial t}+\frac{\partial\left(\rho u_{j} \widetilde{R e}_{\theta t}\right)}{\partial x_{j}}=P_{\theta t}+\frac{\partial}{\partial x_{j}}\left[\sigma_{\theta t}\left(\mu+\mu_{t}\right) \frac{\partial \widetilde{R e}_{\theta t}}{\partial x_{j}}\right]
$$

Onde $P_{\theta t}$ é o termo fonte da equação.

O modelo de transição interage com o modelo de turbulência k- $\omega$ SST, da seguinte forma:

$$
\frac{\partial(\rho k)}{\partial t}+\frac{\partial\left(\rho u_{j} k\right)}{\partial x_{j}}=\widetilde{P}_{k}-\widetilde{D}_{k}+\frac{\partial}{\partial x_{j}}\left[\left(\mu+\sigma_{k} \mu_{t}\right) \frac{\partial k}{\partial x_{j}}\right]
$$

Onde:

$$
\begin{gathered}
P_{k}=\mu_{t} S^{2} ; D_{k}=\beta \rho k \omega \\
\widetilde{P}_{k}=\gamma P_{k} ; \quad \widetilde{D}_{k}=\min (\max (\gamma ; 0,1) ; 1,0) D_{k}
\end{gathered}
$$

A intermitência $\gamma$ é introduzida dentro do termo fonte do modelo turbulento k- $\omega$ SST. No número de Reynolds critico o modelo "SST transition" é ativado. Uma descrição detalhada do modelo pode se encontrar em Menter et al. (2004).

\subsubsection{2.}

\section{Teste de Malha}

O estudo de independência dos resultados com relação à malha é indispensável em todo estudo numérico. No presente caso, isso é especialmente relevante devido aos elevados gradientes de velocidade e pressão na região perto da parede. Neste estudo, a malha foi projetada com elementos retangulares perto da 
parede e elementos poligonais não regulares longe da parede, como mostrado na figura 3.6

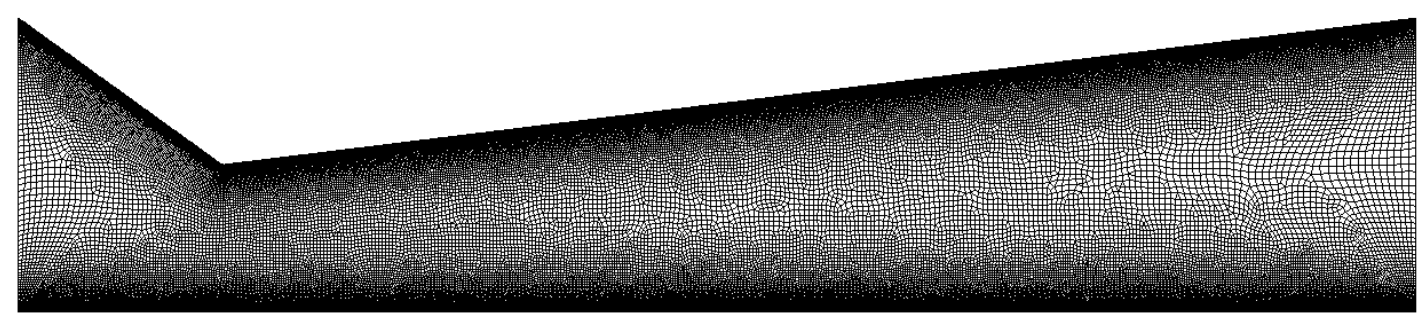

$0.5(\mathrm{~m})$

(a)

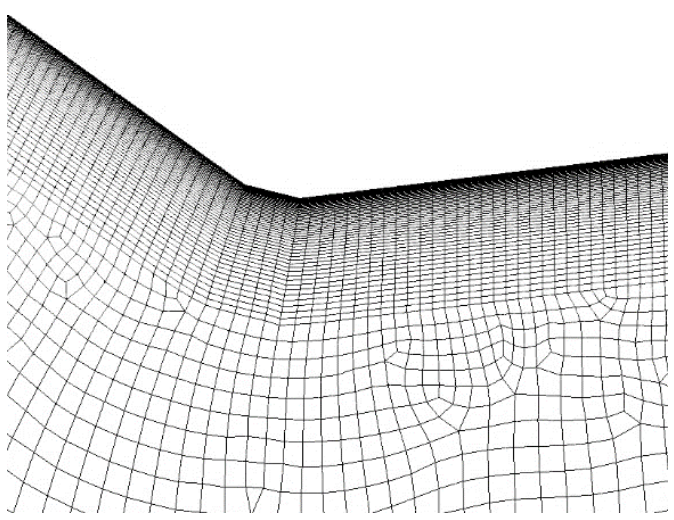

(b)

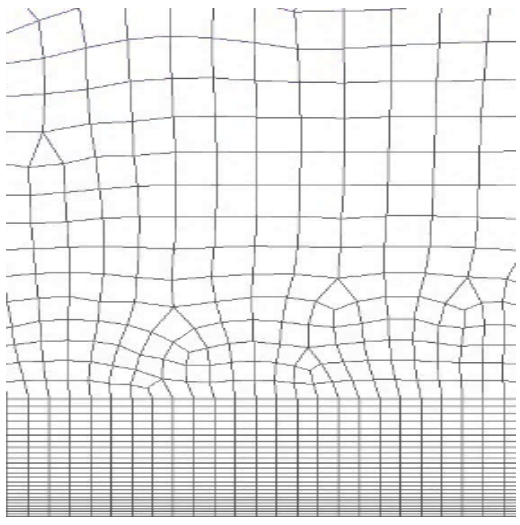

(c)

Figura 3.6 (a) Vista frontal da malha, (b) refinamento da superfície superior (c) refinamento da superfície inferior.

Para capturar os fenômenos de interesse, foi necessário um refinamento em algumas posições ao longo da placa e no sentido normal às paredes. A figura 3.6b, exibe o refinamento na superfície superior. Enquanto que a figura 3.6c, mostra o refinamento sobre a placa plana. Os parâmetros que definem o refinamento são: a taxa de expansão normal à parede e o comprimento longitudinal do elemento.

As condições de contorno utilizadas na simulação foram: $\mathrm{Na}$ entrada, utilizou-se a condição de velocidade impondo um perfil de Blasius que corresponde a um perfil localizado a $378 \mathrm{~mm}$ desde o bordo de ataque de uma placa plana com uma velocidade da corrente livre de $0.15 \mathrm{~m} / \mathrm{s}$. Para simplificação do problema, optou-se por iniciar as simulações somente a partir do início do canal convergente. Assim, considerou-se o desenvolvimento da camada limite desde o bordo de ataque assumindo escoamento sem gradiente de pressão. Nesse caso a camada limite é maior do que a esperada caso o gradiente de pressão tivesse sido incluído. Isso 
favorece a separação do escoamento. Logo, o caso analisado na simulação tende a ser mais conservador do que o que se espera na prática.

A velocidade da corrente livre foi assumida como $0.15 \mathrm{~m} / \mathrm{s}$, que é o valor em que os experimentos deverão ser realizados. Essa velocidade deve ser observada na corrente livre no início da região convergente. Na restrição a velocidade esperada é de $0.3 \mathrm{~m} / \mathrm{s}$, já que a relação de contração é de $2: 1$.

$\mathrm{Na}$ superfície da placa divergente, utilizou-se a condição de velocidade de saída em pequenas secções que representam as ranhuras de sucção, uma estimativa para estas velocidades foi mostrada na secção 3.1.1

Na saída, utilizou-se a condição de pressão, que corresponde à pressão atmosférica. Para as partes restantes foi empregada a condição de parede.

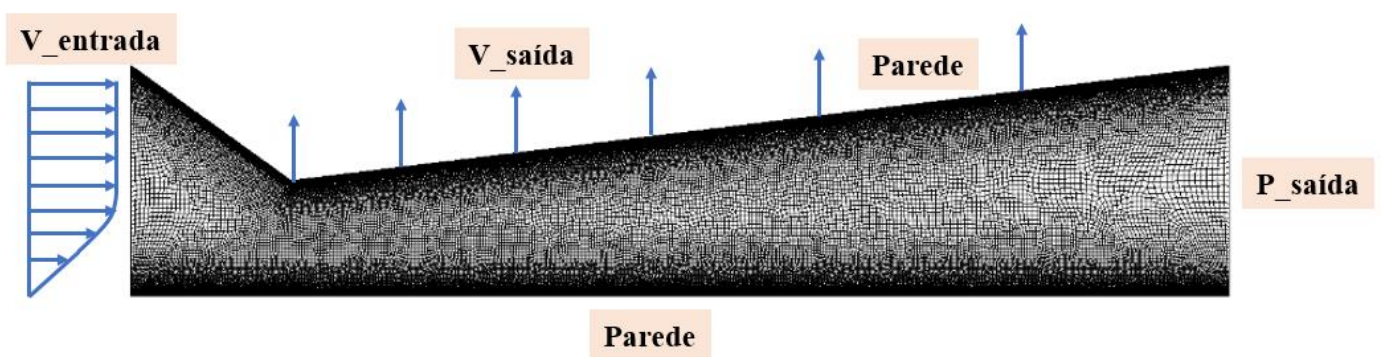

Figura 3.7 Condições de contorno sobre o domínio computacional

A figura 3.7 indica as condições de contorno utilizadas na simulação. Definidas as condições de contorno, pode-se prosseguir com o estudo de independência dos resultados.

O estudo de independência da malha foi iniciado com o refinamento da malha na direção do escoamento. Esse refinamento foi ajustado através do comprimento dos volumes de controle. A tabela 3.2 mostra os parâmetros envolvidos neste teste. A taxa de expansão normal à parede e a altura do primeiro volume de controle foram mantidos fixos, enquanto que foi variada a densidade da malha longitudinal através do comprimento dos elementos. 
Tabela 3.2 Parâmetros envolvidos na verificação do refinamento longitudinal

\begin{tabular}{|l|c|c|c|c|}
\cline { 2 - 5 } \multicolumn{1}{c|}{} & \multicolumn{4}{c|}{ Malha } \\
\cline { 2 - 5 } \multicolumn{1}{c|}{} & M1 & M2 & M3 & M4 \\
\hline $\begin{array}{l}\text { Comprimento longitudinal do } \\
\text { elemento (mm) }\end{array}$ & 0.5 & 1 & 3 & 5 \\
\hline Taxa de expansão normal à parede & 1.05 & 1.05 & 1.05 & 1.05 \\
\hline $\begin{array}{l}\text { altura do primeiro volume de } \\
\text { controle (mm) }\end{array}$ & 0.05 & 0.05 & 0.05 & 0.05 \\
\hline
\end{tabular}

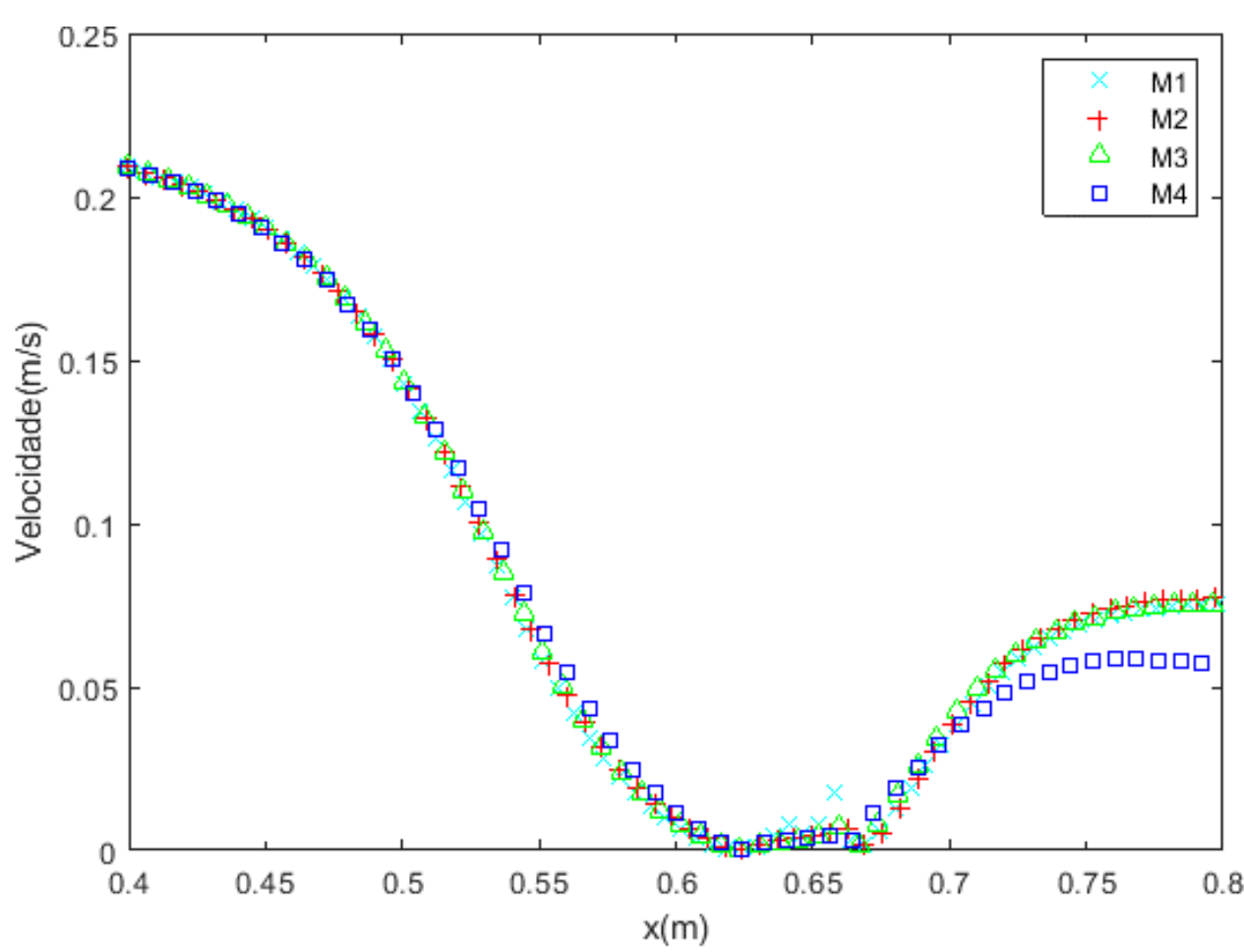

Figura 3.8 Distribuição da velocidade ao longo de uma linha horizontal no interior da bolha para diferentes configurações de malha. (A seguir, $x=0$ encontra-se no extremo inferior esquerdo do domínio computacional)

A Figura 3.8 mostra as distribuições da velocidade para quatro tipos de malha. Os dados foram tomados ao longo de uma linha horizontal que recorre todo o comprimento da bolha a uma altura de $5 \mathrm{~mm}$ da parede. Julga-se que o entorno dessa altura seja a região onde se espera as maiores variações de velocidade. O gráfico indica que para os diferentes valores do comprimento longitudinal dos volumes de controle, as malhas M1, M2 e M3 atingem a condição de independência dos resultados, enquanto que a malha M4 se afasta na região de recolamento da bolha (entre $0.65 \mathrm{~m}$ e $0.75 \mathrm{~m}$ ). No interior da bolha, o caso com maior refinamento (M1) 
apresentou uma variação em relação aos demais casos. Como o objetivo aqui não é a simulação do escoamento no interior da bolha, assumiu-se que o refinamento das malhas M2 e M3, eram adequados para atingir a independência dos resultados e estimar o comprimento da bolha e ponto de separação do escoamento.

Continuando o estudo de malha, é necessário verificar o refinamento normal à parede. Para isso foi tomada como referência a malha M2 e avaliou-se os resultados com a mudança da taxa de expansão normal à parede. A Tabela 3.3 mostra os valores utilizados neste teste.

Tabela 3.3 Parâmetros envolvidos na verificação do refinamento normal à parede

\begin{tabular}{|l|c|c|c|}
\cline { 2 - 4 } \multicolumn{1}{c|}{} & \multicolumn{3}{c|}{ Malha } \\
\cline { 2 - 4 } \multicolumn{1}{c|}{} & M2 & M5 & M6 \\
\hline $\begin{array}{l}\text { Comprimento longitudinal do } \\
\text { elemento(mm) }\end{array}$ & 1 & 1 & 1 \\
\hline Taxa de expansão normal à parede & 1.05 & 1.1 & 1.2 \\
\hline $\begin{array}{l}\text { altura do primeiro volume de controle } \\
\text { (mm) }\end{array}$ & 0.05 & 0.05 & 0.05 \\
\hline
\end{tabular}

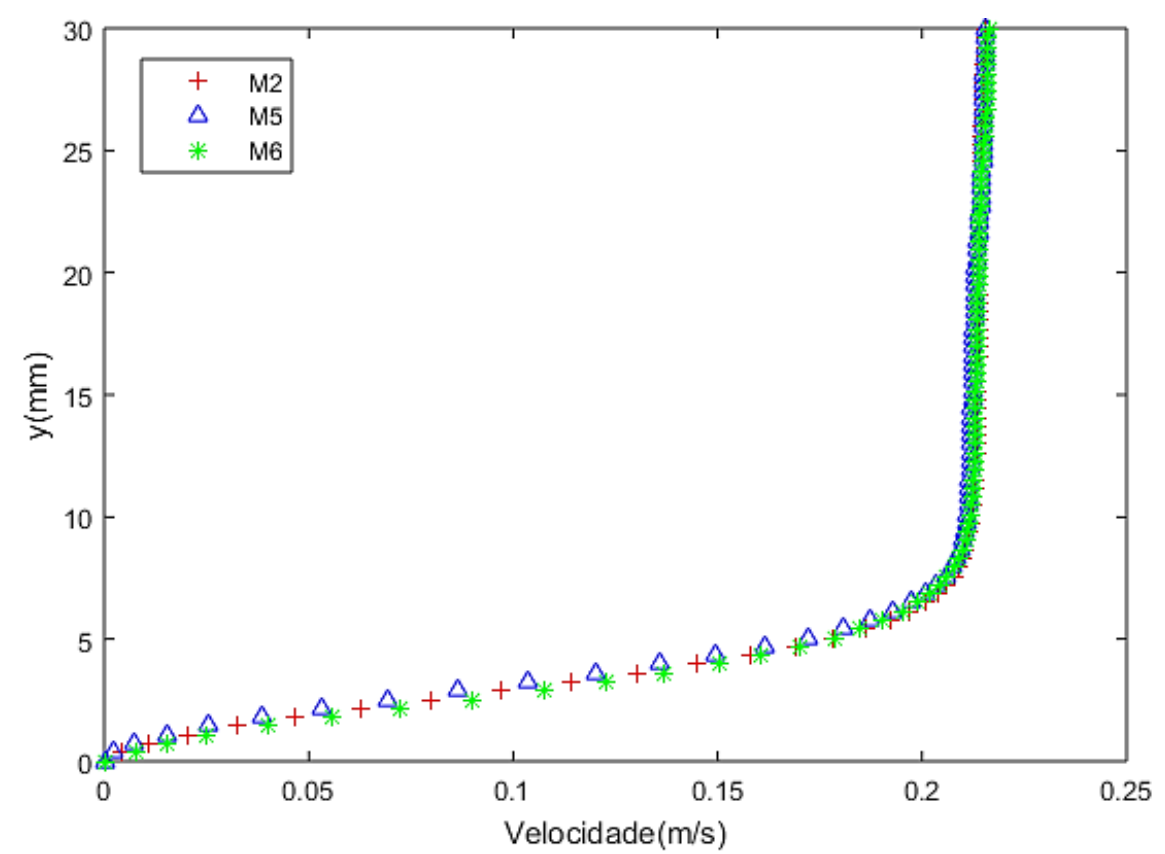

Figura 3.9 perfis de velocidade tomados a montante do ponto de separação, na posição $\mathrm{x}=400 \mathrm{~mm}$.

A figura 3.9 mostra os perfis de velocidade que foram tomados na posição $\mathrm{x}=400$ que corresponde à região com gradiente de pressão adverso, a montante do ponto de separação. Estes perfis indicam que todas as taxas de expansão normal à parede testadas satisfazem a condição de independência da malha. No entanto, vamos considerar em este trabalho os valores recomendados por FLUENT para a 
taxa de expansão normal à parede em fluxos com gradientes de pressão, que é recomendado como inferior a 1.1. Portanto, a malha selecionada é a malha M2. Em resumo, a malha apresenta as caraterísticas especificadas na Tabela 3.4

Tabela 3.4 Parâmetros da malha selecionada

\begin{tabular}{|l|r|}
\hline Número de nós & 253074 \\
\hline Número de elementos & 251166 \\
\hline Comprimento longitudinal do elemento $(\mathrm{mm})$ & 1 \\
\hline Taxa de expansão normal à parede & 1.05 \\
\hline Altura da primeira camada $(\mathrm{mm})$ & 0.05 \\
\hline Qualidade ortogonal mínima & 0.25 \\
\hline Máxima relação de aspecto & 21 \\
\hline
\end{tabular}

\subsubsection{3.}

\section{Resultados da Simulação}

A simulação conseguiu prever a formação da bolha de separação laminar sobre a placa plana, no caso com ângulo $\beta=7^{\circ}$. A figura 3.10 mostra o quadro de linhas de corrente contornando as superfícies. A bolha se forma na superfície da placa mais a jusante da contração, para ter uma melhor visualização a figura 3.11 mostra uma ampliação dessa região.

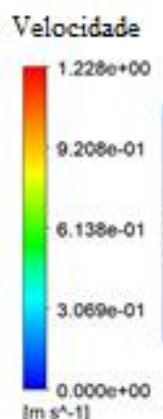

Figura 3.10 Quadro de linhas de corrente no interior da região formada pelas placas. O fluxo de entrada é laminar

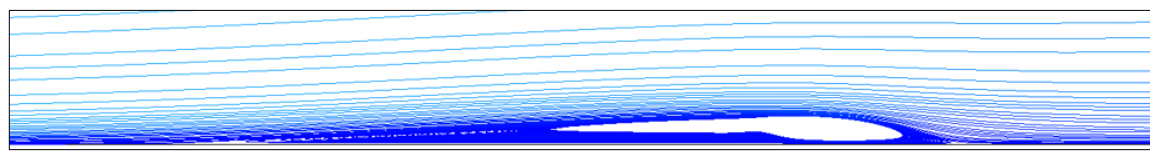

Figura 3.11 Bolha de separação laminar sobre a superfície da placa plana 
A BSL prevista pela simulação tem um comprimento aproximado de $180 \mathrm{~mm}$ e uma altura de $15 \mathrm{~mm}$, o ponto de separação está localizado a $854 \mathrm{~mm}$ desde o bordo de ataque.

$\mathrm{Na}$ região perto da parede da placa divergente, as linhas de corrente não mostraram efeitos de sumidouro devido à sucção excessiva, isto sugere que a estimativa inicial baseada na diferença de pressão foi adequada. No entanto para verificar isso foram feitas simulações mudando o valor das velocidades, os resultados deste teste são apresentados na tabela 3.5

Tabela 3.5 verificação da sucção para $\beta=7^{\circ}$

\begin{tabular}{|c|c|c|c|c|c|c|c|}
\cline { 2 - 7 } \multicolumn{1}{c|}{} & \multicolumn{6}{c|}{ Pontos de sucção, placa divergente, $\beta=7^{\circ}$} \\
\cline { 2 - 7 } \multicolumn{1}{c|}{} & 1 & 2 & 3 & 4 & 5 & 6 & 7 \\
\hline$V_{\text {sucção }}$ & ok & ok & ok & ok & ok & ok & ok \\
\hline $2 * V_{\text {sucção }}$ & \multicolumn{8}{|c|}{ efeitos de sumidouro } \\
\hline $0.5 * V_{\text {sucção }}$ & \multicolumn{6}{|c|}{ Espessamento da camada limite, iminência de separação } \\
\hline
\end{tabular}

Os resultados mostrados na tabela 3.5 confirmaram que a vazão de sucção imposta para cada ponto foi apropriada. Os resultados sugerem que no caso com $\beta=7^{\circ}$, as vazões de sucção podem ser reduzidas pela metade sem que haja separação. Isso é interessante e demonstra que a faixa de operação do experimento não é muito restrita, o que facilita o ajuste dos ensaios. De qualquer maneira, daqui em diante utilizou-se nas simulações somente a velocidade de sucção prevista inicialmente $\left(V_{\text {suç̧ão}}\right.$, de acordo com a tabela 3.1). Verificou-se também a efetividade desta vazão de sucção para outros ângulos de divergência $(\beta)$. Os resultados destas simulações são apresentados na tabela 3.6 
Tabela 3.6 Verificação da sucção para diferentes ângulos de divergência mantendo a vazão constante

\begin{tabular}{|c|c|c|c|c|c|c|c|}
\cline { 2 - 8 } \multicolumn{1}{c|}{} & \multicolumn{7}{c|}{ Pontos de sucção, placa divergente } \\
\cline { 2 - 8 } \multicolumn{1}{c|}{} & 1 & 2 & 3 & 4 & 5 & 6 & 7 \\
\hline$\beta=4^{\circ}$ & ok & ok & ok & ok & ok & ok & ok \\
\hline$\beta=7^{\circ}$ & ok & ok & ok & ok & ok & ok & ok \\
\hline$\beta=9^{\circ}$ & ok & ok & ok & ok & ok & ok & ok \\
\hline$\beta=12^{\circ}$ & \multicolumn{8}{c|}{ Precisa incrementar a vazão } \\
\hline
\end{tabular}

Depois de realizada a verificação da sucção através dos dados fornecidos pelas simulações, temos uma estimativa da faixa de vazões de trabalho, e com isso, das bombas que devem ser escolhidas.

$\mathrm{Na}$ condição em que a sucção é desativada, o efeito sobre a camada limite é imediato, para visualizar isto, foi realizada uma simulação sem sucção, os resultados são mostrados na figura 3.12, onde pode-se ver a região de recirculação formada após o fluxo passar pelo vértice formado entre as placas convergente e divergente, a geração desta região e os vórtices que se desprendem dela são prejudiciais para nosso estudo mesmo que a bolha ainda seja formada.
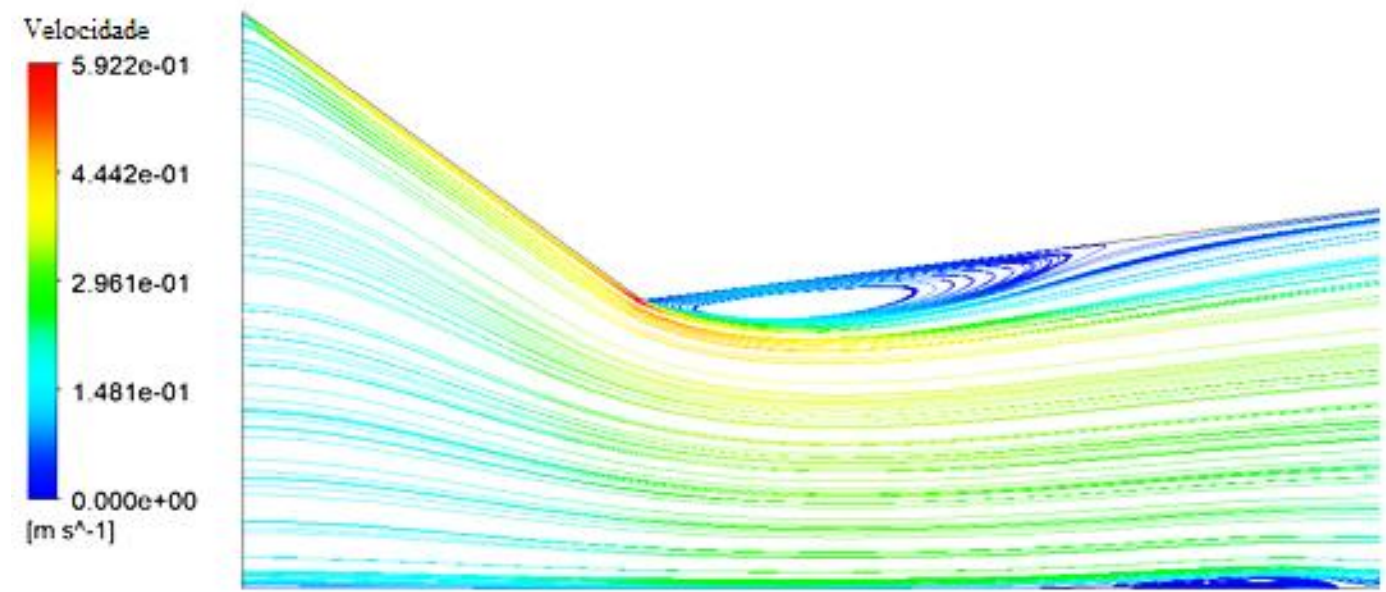

Figura 3.12 Quadro de linhas de corrente no interior da região formada pelas placas, para o caso sem sucção da camada limite. 
Um fenômeno de importância em nosso estudo é a interação entre o jato inserido e a camada limite. Devido à complexidade de esse tipo de simulação, em este trabalho apenas vamos simular o caso em que a perturbação foi tal que o fluxo a jusante da injeção tornou-se turbulento. Nessa condição, espera-se que a bolha não seja formada. Isto será aproximado mudando o modelo "SST Transition", para o modelo turbulento "k- $\omega S S T$ " com uma intensidade turbulenta na entrada de $10 \%$, a especificação dos detalhes do modelo "k- $\omega S S T$ " estão além do escopo deste trabalho. Os resultados desta simulação são mostrados na figura 3.13 e 3.14

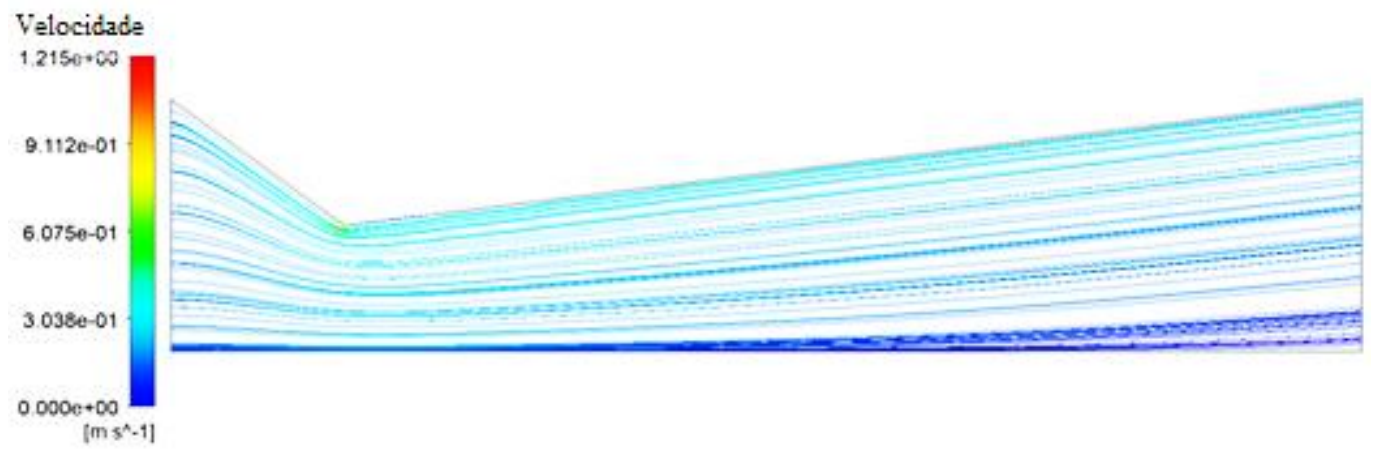

Figura 3.13 Quadro de linhas de corrente no interior da região formada pelas placas, para um fluxo de entrada turbulento

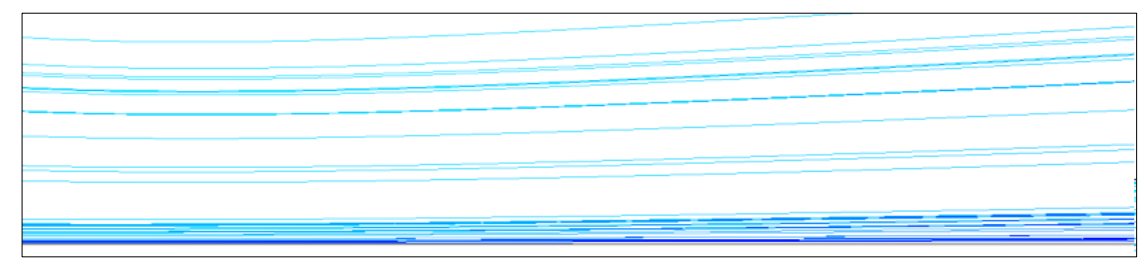

Figura 3.14 Ampliação da região perto da parede, onde se verifica que a bolha não foi formada

As bolhas de separação laminar têm uma influência significativa na distribuição de pressão, tomando os dados da simulação viscosa e adicionalmente realizando uma simulação invíscida, podemos encontrar a curva característica que representa seu efeito, como mostrado na figura 3.15 


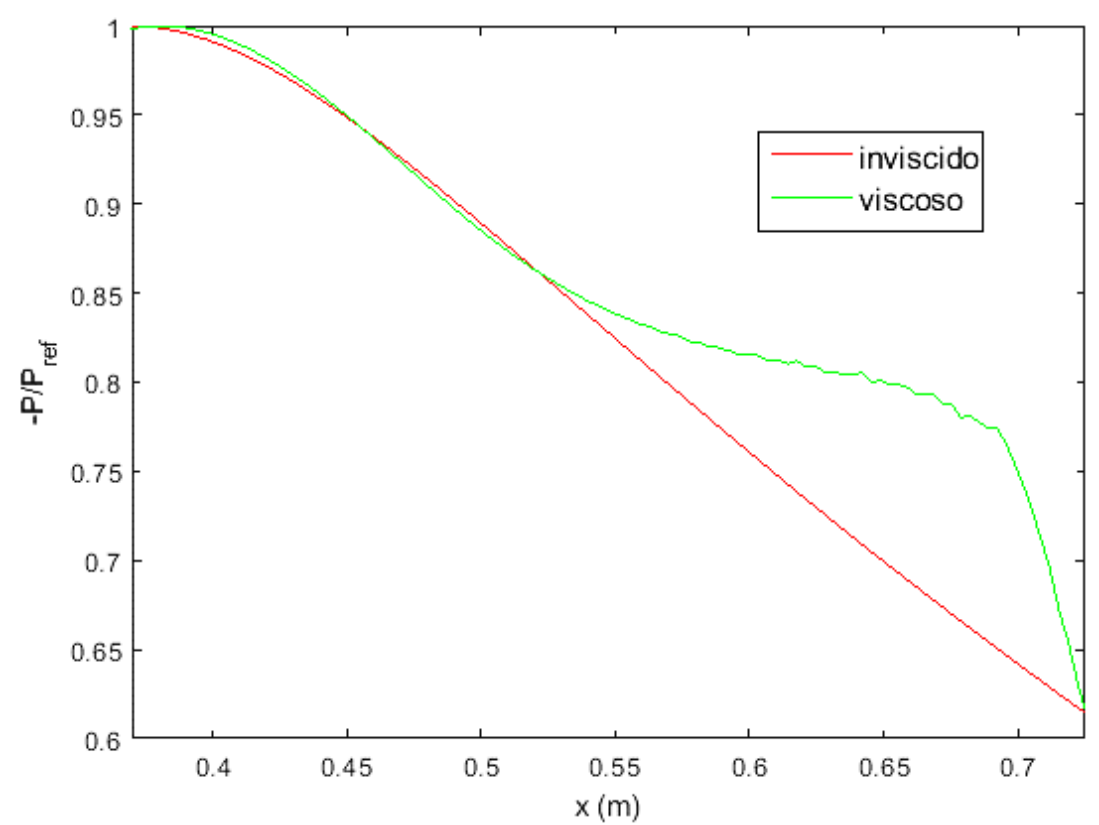

Figura 3.15 Influência da bolha de separação na distribuição da pressão

Simulações numéricas para os ângulos de divergência de $7^{\circ}, 9^{\circ}$ e $12^{\circ}$ foram

feitas com o intuito de caracterizar a topologia geral da bolha se desenvolvendo baixo diferentes gradientes de pressão. A tabela 3.7 exibe os resultados encontrados.

Tabela 3.7 Características gerais da topologia da bolha para diferentes ângulos de divergência.

\begin{tabular}{|l|c|c|c|c|}
\cline { 2 - 5 } \multicolumn{1}{c|}{} & $\begin{array}{c}\text { Ponto de } \\
\text { separação } \\
\mathrm{x}(\mathrm{m})\end{array}$ & $\begin{array}{c}\text { Ponto de } \\
\text { reconexão } \\
\mathrm{x}(\mathrm{m})\end{array}$ & $\begin{array}{c}\text { Comprimento } \\
\text { da bolha } \\
\Delta x(\mathrm{~mm})\end{array}$ & $\begin{array}{c}\text { Altura da } \\
\text { bolha } \\
\Delta \mathrm{y}(\mathrm{mm})\end{array}$ \\
\hline$\beta=7^{\circ}$ & 0,49 & 0,72 & 220 & 9 \\
\hline$\beta=9^{\circ}$ & 0,45 & 0,69 & 240 & 11 \\
\hline$\beta=12^{\circ}$ & 0,40 & 0,71 & 310 & 11 \\
\hline
\end{tabular}

Destes resultados encontramos que enquanto o ângulo de divergência se incrementa o gradiente de pressão adverso é maior e consequentemente o ponto de separação se adianta. Por sua vez, o ponto de reconexão não apresentou uma mudança significativa. Enquanto que a altura da bolha teve um ligeiro incremento. Essas informações sevem como guia, para a montagem dos equipamentos de medição. 


\section{2.}

\section{Placa plana}

A placa plana foi construída em policarbonato transparente e consiste em três regiões: O bordo de ataque, a placa plana propriamente dita e o flap. As dimensões gerais do conjunto são 3160x830x12mm, correspondendo ao comprimento, largura e espessura, respetivamente. O desenho geral da placa plana pode ser observado na figura 3.16

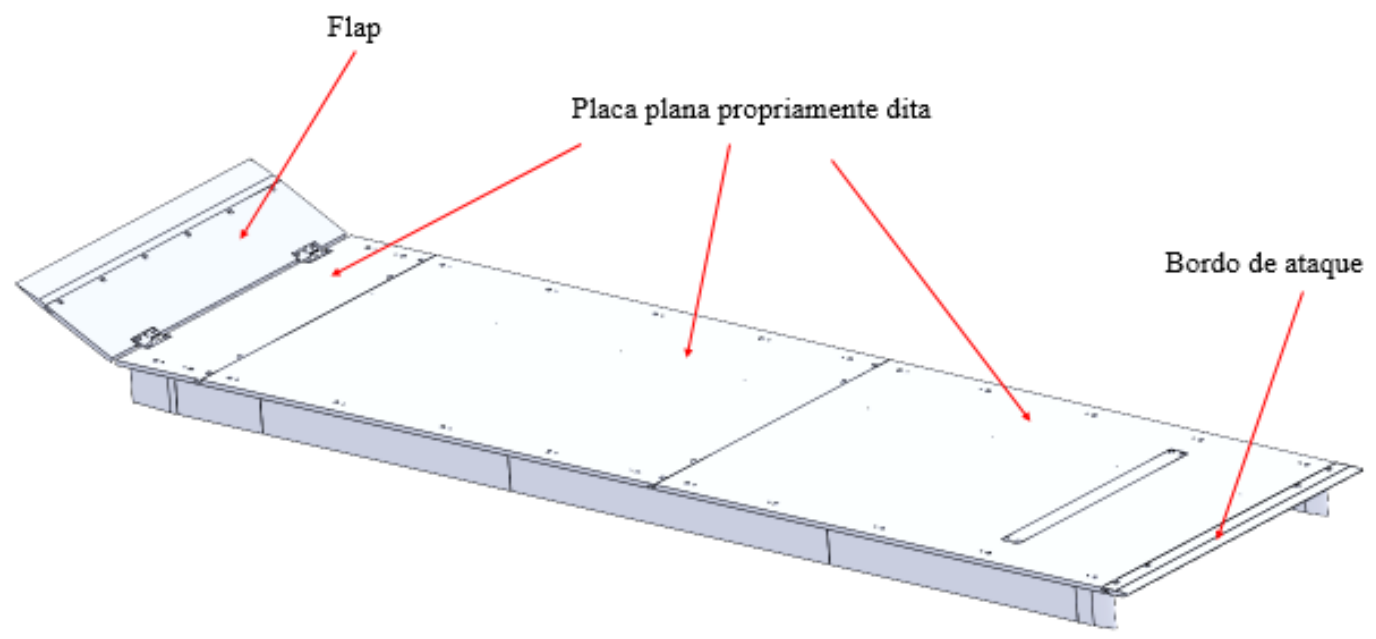

Figura 3.16 Desenho do conjunto da placa plana

A escolha do policarbonato como material de construção para a placa plana foi devido a transparência, facilidade de usinagem, maior resistência mecânica e melhor controle dimensional em relação ao acrílico. Já a placa divergente foi construída em acrílico, pois as tolerâncias dimensionais de montagem eram menos rígidas. Ambos materiais possuem bom acabamento superficial e qualidades óticas adequadas para uso com técnicas ópticas de medição.

O bordo de ataque da placa plana teve que ser especialmente projetado, pois de acordo com Lin et al. (1992) a junção entre o bordo de ataque e a placa pode-se tornar uma fonte de elevada receptividade. Logo, tomou-se extremo cuidado no alinhamento das superfícies e a vedação da junção. A geometria desse bordo foi projetada com um perfil de dupla elipse que ajuda a manter estável o ponto de estagnação. Essa geometria é utilizada em diversos trabalhos da literatura, dentre os quais destaca-se o estudo de Gaster (1969). As equações das elipses são: 
$\frac{x^{2}}{36^{2}}+\frac{y^{2}}{10^{2}}=1$ e $\frac{x^{2}}{36^{2}}+\frac{y^{2}}{2^{2}}=1$, com as dimensões em milímetros. A figura 3.17 mostra o desenho do bordo de ataque.

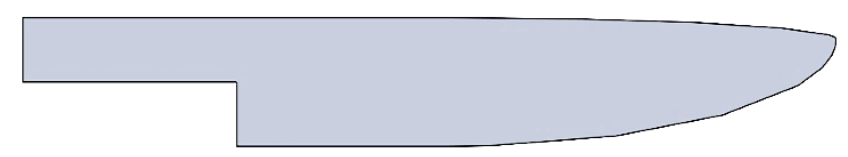

Figura 3.17 Desenho do bordo de ataque, baseado em um perfil de dupla elipse

As medidas do conjunto da placa plana propriamente dita são 2850x830x12mm e está composta de três partes. A placa localizada imediatamente depois do bordo de ataque tem uma fenda na direção transversal a $425 \mathrm{~mm}$ do bordo de ataque, que permite colocar uma peça para orientar a injeção do jato de perturbação ou algum elemento que faz outro tipo de excitação de ondas de instabilidade. $\mathrm{O}$ conjunto das três placas estão montados com um sistema de porca e contra porca sobre apoios laterais que nos dá a flexibilidade para realizar ajustes finos no nível das placas. A figura 3.18 mostra a posição da fenda.

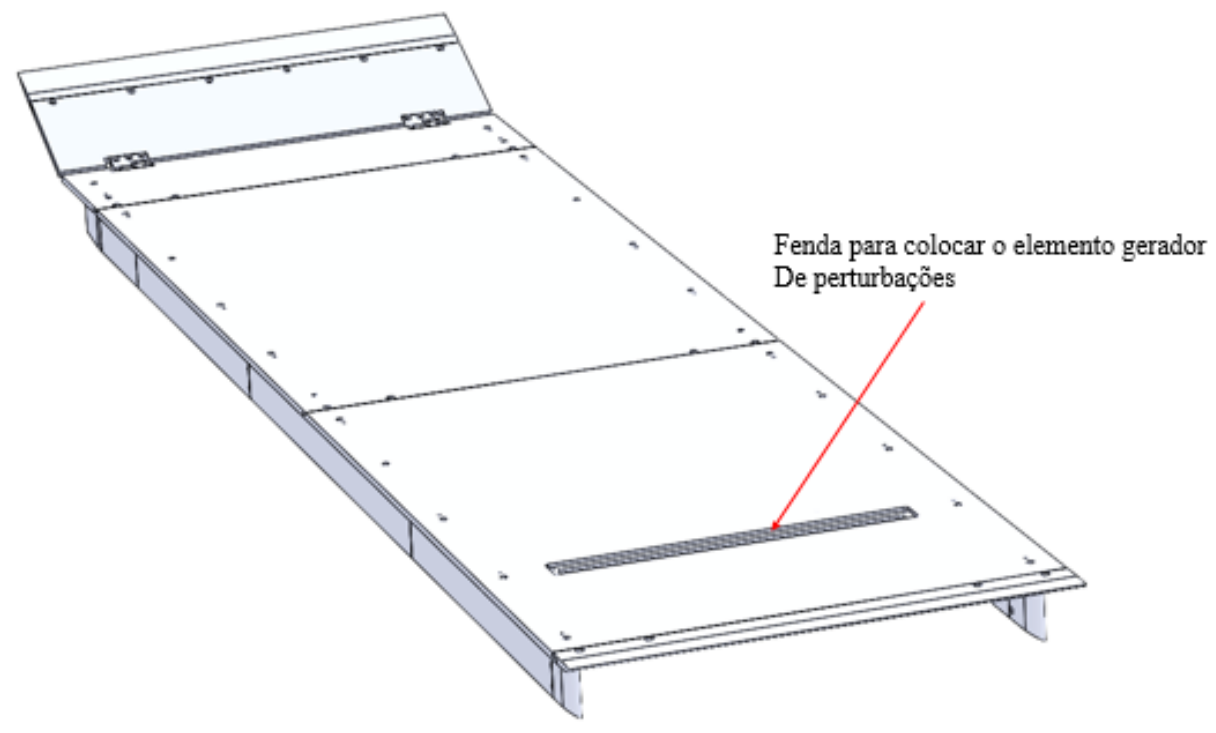

Figura 3.18 Posição da fenda sobre a placa plana

Na região traseira, seguindo a Gaster (1969) utilizou-se um flap para o controle do ponto de estagnação cujas dimensões são 290x830x12mm. O flap foi utilizado para compensar a diferença de pressão entre as partes superior e inferior da placa. O objetivo do dispositivo é forçar o ponto de estagnação do escoamento a ficar na parte superior do bordo de ataque. Assim, a camada limite se inicia na 
superfície de trabalho da placa e evita-se a separação do escoamento no bordo de ataque.

O conjunto da placa plana está montado a uma altura de $150 \mathrm{~mm}$ acima da superfície inferior do canal e 400mm a jusante da secção de entrada do fluxo.

\section{3.}

\section{Imposição do gradiente de pressão}

A imposição do gradiente de pressao foi feito através de uma estrutura de duas placas planas articuladas com dobradiças, as placas dividem a secção de testes numa região convergente e posteriormente divergente seguindo o sentido da corrente. $\mathrm{O}$ desenho da placa divergente foi feito de tal forma que permita a modificação da distribuição de pressão imposta, mudando o ângulo de divergência. A faixa do ângulo de divergência é de $4^{\circ}$ até $12^{\circ}$ e o ângulo de convergência tem um valor fixo de $34^{\circ}$. Cabe sinalar que a escolha de um vértice na constrição e não de uma região de transição suave entre as placas se deve ao fato da sua facilidade de fabricação.

A influência do gradiente de pressão favorável na região convergente e seu efeito estabilizante foi levado em conta na localização do elemento gerador de perturbações. A localização desse dispositivo deve ser tal que as perturbações consigam atravessar a região estabilizante sem perda excessiva de potência e atingir a região do gradiente de pressão adverso para excitar o processo de transição da camada limite. Além disso, faz-se uso da região estável para que o escoamento filtre perturbações indesejadas de alta frequência e alto número de onda espacial (spanwise).

$\mathrm{Na}$ parte divergente foram projetadas regiões de sucção através de fendas transversais ao longo da placa, a primeira fenda está localizada no vértice das placas e é a posição mais crítica devido à abrupta mudança na direção do fluxo, em essa posição a vazão de sucção é mais elevada. O cálculo da posição para cada fenda seguinte no sentido longitudinal foi exposto na secção 3.1.1

Em cada secção foram instaladas bombas de sucção cujas vazões podem ser ajustadas através de potenciômetros, o fluxo sugado é novamente inserido no canal de água, depois do final da seção de testes, estima-se que a sua inserção no fluxo 
principal não causa perturbações significativas para nosso estudo. Um esquema da placa convergente-divergente pode ser observado na figura 3.19

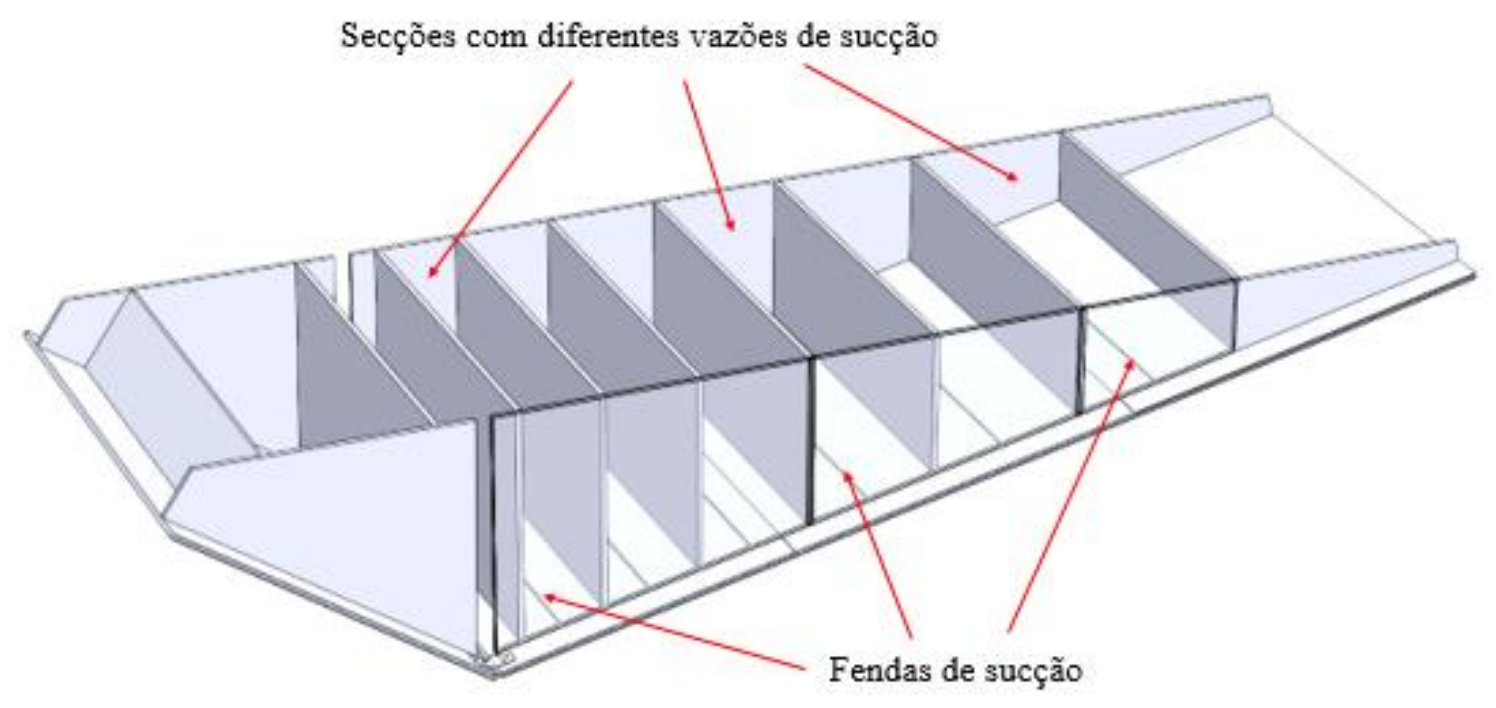

Figura 3.19 Desenho da placa convergente - divergente

\section{4. Excitação artificial de ondas de instabilidade}

O sistema de excitação artificial é responsável de perturbar a camada limite para introduzir ondas de instabilidade. Este sistema está composto por uma bomba e uma peça que orienta a perturbação. O jato perturbador está orientado na direção normal à parede da placa plana. Para a injeção do jato foi desenhada uma peça em forma de barra de $600 \times 50 \times 12 \mathrm{~mm}$ de comprimento, largura e espessura respectivamente, possui 83 furos de $2.5 \mathrm{~mm}$ de diâmetro interno distribuídos longitudinalmente em sua parte inferior, além disso na sua superfície superior tem uma fenda de $500 \mathrm{~mm}$ de comprimento e $0.3 \mathrm{~mm}$ de largura que comunica os furos da parte inferior da peça com a superfície da placa plana em sua parte superior, tal como mostrado na figura $3.20 \mathrm{~b}$. A grande quantidade de tubos por onde se pode inserir o jato fornece a possibilidade de configurar distintas formas de perturbação.

O escoamento oscilatório foi induzido por uma bomba de seringa projetada no âmbito deste trabalho conforme ilustrado na Figura 3.20a. O mecanismo possui um movimento alternativo que permite realizar injeção e sucção do jato com uma frequência de até $0.30 \mathrm{~Hz}$. Esse limite na frequência pode ser modificado facilmente mudando o Servo motor que impulsiona o mecanismo. A frequência de 
excitação foi escolhida com base na curva de estabilidade neutra da camada limite (Figura 2.13). Na forma adimensional, a frequência de $0.30 \mathrm{~Hz}$ corresponde a uma frequência de 70E-6, que de acordo com a Figura 2.13 está na faixa de ondas Tollmien-Schlichting mais instáveis.

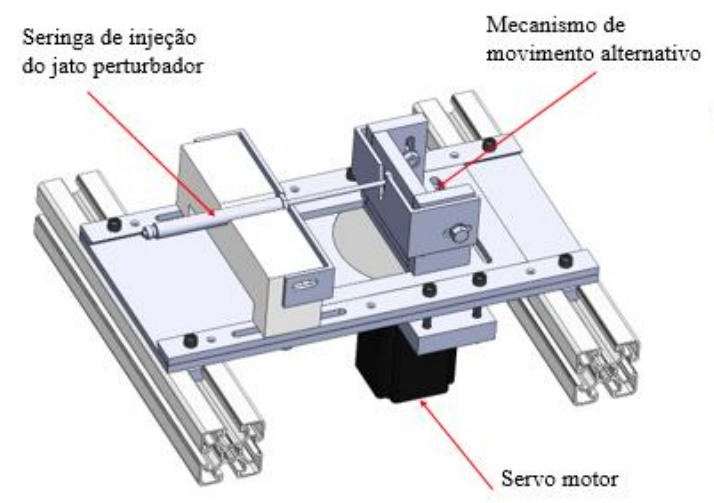

(a)

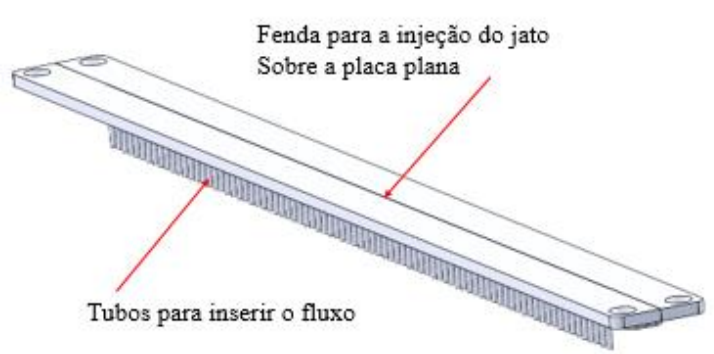

(b)

Figura 3.20 (a) bomba de seringa, (b) peça encarregada de gerar o jato

A dinâmica da inserção das ondas de instabilidade consiste na formação de um jato artificial que é injetado na camada limite. Se o fluxo supera o número de Reynolds crítico baseado na espessura de deslocamento e a injeção da perturbação se realiza com uma frequência instável se desencadeará o processo de crescimento das perturbações. Neste trabalho o elemento gerador de perturbações ficou localizado a $175 \mathrm{~mm}$ no montante da contração. A figura 3.21 mostra um esquema do processo de inserção de ondas de instabilidade.

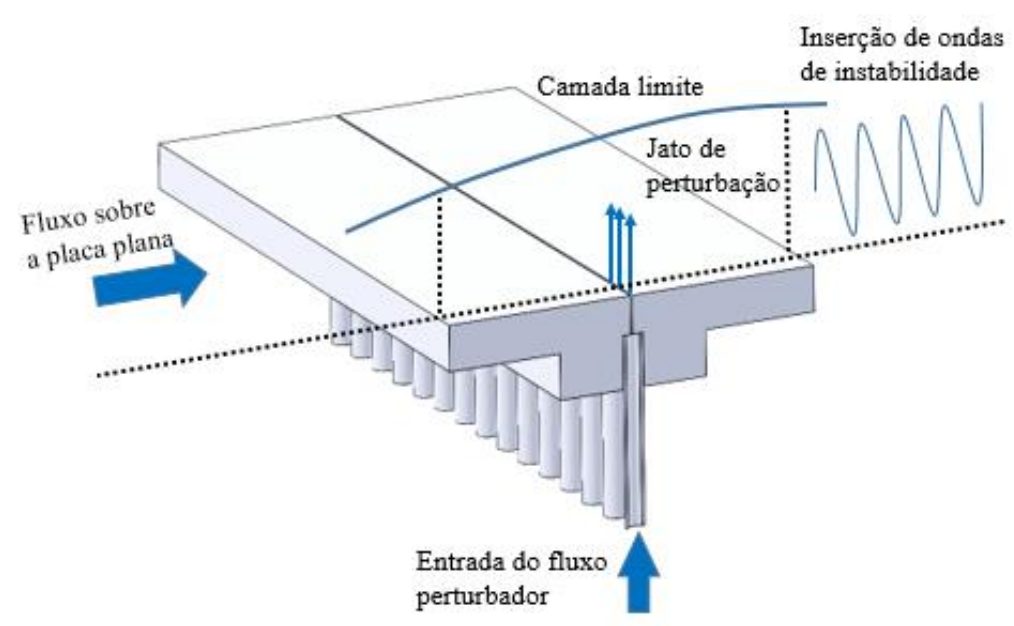

Figura 3.21 Dinâmica da inserção de ondas de instabilidade 
Para filtrar algum ruído indesejado que venha a ser introduzido pelo gerador de perturbações, optou-se por colocá-lo a montante do Reynolds crítico (que tem um valor aproximado de 500) de acordo com a solução do problema de OrrSommerfeld. Assim, o próprio escoamento se encarrega de filtrar perturbações com alta frequência e elevados números de onda na direção transversal. Utilizou-se a curva neutra da Figura 3.22 para se ter uma estimativa da faixa de frequências $(f)$ das ondas de Tollmien-Schlichting nas condições do presente estudo. Esta figura foi mostrada anteriormente (Figura 2.13) no entanto, aqui foi adicionada a linha tracejada vermelha que indica aproximadamente o número de Reynolds baseado na espessura de deslocamento na posição de inserção das ondas e seu desenvolvimento foi representado pela curva continua azul ao longo das diferentes regiões que atravessa, de estabilidade ou instabilidade.

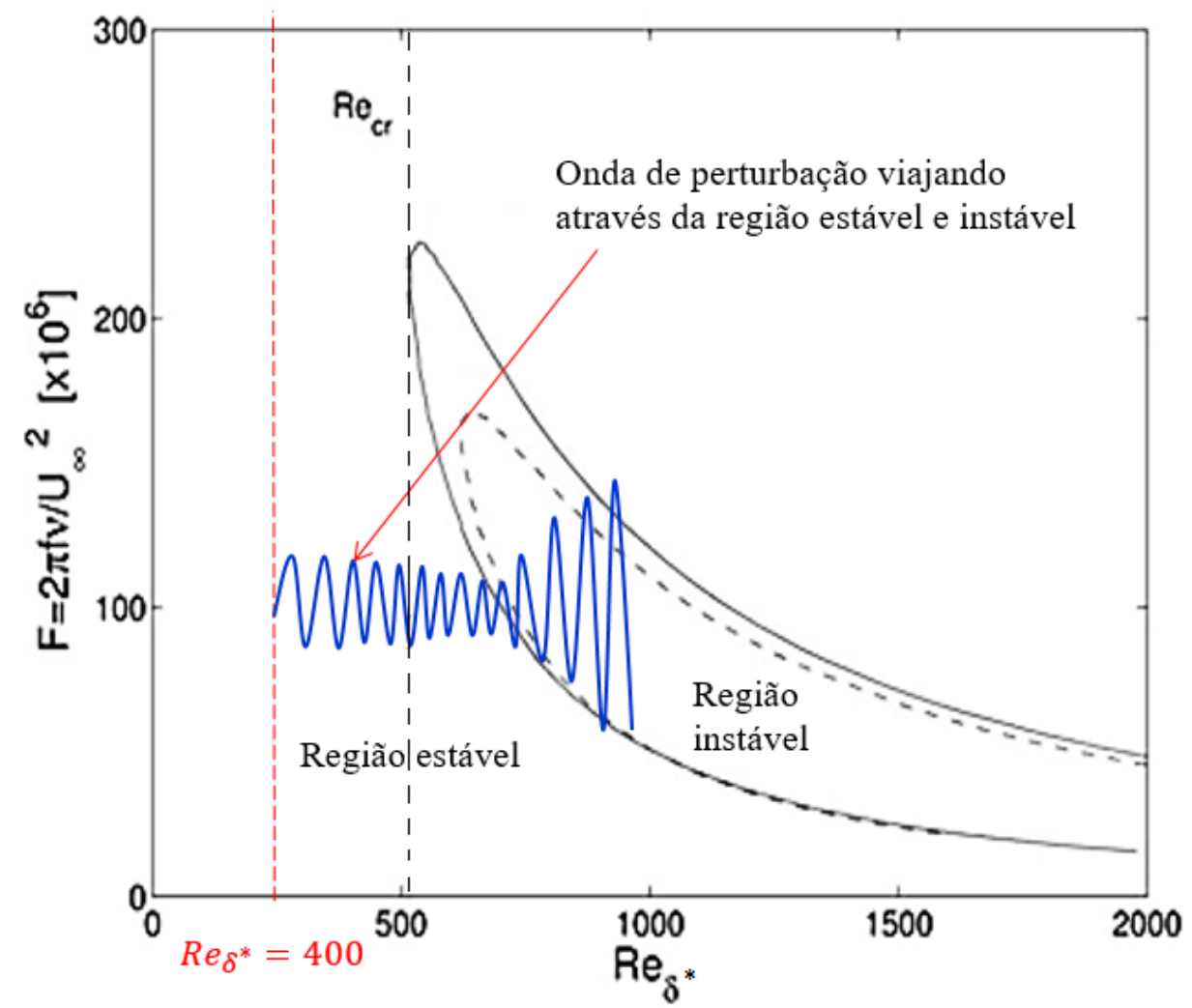

Figura 3.22 Localização do ponto de inserção de ondas de instabilidade 


\section{5. \\ Montagem}

O conjunto da placa plana, placa convergente-divergente, e demais acessórios, foram montados na secção de testes do canal de agua do Laboratório de Engenharia de Fluidos da PUC-Rio. A disposição geral projetada é mostrada na figura 3.23 e a figura 3.24 mostra uma fotografia do aparato experimental depois de fabricado e montado na secção de testes do canal de agua.

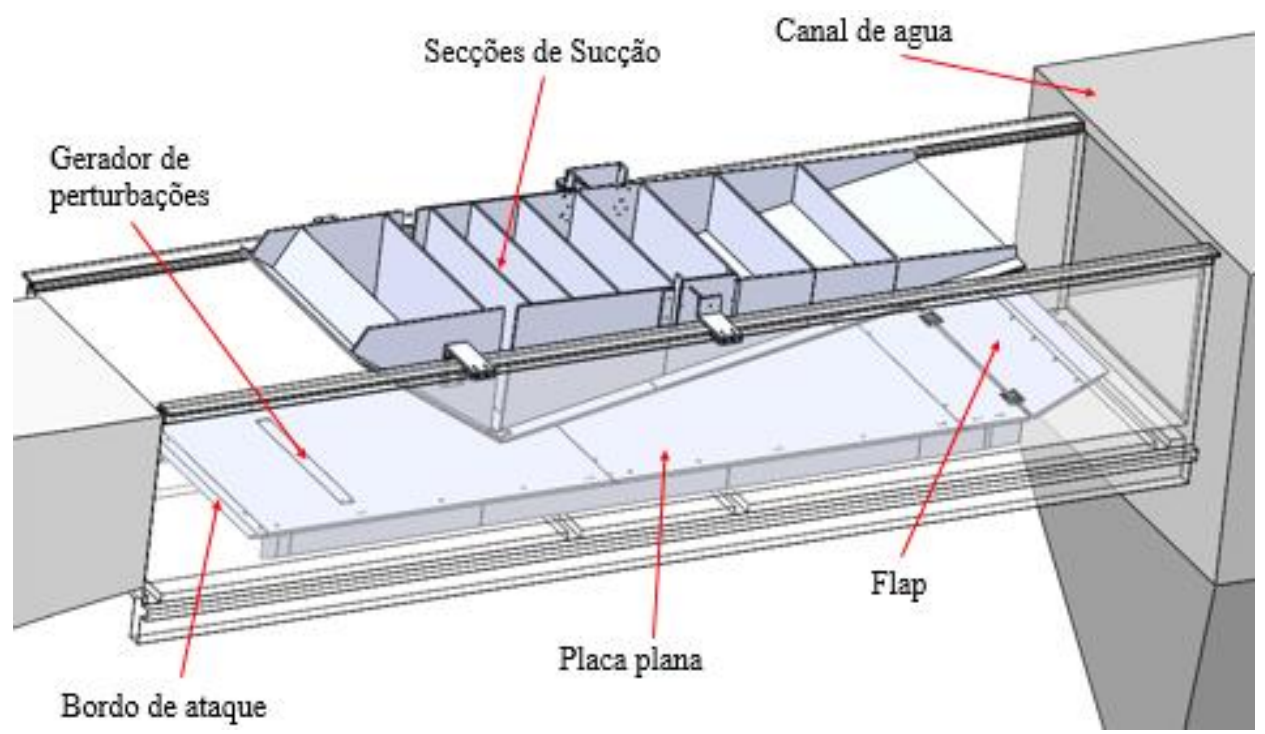

Figura 3.23 Arranjo experimental projetado para o estudo das bolhas de separação laminar

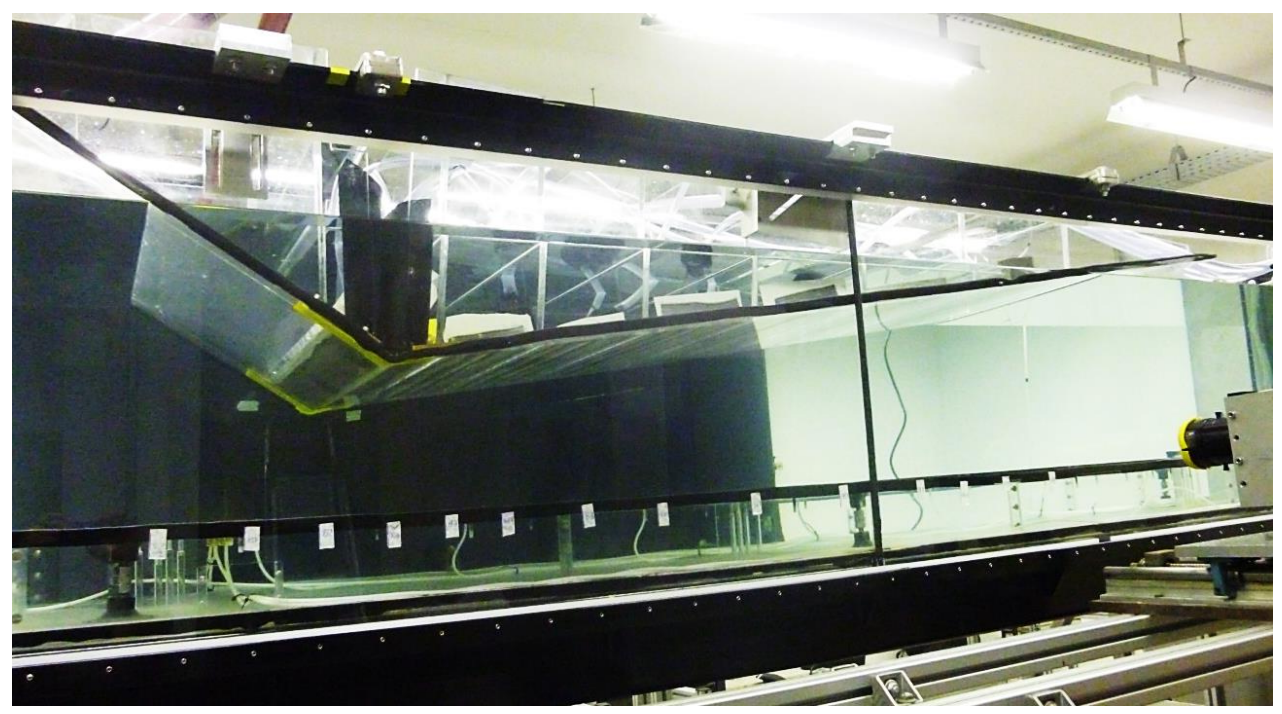

Figura 3.24 Aparato experimental fabricado e montado no canal de agua para o estudo das bolhas de separação laminar 


\section{4 \\ Metodologia experimental}

Neste capitulo será feito uma breve descrição das técnicas experimentais empregadas, dos equipamentos utilizados e do procedimento experimental adotado nos ensaios.

\section{1}

\section{Canal de água}

Os testes experimentais do presente trabalho foram realizados no canal de água do Laboratório de Engenharia de Fluidos da PUC-Rio. O desenho geral do canal de água pode ser observado na figura 4.1. O sentido do escoamento é indicado por setas azuis.

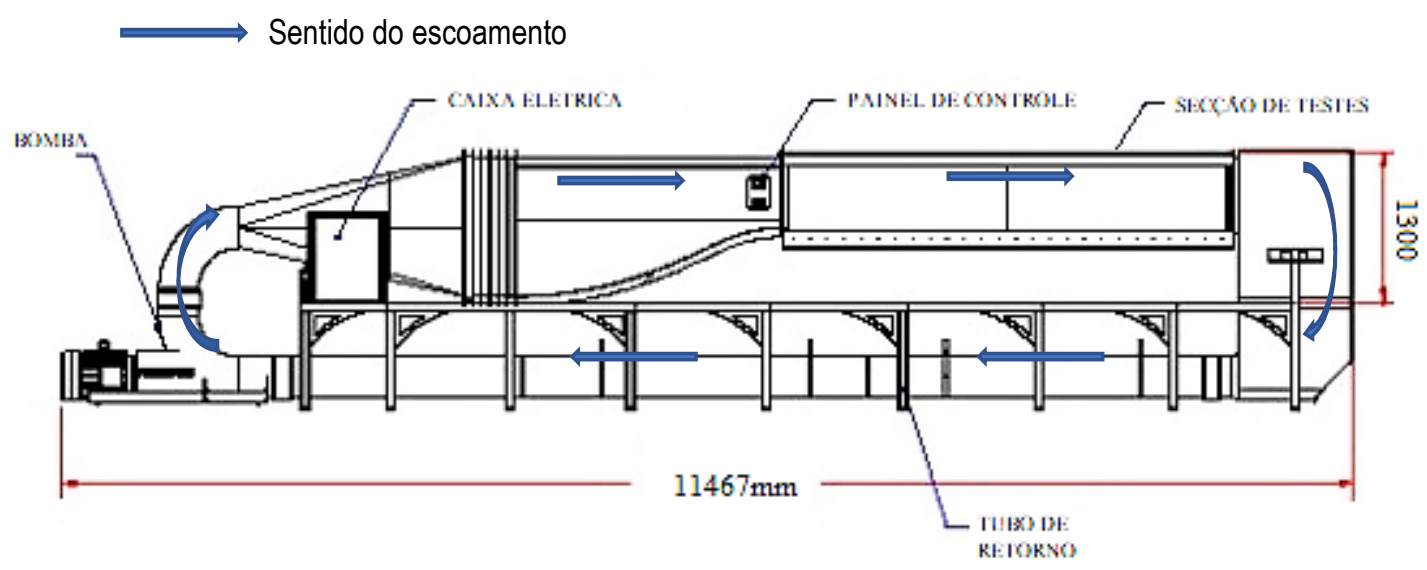

Figura 4.1 Canal de água do laboratório de Engenharia de Fluidos da PUC-Rio.

O canal tem uma secção de testes aberta de $4 \times 0.86 \times 0.64 \mathrm{~m}$ (comprimento $\mathrm{x}$ largura x altura) e um nível de turbulência médio de $0.5 \%$ na faixa de 0.1 até $10 \mathrm{~Hz}$ da frequência do motor. Todas as paredes da secção de testes são de vidro pelo qual temos um acesso óptico ao escoamento em cada lado. A água flui por um sistema de recirculação fechado impulsado por uma bomba de 40HP. Para obter um fluxo laminar com baixa intensidade turbulenta na secção de testes o canal conta com uma secção de condicionamento de fluxo. Essa seção consiste em uma colmeia seguida de uma série de telas de aço inoxidável com diferentes tamanhos de malha. 
A colmeia é responsável por reduzir a circulação do escoamento. Já as telas são utilizadas para quebrar os vórtices presentes no escoamento em vórtices menores que se dissipam rapidamente na câmara de estabilização. Após essa câmara o escoamento é acelerado por uma contração com razão de redução de área de 4:1. Essa razão é menor do que as comumente utilizadas para túneis de vento de baixa turbulência. No entanto, razões de contração altas não funcionam bem para canais de água e razões de 4:1 são mais indicadas (Arndt e Weitendorf, 1990).

A água foi tratada regularmente através de um filtro e uma lâmpada UV (ultravioleta) para evitar a proliferação de algas, bactérias e outros microorganismos. A bancada experimental foi montada na plataforma de operação adjacente à secção de testes, de forma que permita um fácil posicionamento e deslocamento longitudinal dos equipamentos de medição. O nível da água na secção de testes foi mantido a $512 \mathrm{~mm}$ em relação ao fundo do canal para todos os experimentos realizados. A figura 4.2. Mostra a secção de testes e a plataforma de operação.

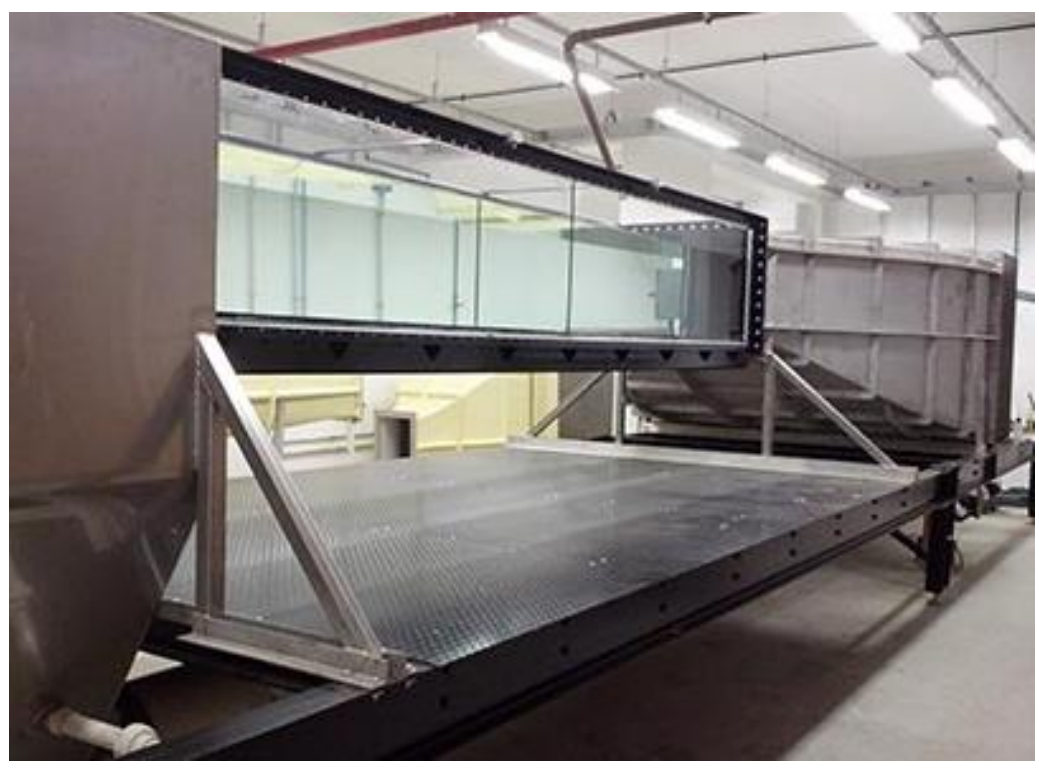

Figura 4.2 Secção de testes do canal de água no laboratório de Engenharia de Fluidos da PUC-Rio.

Para conhecer a velocidade do fluxo livre na secção de testes é necessário realizar um procedimento de calibração. Para isto utilizou-se o laser Doppler, quem forneceu os dados de velocidade de referência em contraposição com a frequência de rotação do motor. A curva de calibração é mostrada na figura 4.3 
A velocidade de operação escolhida para os ensaios foi de $0.15 \mathrm{~m} / \mathrm{s}$. De acordo com a curva da Figura 4.3 isso corresponde a uma frequência de $7.14 \mathrm{~Hz}$. No entanto, devido à perda de carga induzida pela placa convergente-divergente e demais itens inseridos na seção de testes foi necessário realizar uma correção da frequência de rotação. $\mathrm{O}$ ajuste fino da velocidade foi feito através de medições com o Laser Doppler quando todos os dispositivos estavam montados na seção de testes. Assim, a frequência de operação ficou em $8 \mathrm{~Hz}$.

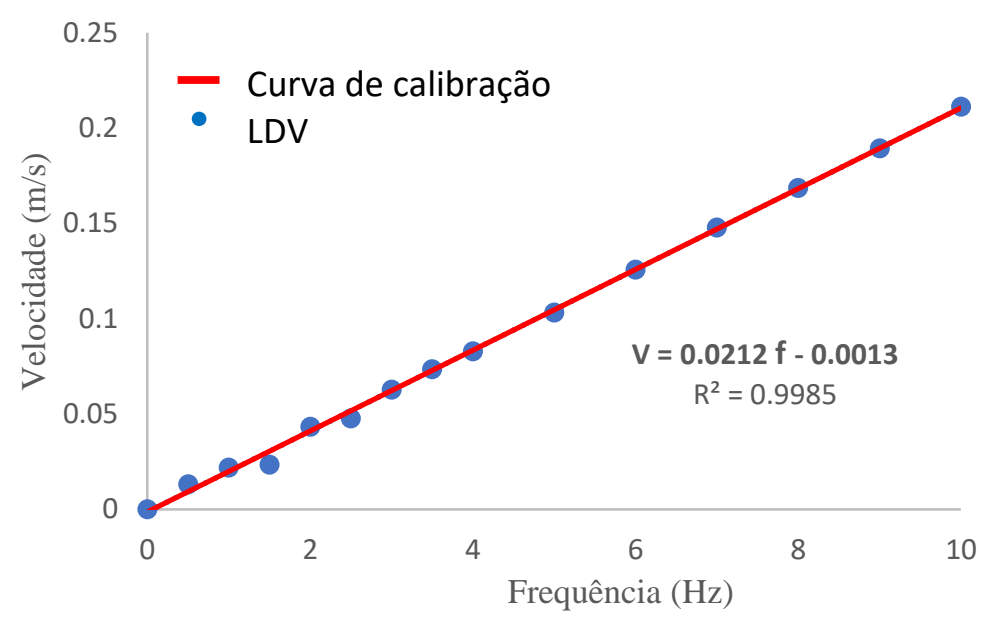

Figura 4.3 Curva de calibração da velocidade na secção de testes do canal de agua

\section{2 \\ Técnicas Experimentais}

Nesta secção é apresentada uma breve descrição dos aspectos gerais das técnicas utilizadas para medição de velocidade do escoamento.

\subsection{1}

\section{Velocimetría a Laser Doppler}

A Velocimetría Laser por efeito Doppler é um método já bem estabelecido que permite estimar a velocidade em um ponto no espaço. Neste subitem apresentase uma descrição da técnica. 


\subsubsection{1}

\section{Aspectos gerais da técnica}

A Velocimetría Laser Doppler ou LDV é uma técnica de medição óptica que permite a determinação da velocidade de um fluido com alta resolução temporal. A velocidade é virtualmente medida em um único ponto conhecido como volume de medição. O escoamento médio, assim como os campos de fluxo turbulentos e transitórios podem ser investigados com uma precisão espacial e temporal alta.

Por ser uma técnica óptica, o LDV oferece excelentes vantagens em comparação com os dispositivos tradicionais de medição de fluxo, tais como o anemômetro de fio quente ou tubo de Pitot, devido ao princípio de medição não invasivo. Logo, nas medições com o LDV o escoamento não é perturbado pela sonda. Portanto, a técnica é adequada para aplicações onde a inserção de sondas no escoamento não é conveniente, como por exemplo em motores de combustão interna, etc. Uma outra vantagem é que a técnica é de medição absoluta e, portanto, não precisa calibração.

\subsubsection{2 Princípio de funcionamento}

A técnica de Velocimetría Laser Doppler mede a velocidade de pequenas partículas que se movem num fluido de interesse. Assumindo que as partículas são pequenas, a velocidade dessas partículas pode ser assumida como a velocidade do próprio fluido. A interseção de dois feixes de laser (para cada componente de velocidade) resulta num padrão de franjas, uma serie de franjas claras e escuras. Conforme uma partícula se move através do volume de medição, dispersa luz quando cruza uma franja brilhante e não dispersa a luz quando passa por uma franja escura. Isso resulta em um padrão flutuante de intensidade da luz dispersa com uma frequência proporcional à velocidade da partícula. A figura 4.4 mostra um esquema do padrão de interferência. 


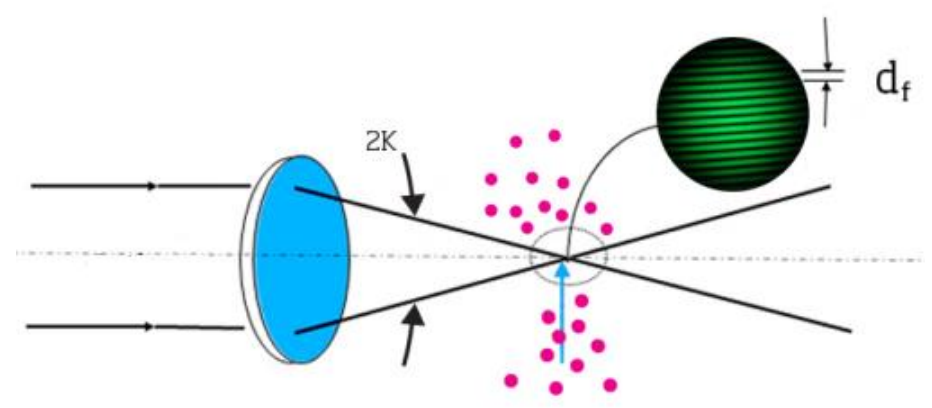

Figura 4.4 Esquema do padrão de franjas de interferência formado na interseção dos feixes incidentes. O espaçamento entre franjas é $d_{f}$. Retirado de http://www.tsi.com/

Conhecendo alguns parâmetros do sistema é possível estimar a geometria do volume de medição, conforme ilustrado na Figura 4.5

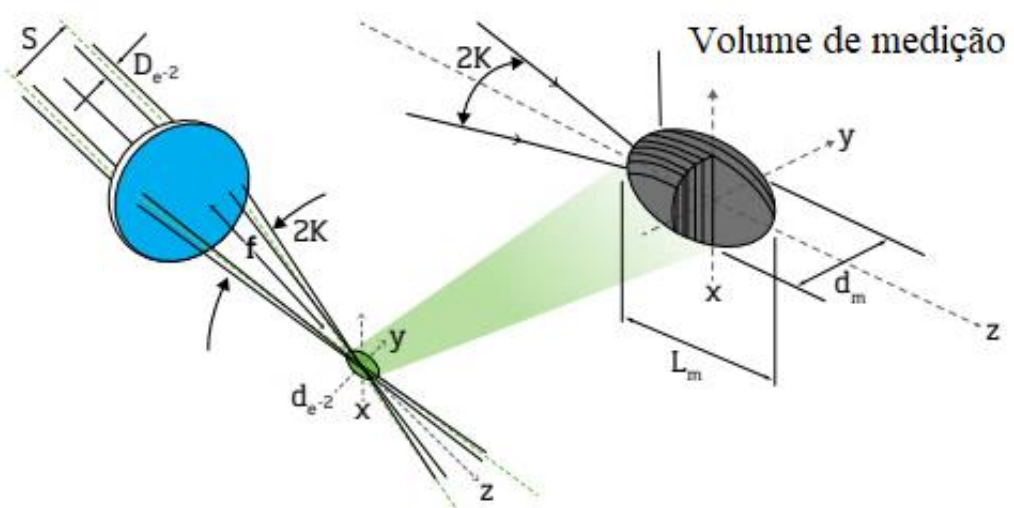

Figura 4.5 Parâmetros geométricos do volume de medição. Adaptado de http://www.tsi.com

Vamos definir os parâmetros mais importantes do volume de medição:

$$
\begin{gathered}
V o l_{m}=\frac{\pi\left[d_{e^{-2}}\right]^{3}}{6(\cos k)^{2} \sin k} \\
L_{m}=\frac{d_{e^{-2}}}{\sin k}
\end{gathered}
$$




$$
\begin{gathered}
N_{F R}=\frac{4 S}{\pi D_{e^{-2}}} \\
d_{e^{-2}}=\frac{4 f \lambda}{\pi\left[D_{e^{-2}}\right]} \\
d_{m}=\frac{d_{e^{-2}}}{\cos k} \\
d_{f}=\frac{\lambda}{2 \sin k}
\end{gathered}
$$

Onde:

$V l_{m}$ : volume de medição

$D_{e^{-2}}$ : diâmetro do feixe do laser

$d_{e^{-2}}$ : diâmetro do feixe focalizado

$S$ : comprimento da separação dos feixes

$K$ : ângulo do feixe

$f$ : comprimento focal da ótica de transmissão

$d_{f}$ : espaçamento entre franjas

$N_{F R}$ : número de franjas

Nas medições feitas com o sistema laser doppler os parâmetros envolvidos nas equações anteriores tem os seguintes valores: o feixe de luz verde tem um comprimento de onda de $\lambda=532 \mathrm{~nm}$, o comprimento focal no ar é de $f=$ $512 \mathrm{~mm}$, no entanto devido a refração no vidro e a agua, o comprimento focal fica em $f=600 \mathrm{~mm}$, o ângulo do feixe tem um valor de $K=2.8^{\circ}$ no ar, igualmente, devido à refração no vidro e a agua fica em $K=2.1^{\circ}$, o comprimento de separação dos feixes é de $S=50 \mathrm{~mm}$, enquanto que o diâmetro do feixe do laser tem um valor de $D_{e^{-2}}=2.65 \mathrm{~mm}$. Estes dados são fornecidos pelo fabricante do equipamento e a partir deles podemos determinar o seguinte: $\mathrm{O}$ volume de medição tem $N_{F R}=$ 29 franjas, o diâmetro focalizado tem um valor de $d_{e^{-2}}=0.153 \mathrm{~mm}$, consequentemente o volume de medição é $\operatorname{Vol}_{m}=0.05 \mathrm{~mm}^{3}$ e a distância entre franjas $d_{f}=0.007 \mathrm{~mm}$.

Como a distância entre as franjas e o tempo para a partícula ir de uma franja para a próxima (inversa da frequência do sinal) são conhecidos, a velocidade da partícula pode ser determinada. Mais detalhadamente a luz dispersada pelas partículas é coletada por dispositivos ópticos e convertida em sinais elétricas por tubos fotomultiplicadores (PMTs). A frequência do sinal conhecida como 
frequência Doppler $f_{D}$ é medido e então a velocidade $u$ é calculado multiplicando a frequência pelo espaçamento entre franjas $d_{f}$, isto é:

$$
u=d_{f} f_{D}
$$

Assim uma partícula cruzando através do volume de medição resultara em um padrão de luz dispersa similar ao mostrado na figura 4.6. Se os dois feixes de laser que interferem são exatamente da mesma frequência as franjas serão estacionarias no volume de medição. Um problema com isto é que partículas com uma certa velocidade se movendo através das franjas podem ter exatamente a mesma frequência que as partículas (com a mesma magnitude de velocidade) se movendo na direção oposta. Assim não haveria maneira de determinar se as partículas estavam se movendo em uma direção de fluxo positiva ou negativa. Para eliminar este problema em sistemas LDV, um dos dois feixes do laser é deslocado em frequência por uma célula Bragg por $40 \mathrm{MHz}$. Isso resulta em franjas que estão essencialmente se movendo a uma taxa de $40 \mathrm{MHz}$ no volume de medição. As partículas que atravessam o volume de medição terão agora uma frequência acima ou embaixo de $40 \mathrm{MHz}$, dependendo de sua direção. Assim a frequência da luz dispersa por uma partícula será $40 \mathrm{MHz}$ mais ou menos uma quantidade devido a sua própria velocidade.

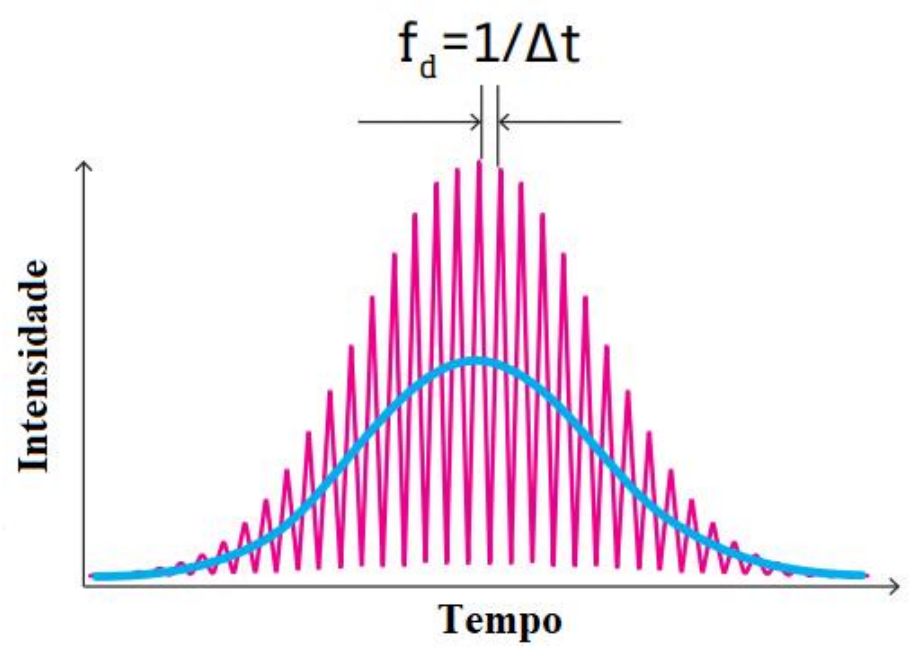

Figura 4.6 Dispersão de luz por uma partícula passando através do volume de medição do LDV. Retirado de http://www.tsi.com/

A luz dispersada é coletada e transmitida para os PMTs através de uma fibra óptica. Os PMTs geram sinais elétricos que representam os sinais ópticos de entrada. A saída do PMT passa primeiro por um filtro passa alta para remover a 
porção de baixa frequência do sinal devido aos feixes gaussianos. As frequências do sinal são então medidas usando o processador de sinal, Andreas E. et al. (2001). A figura 4.7 mostra um esquema de condicionamento do sinal.

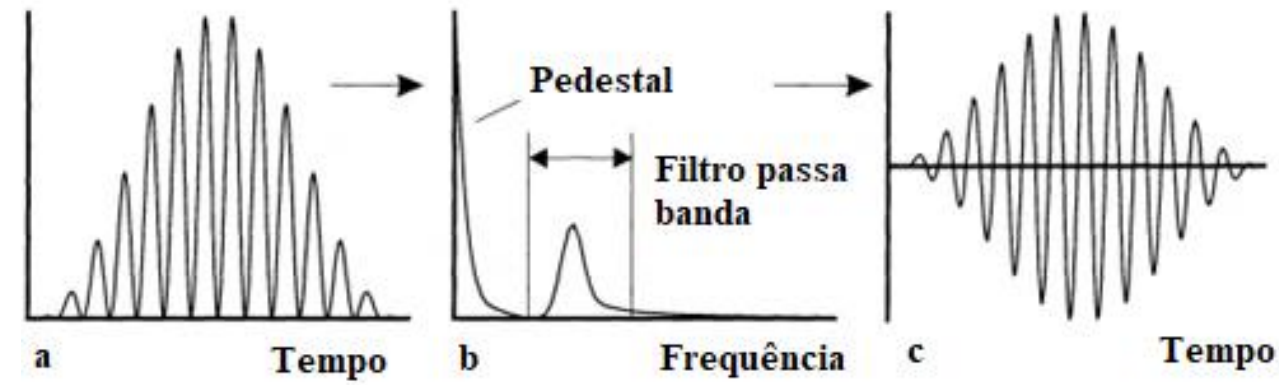

Figura 4.7 Acondicionamento do sinal (a) aquisição de dados, (b) filtro passa banda, no domínio das frequências (c) reconversão ao domínio do tempo.

\subsection{2}

\section{Velocimetría por Imagem de Partículas}

A velocimetría por imagem de partículas é uma técnica de medição laser que combina a precisão das medições pontuais não intrusivas com a capacidade de geração de imagens de visualização de fluxo global. Em esta secção será feita uma breve descrição da técnica.

\subsubsection{1}

\section{Aspectos gerais da técnica}

A velocimetría por imagens de partículas ou PIV é uma técnica de medição ótica não intrusiva para medição de campos instantâneos de velocidade. A velocidade é estimada através de medições do deslocamento de grupos de partículas traçadoras dispersas no fluido. Esses traçadores são iluminados externamente por um plano de luz pulsada comumente produzida por uma fonte laser. A posição das partículas é registrada por uma câmera fotográfica em dois instantes de tempo consecutivos conhecidos. Algoritmos de processamento de imagens são utilizados para determinar o campo de deslocamento das partículas, como o intervalo de tempo entre os pulsos é conhecido pode-se determinar o campo de velocidades (Abrantes et al., 2012). 
Entre as principais características do PIV, tal como foram indicadas por Raffel et al. (2007) temos:

- A medição da velocidade é não intrusiva, em contraste com as técnicas que empregam sondas, como tubos de pressão ou fios quentes. Isso permite a medição em escoamentos onde a presença de sondas é inconveniente.

- A medição da velocidade é indireta, da mesma forma que com a velocimetría laser Doppler. A velocidade é estimada pelo deslocamento de traçadores.

- A resolução espacial do PIV não é fixa, e depende da concentração de partículas traçadores, das câmeras e da janela de processamento selecionada. A resolução temporal pode chegar até alguns $\mathrm{kHz}$ nos sistemas com alta resolução temporal. Isso ainda é significativamente menor que, por exemplo a anemometria a fio quente onde frequências da ordem de centenas de $\mathrm{kHz}$ podem ser medidas.

- A medição de campos instantâneos de velocidade permite a detecção de estruturas espaciais. Isso é interessante em casos onde não é possível realizar a sincronização das medições com as flutuações de velocidade do escoamento, como no caso de escoamentos turbulentos.

\subsubsection{2}

\section{Princípio de funcionamento}

Uma breve descrição sobre a técnica é apresentada neste subitem. A Figura 4.8 mostra de forma esquemática a versão padrão de um sistema PIV nesta configuração dois pulsos de luz na forma de um plano são produzidos pela fonte de iluminação. Normalmente são utilizadas fontes de iluminação laser pela elevada densidade de energia produzida e facilidade de controle de intervalos entre pulsos. Um duplo pulso de luz ilumina partículas traçadoras previamente dispersas de modo homogêneo no fluido. Estas partículas devem ser cuidadosamente selecionadas de modo a seguir fielmente o escoamento e ainda assim espalhar luz suficiente para que suas imagens possam ser registradas na câmera fotográfica. 


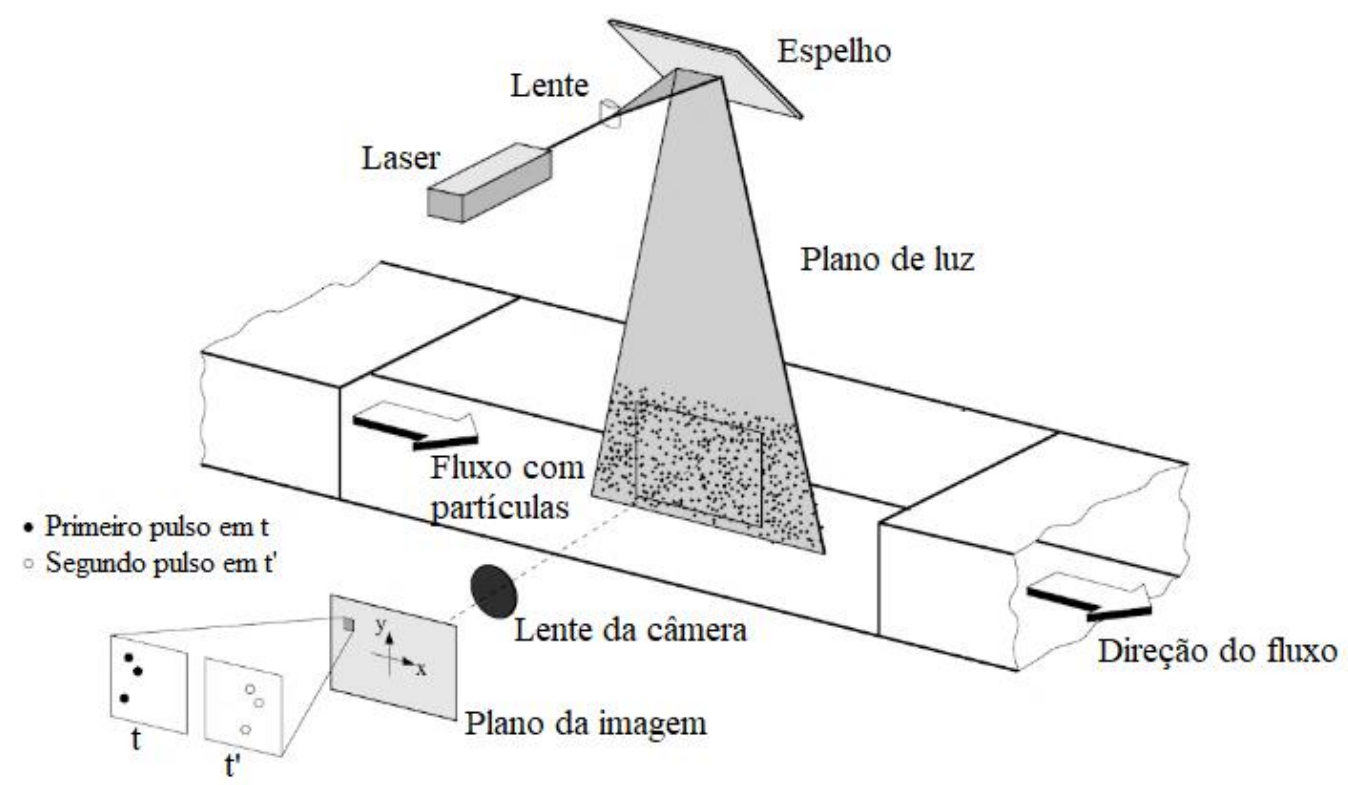

Figura 4.8 Desenho esquemático de um sistema PIV Bidimensional de dois componentes. Adaptado de Raffel et al. (2007)

A figura 4.9 apresenta um esquema mais detalhado do sistema, com os principais parâmetros óticos de formação de imagem envolvidos. A câmera fotográfica que registra a posição das partículas no plano de iluminação é montada ortogonalmente ao plano de luz. A distância da lente ao plano da imagem $z_{0}$ entre a distância da lente ao plano iluminado em foco $Z_{0}$, é a magnificação, tal como indica a equação 4.8

$$
M=\frac{Z_{0}}{Z_{0}}
$$

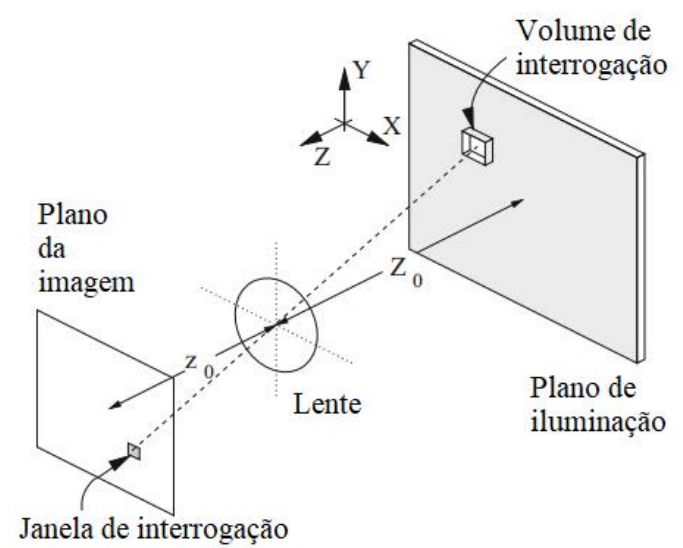

Figura 4.9 Parâmetros envolvidos no registro de imagens PIV. Adaptado de Raffel et al. (2007) 
Uma lente apropriada define o grau de magnificação da imagem garantindo que o campo de visão cubra a região desejada a ser investigada no escoamento e que a imagem das partículas seja registrada com resolução adequada no sensor da câmera.

As imagens PIV são gravadas pelas câmeras com sensores CCD ou CMOS. Hoje, a tendência é usar câmeras CMOS devido à redução de custo desses componentes e aumento da sensibilidade. Além disso, sensores CMOS possuem resposta mais rápida.

As imagens armazenadas são pre-processadas e analisadas por algoritmos especializados. O objetivo do pré-processamento é melhorar a qualidade da imagem das partículas, já que esta pode ser afetada por diversos fatores como variações de iluminação, reflexões provenientes de superfícies sólidas, etc.

$\mathrm{Na}$ etapa de análise das imagens, busca-se determinar o campo de deslocamento das partículas traçadoras. A determinação do campo de deslocamentos é feita por métodos estatísticos. O procedimento inclui a divisão das imagens em sub-regiões chamadas de janelas de interrogação. Cada janela tem dimensão pequena o suficiente para ser considerada com um ponto no escoamento. A dimensão da janela de interrogação determina a resolução espacial da técnica de medição. Através de técnicas de correlação de imagens, é possível determinar o deslocamento do grupo de partículas e associá-lo ao ponto em análise. Este procedimento é repetido alterando-se posição da janela, até que toda a imagem tenha sido analisada e o campo de deslocamento determinado. Abrantes et al. (2012).

Uma vez determinado o campo de deslocamentos, a velocidade é determinada através da divisão pelo intervalo de tempo conhecido entre pulsos de iluminação:

$$
\bar{U}=\frac{\Delta \bar{X}(\bar{X}, t)}{M \Delta t}
$$

Onde, $\Delta \bar{X}(\bar{X}, t)$ é o deslocamento das partículas em unidades de comprimento, $\Delta t$ é o intervalo de tempo entre os pulsos de iluminação, e $M$ é a magnificação.

Um detalhe importante para o caso do PIV bidimensional, é que é possível converter o campo de deslocamento em pixels para o campo de deslocamento em 
unidades de comprimento apenas usando uma relação pixels/(unidades de comprimento), isto é, entre um objeto e sua imagem.

A estimação dos vetores deslocamento pode ser feita utilizando-se a correlação, R:

$$
R_{I_{1}} R_{I_{2}}(\Delta i, \Delta j)=\sum_{i} \sum_{j} I_{1}(i, j) I_{2}(i+\Delta i, j+\Delta j)
$$

onde $I_{1}$ e $I_{2}$ são as intensidades da luz nas janelas de interrogação, e $i$ e $j$ se referem aos índices dos pixels nestas janelas. Na prática, a correlação é calculada no domínio da frequência e depois convertida para o espaço para aumentar a velocidade de processamento. O deslocamento para cada janela de interrogação é então avaliado diretamente a partir da localização do pico no mapa de correlação. A figura 4.10 mostra um exemplo do resultado obtido por correlação cruzada.

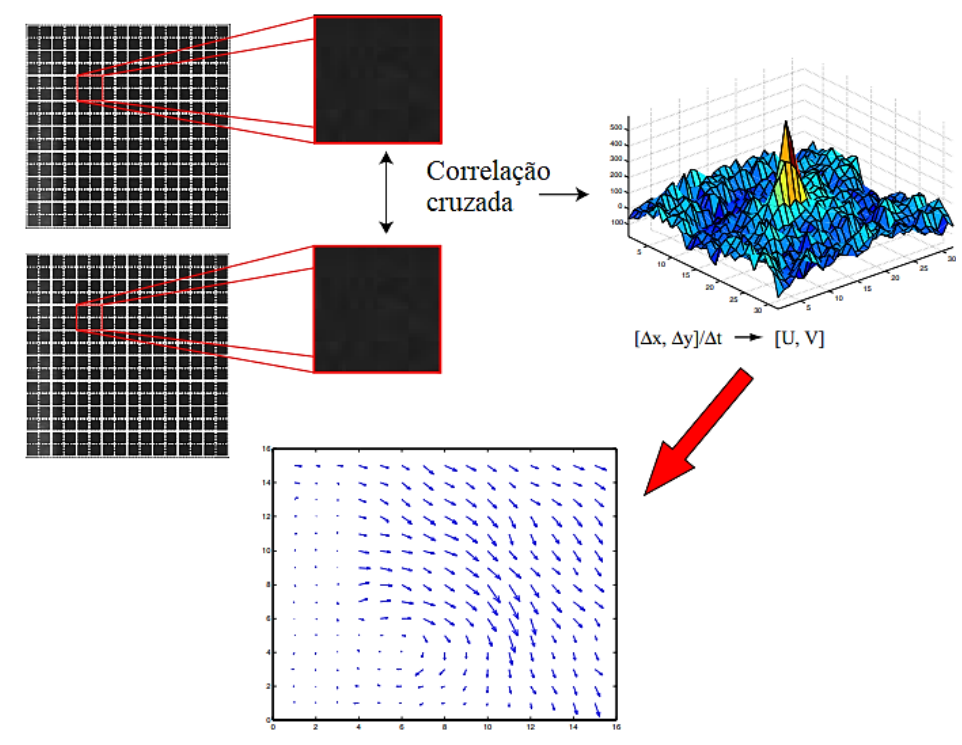

Figura 4.10 Exemplo de resultado obtido por correlação cruzada. Adaptado de Törnblom (2004)

Tal como foi dito anteriormente o PIV precisa da inserção de partículas traçadoras no escoamento, as propriedades destas partículas são importantes para garantir a fidelidade no seguimento do escoamento e uma boa capacidade de espalhar a luz.

Se o número de Reynolds da partícula for suficientemente pequeno, pode-se usar a lei de Stokes para estimar o retardo de velocidade, então: 


$$
U_{p}-U=d_{p}^{2} \frac{\left(\rho_{p}-\rho_{f}\right)}{18 \mu_{f}} \bar{a}
$$

onde $\bar{a}$ é a aceleração do fluido, $d_{p}$ é o diâmetro das partículas, $\rho_{p}$ é a densidade das partículas, $\rho_{f}$ é a densidade do fluido, $\mu_{f}$ é a viscosidade dinâmica do fluido e $U_{p}$ é a velocidade da partícula e segue uma lei exponencial:

$$
U_{p}(t)=U\left[1-\exp \left(-\frac{t}{t_{p}}\right)\right]
$$

Com o tempo de resposta $t_{p}$ que representa a habilidade da partícula em seguir fielmente o fluido em aceleração e é dada pela seguinte equação:

$$
t_{p}=d_{p}^{2} \frac{\rho_{p}}{18 \mu_{f}}
$$

Desta equação podemos ver que enquanto menor seja o diâmetro da partícula menor é o tempo de resposta, ou seja, a partícula atinge a velocidade do fluido mais rapidamente.

Outro parâmetro importante é a definição da quantidade de partículas que devem ser inseridas no escoamento. Uma revisão útil pode ser encontrada em Fernandes, L. Soares (2017). De acordo com a revisão apresentada naquele trabalho, a massa das partículas para um sistema PIV pode ser estimada com a seguinte equação:

$$
M_{\text {part }}=\left(\frac{M}{\Delta_{\text {pixel }}}\right)^{2} \frac{p p p}{\Delta_{z}} V_{\text {sol }} \frac{\rho_{p} \pi d_{p}^{3}}{6}
$$

Onde:

M: é a magnificação

$\Delta_{\text {pixel }}$ : é o tamanho de um pixel em milímetros, segundo as caraterísticas da câmera $p p p$ : é o número médio de partículas por pixel

$\Delta_{Z}$ : é a espessura do plano

$V_{\text {sol }}$ : é o volume da solução onde as partículas serão semeadas

Os valores estimados com esta equação e a especificação dos parâmetros empregados são mostrados na secção 4.3.2.6 


\section{3 \\ Procedimento experimental}

Nesta seção são apresentadas as principais características dos equipamentos utilizados e as configurações adotadas nos ensaios.

\subsection{1}

\section{Aquisição de dados com a técnica LDV}

As medições com a técnica Anemometria Laser Doppler foram realizadas com um sistema PowerSight da TSI. Existem dois módulos principais para este sistema, o módulo PowerSight Laser Velocimeter, e o módulo PowerSight Controller, os quais são mostrados na figura 4.11. Os módulos contêm toda a parte óptica do sistema, incluindo o sistema de potência para acionamento dos lasers.
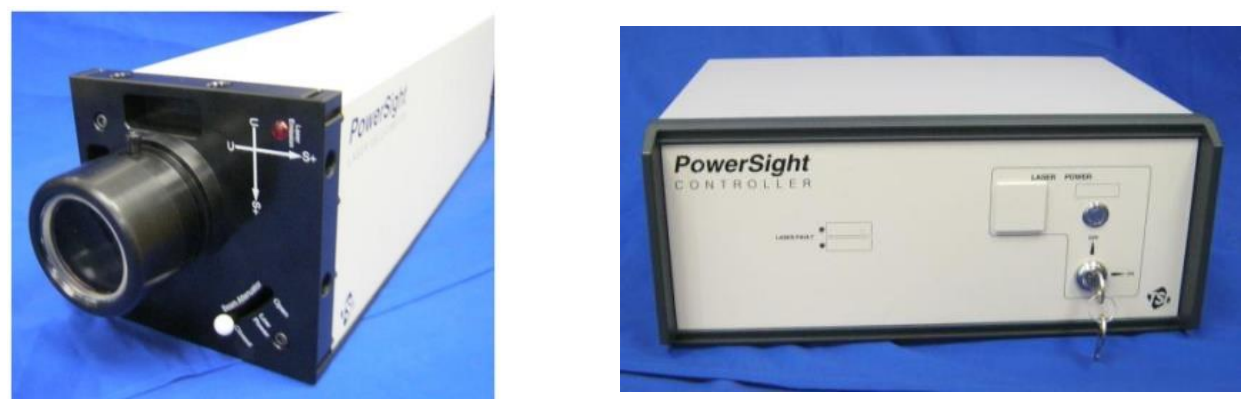

Figura 4.11 Esquerda: Módulo PowerSight laser Velocimeter, Direita: Módulo PowerSight Controller.

O módulo PowerSight Laser velocimeter é composto pelo conjunto de transmissão do feixe do laser e pelo fotodetector. O conjunto de transmissão de feixe do laser inclui o laser de estado solido, a célula Bragg, e a óptica para fornecer dois feixes do laser com 50mm de espaçamento. O conjunto de recepção da luz refletida pelas partículas consiste na lente focal de recepção e na óptica do colimador para permitir que a luz dispersa seja coletada e transmitida através de uma fibra óptica multimodo para o Módulo Foto Detector (PDM).

O processamento do sinal óptico de saída é feito pelo PDM. O condicionamento da sinal e filtragem são realizados pelo Módulo Processador Digital Multibit (FSA 3500). A figura 4.12 mostra todo o conjunto montado para medições no canal de água. 


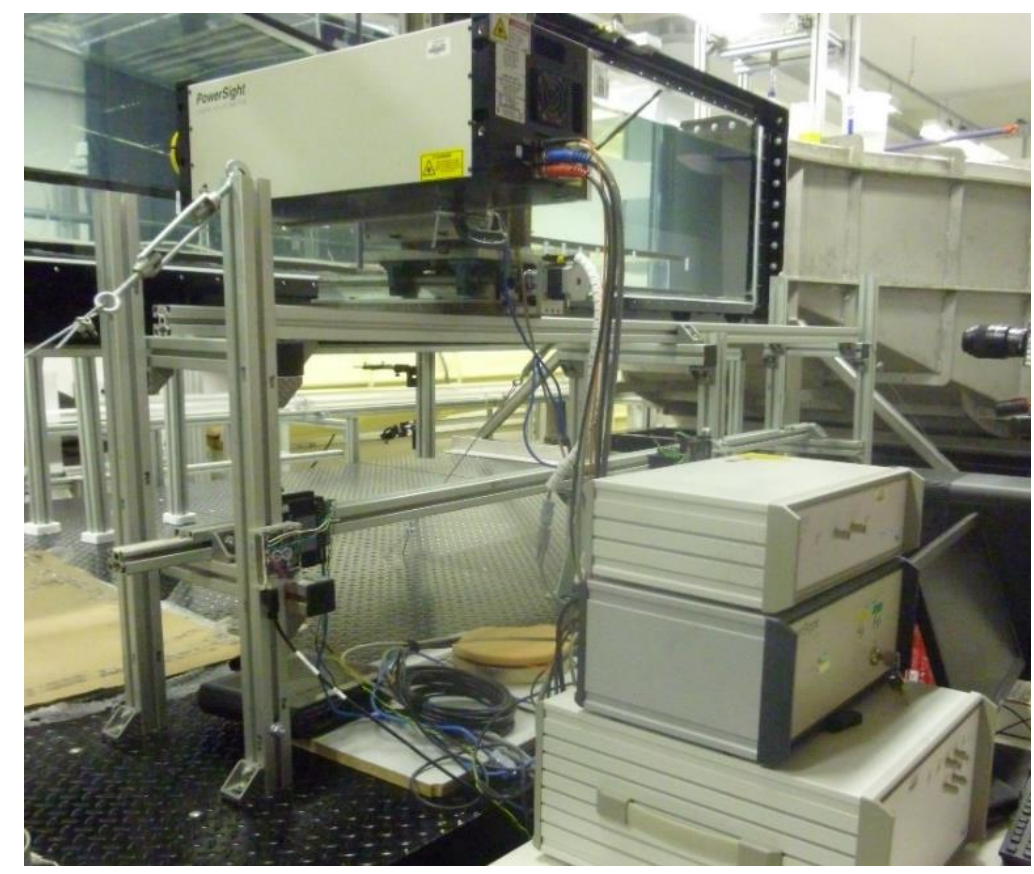

Figura 4.12 Arranjo experimental para o sistema LDV

O módulo PowerSight Laser Velocimeter foi montado em um traverso que se pode deslocar em três eixos. Os eixos normal e transversal à parede inferior do canal foram dotados de servo motores para deslocamento automático. O controle dos motores foi feito com micro controladores Arduino Uno e drivers de potência Tb6600 para motores de até 4.5A. A interface de controle do sistema foi criada num ambiente LabView.

O deslocamento na direção vertical do módulo PowerSight Laser Velocimeter é de especial importância devido a que o espaçamento entre dois pontos consecutivos define o espaçamento entre os pontos do perfil de velocidade aquisitado. Este espaçamento dentro da camada limite foi escolhido de forma variável, sendo de $0.5 \mathrm{~mm}$ na região mais perto da parede, $1 \mathrm{~mm}$ na região intermediaria e $2 \mathrm{~mm}$ até atingir a velocidade do fluxo livre. A quantidade de pontos para cada perfil depende da altura e o regime do fluxo na camada limite, mudando de 20 até 35 pontos.

Para o volume de medição se encontrar na posição transversal requerida dentro do canal de água é preciso ter em conta a refração do feixe de luz incidente que passa através de três meios com diferentes índices de refração: o ar, o vidro e a água. A natureza do fenômeno de refração da luz faz mudar o ângulo de 
convergência dos feixes incidentes mudando assim o comprimento focal definido pela lente, mas não muda a frequência da luz, portanto, não tem influência na medição da velocidade. Levando em conta a lei de Snell é possível fazer uma estimativa da posição real do volume de medição, sendo encontrado $88 \mathrm{~mm}$ mais afastado da posição indicada pelo comprimento focal da lente que foi de $512 \mathrm{~mm}$ para um ângulo de convergência de $2.8^{\circ}$. A figura 4.13 mostra uma foto da intersecção dos feixes do laser dentro do canal de água, o volume de medição se forma acima da placa plana, esta foto foi tirada desde a parte inferior do canal.

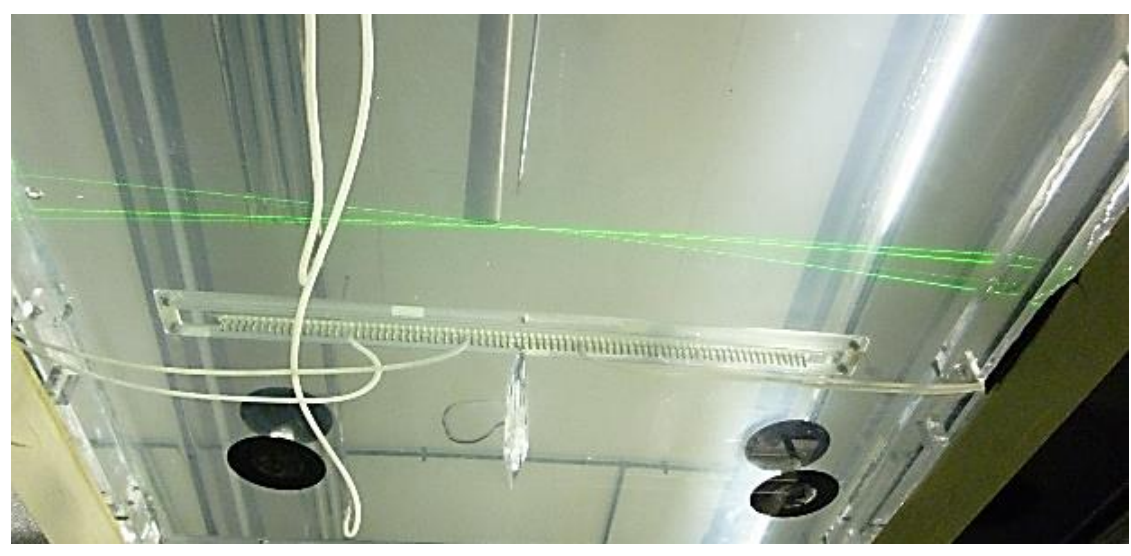

Figura 4.13 Intersecção dos feixes do laser e formação do volume de medição dentro do canal de água.

No processo de aquisição dos perfis de velocidade da camada limite é importante aquisitar dados o mais próximo possível da superfície da placa plana. Para ajustar o volume de medição nessa posição, inclinou-se o modulo PowerSight Laser Velocimeter, conforme ilustrado na Figura 4.14. Um detalhe que não é mostrado na figura 4.14 é a refração da luz que ocorre entre o ar e a parede de vidro, e entre a parede de vidro e a agua. Isso foi levado em conta no deslocamento do laser durante as medições. A figura 4.15 mostra a trajetoria seguida pelo volume de medição. Os pontos onde os dados são aquisitados são mostrados em cor verde, todos esses pontos são coplanares num plano transversal à direção do escoamento, a distancia entre dois linhas verticais de aquisição de dados (em cor verde) é de $20 \mathrm{~mm}$, em total foram aquisitados dados em 15 linhas que correspondem a 15 perfis de velocidade, compondo um plano para evaluação da bidimensionalidade do escoamento base. 


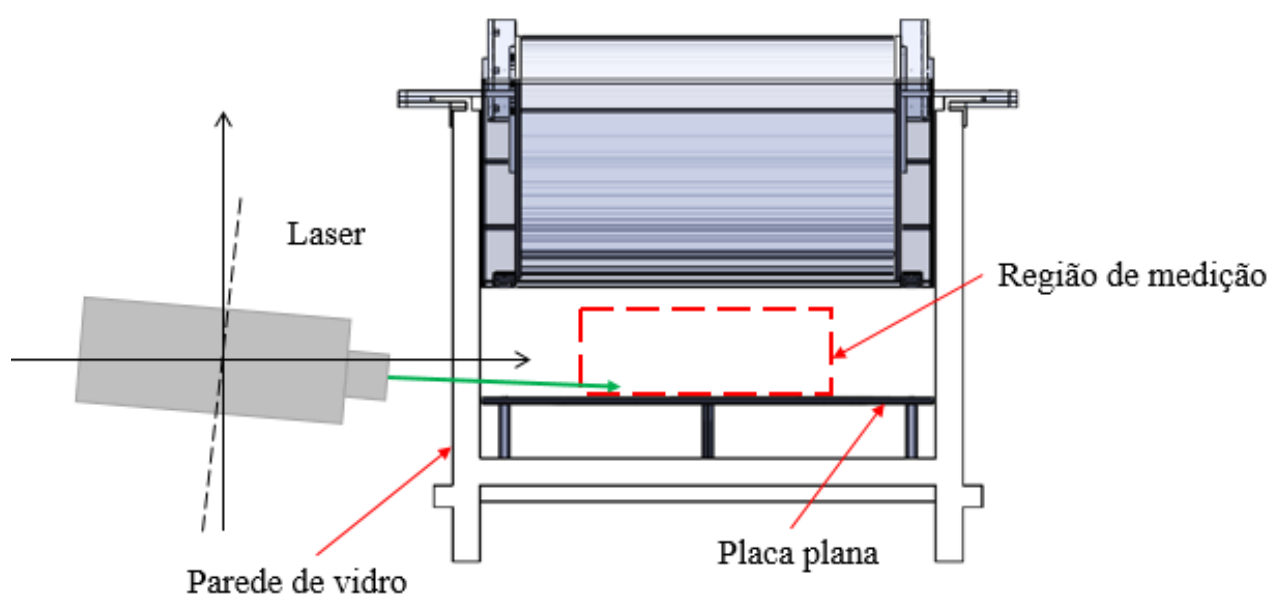

Figura 4.14 Inclinação do modulo PowerSight Laser Velocimeter e região de medição com o sistema LDA

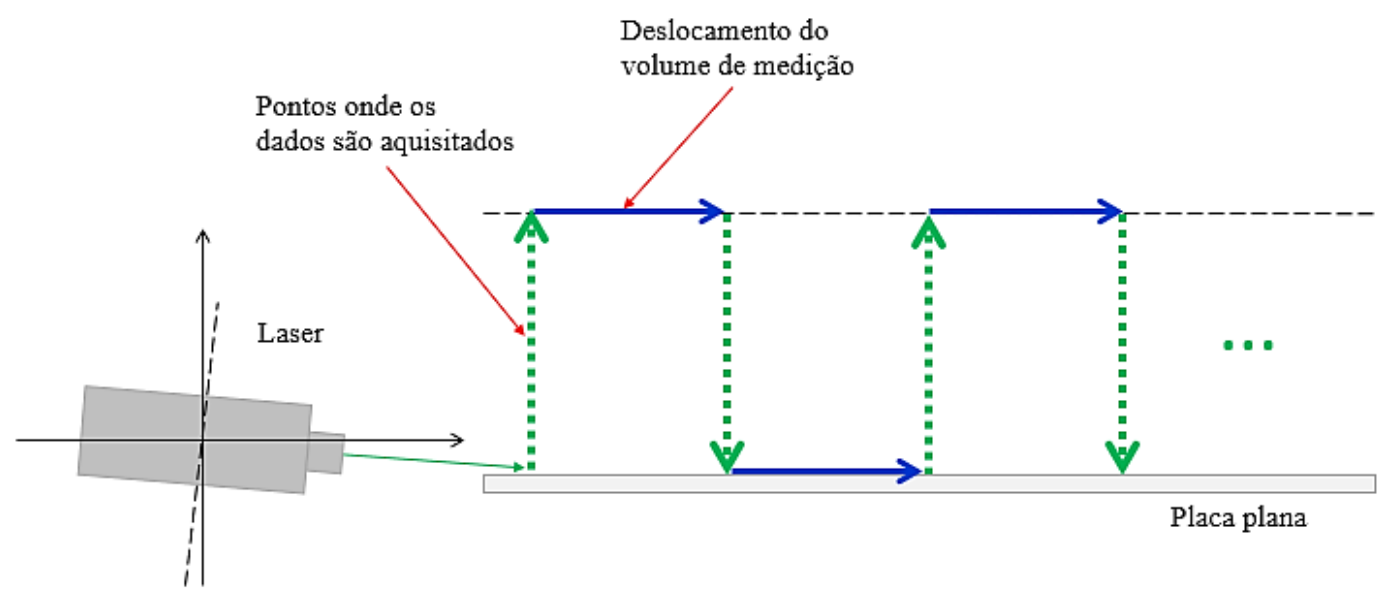

Figura 4.15 Trajetória que recorre o volume de medição no processo de aquisição dos dados.

Mesmo que a inclinação do laser tenha permitido chegar bem mais próximo da superfície da placa plana não é possível realizar medições exatamente sobre a placa. Logo, sempre há um espaçamento entre a parede e o primeiro ponto de medição. Esse deslocamento é possível de ser calculado conhecendo-se o perfil de velocidades teórico. No caso da camada limite sem gradiente de pressão utilizou-se o perfil de blasius. A metodologia consiste em sobrepor os pontos experimentais sobre a curva teórica, se estes pontos batem sobre a curva pode-se considerar que os pontos experimentais constituem um perfil de blasius, consequentemente pode- 
se encontrar o valor da coordenada vertical deslocada para cada ponto experimental através de um algoritmo de mínimo erro entre as novas coordenadas $y$ dos pontos experimentais e as coordenadas $y$ da curva teórica, este algoritmo fornece um valor $Y$ de correção que depois é adicionando aos dados $y$ dos perfis experimentais originais, se obtendo assim a correção do perfil. A figura 4.16 Mostra o perfil que resulta deste procedimento. Nos ensaios essa correção foi da ordem de $0.4 \mathrm{~mm}$, mas o valor não foi fixo e variou um pouco de acordo com o local de medição. Os valores de deslocamento obtidos para cada posição ao longo da direção longitudinal da placa foram posteriormente utilizados para a correção dos perfis no caso das medições com o escoamento turbulento.

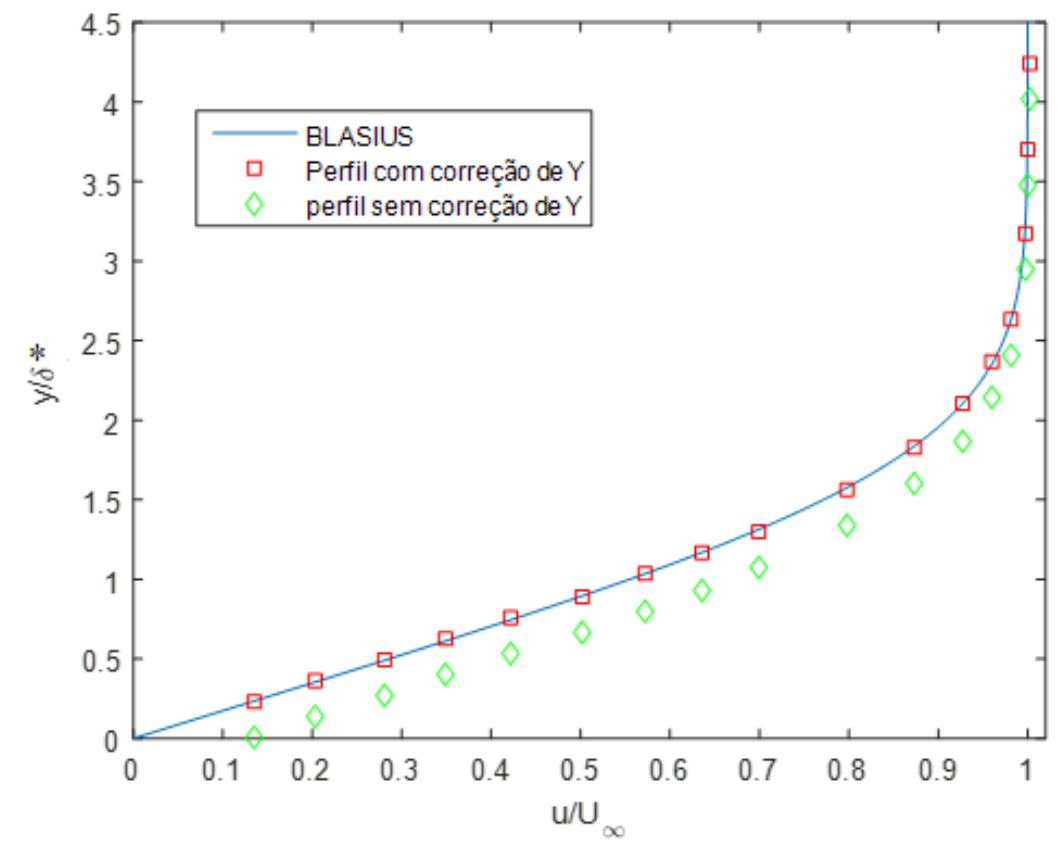

Figura 4.16 Correção do perfil de velocidade

\subsection{2}

\section{Aquisição de dados com a técnica PIV}

Neste subitem são descritas as principais características dos equipamentos utilizados nas medições com a técnica PIV. Descreve-se também o procedimento de calibração adotado. 


\subsubsection{1 \\ Fonte de iluminação}

Foi utilizado um sistema laser da série LDY-300 como fonte de iluminação. Esse laser possui dois ressonadores laser CW Q-comutados, produzindo luz laser infravermelha de $1053 \mathrm{~nm}$, que é convertida em luz laser visível de 527nm por um gerador harmônico de intra-cavidade. O gerador harmônico produz uma saída de laser de $527 \mathrm{~nm}$, isto é, luz visível verde. O uso de dois ressonadores controlados e pulsados independentes permite a geração de uma saída de pulso duplo com tempos de separação entre pulsos mínimo de pouco menos de dez nano segundos. A curta duração de pulso alcançada pela Q-comutação ótica-acústica do ressonador laser permite que o movimento rápido de partículas seja congelado na imagem. A figura 4.17 mostra o laser de alta energia utilizado.

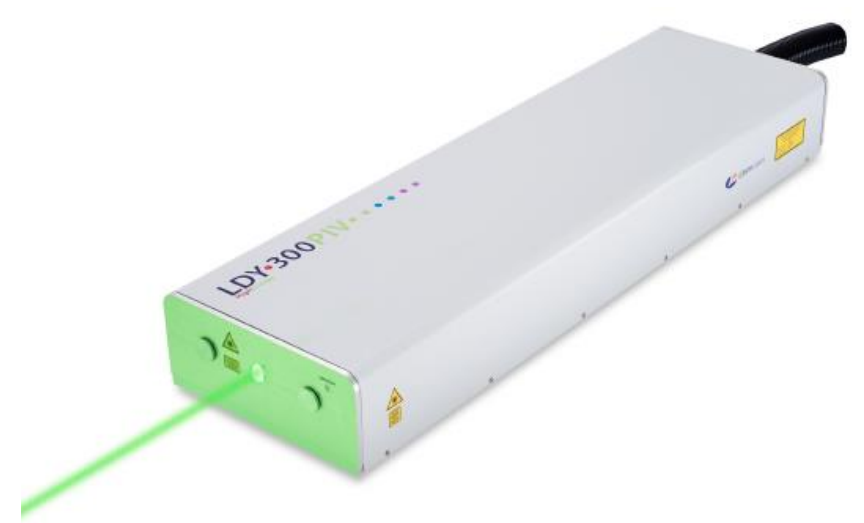

Figura 4.17 Laser, LITRON da série LDY-300

\subsubsection{2}

Câmera

Para gravar as imagens se utilizou uma câmera de alta velocidade MotionPro X3Plus. Essa câmera possui uma resolução de 1280x1024pixels a uma taxa de amostragem de até 2000 quadros por segundo. A câmera possui modo de dupla captura, especial para PIV com 100 ns de intervalo de comutação dos quadros.

Nos testes de verificação da sucção da camada limite as medições foram feitas com uma taxa de amostragem de $250 \mathrm{~Hz}$ e um tempo de exposição do primeiro quadro de $2800 \mu \mathrm{s}$. Essa frequência esta por acima da frequência mínima de disparo do laser, que é de $200 \mathrm{~Hz}$, abaixo da qual a potência do laser é severamente reduzida. 
Nos testes de validação do mecanismo de sucção utilizou-se uma lente Nikkor de $50 \mathrm{~mm}$, com abertura de f2.8. Isso permitiu a captura de imagens em uma área grande sobre a placa divergente. No caso das medições na camada limite com a bolha de separação, utilizou-se uma lente Nikkor de 105mm para uma melhor visualização do escoamento, isto é, uma região de visualização menor e com maior resolução.

A aquisição das imagens foi feita com o software Motion Studio, fornecido pelo fabricante da Câmera. Toda a configuração da câmera foi feita nesse software e os instantes de aquisição de imagens foram controlados com um sincronizador.

\subsubsection{3}

\section{Sincronizador}

Para disparar os eventos na sequência correta foi empregado um sincronizador modelo 610036 da TSI que é o mesmo sincronizador fornecido pela Berkley instruments modelo Pulse Generator 575. A resolução do sincronizador é de $1 \mathrm{~ns}$. Esse equipamento atua como um controlador mestre dos componentes do sistema e fornece o sinal de gatilho para os pulsos de cada laser e para disparo da câmera. A frequência de amostragem também é controlada pelo sincronizador. O dispositivo é configurado por uma interface feita no laboratório de Engenharia de Fluidos na plataforma LabView. Nos testes realizados para a verificação da sucção da camada limite e de medição do escoamento na bolha de separação, o sincronizador trabalhou com os parâmetros mostrados na tabela 4.1.

Tabela 4.1 parâmetros do sincronizador

\begin{tabular}{|c|c|l|c|}
\hline \multirow{3}{*}{ Synchronizer } & \multirow{2}{*}{ Camera } & width & $1.00 \mathrm{E}-04$ \\
\cline { 2 - 4 } & delay & 0 \\
\cline { 2 - 4 } & \multirow{2}{*}{ laser1 } & width & $1.00 \mathrm{E}-05$ \\
\cline { 2 - 4 } & & delay & $1 \mathrm{E} 10-4$ \\
\cline { 2 - 4 } & \multirow{2}{*}{ laser2 } & width & $1.00 \mathrm{E}-05$ \\
\cline { 2 - 3 } & \multicolumn{2}{|c|}{ delay } & $3.00 \mathrm{E}-03$ \\
\cline { 2 - 3 } & \multicolumn{2}{|c|}{ system period } & $5.00 \mathrm{E}-03$ \\
\hline
\end{tabular}




\subsubsection{4}

\section{Arranjo experimental para a medição das BSL}

Nas medições com a técnica de PIV planar são necessários dois acessos ópticos ao escoamento, sendo um para o plano de iluminação e outro para a câmera.

O caminho ótico esta composto por uma lente esférica com distância focal de 1000mm que reduze a espessura do plano de iluminação na região de medição, uma lente cilíndrica com distância focal de $-25 \mathrm{~mm}$ que abre o plano de luz e um espelho de reflexão laser de alta energia que foi utilizado para refletir o plano para o interior do canal de água. A câmera foi orientada perpendicularmente ao plano de luz para a captura das imagens das partículas no escoamento, tal como mostrado na figura 4.18

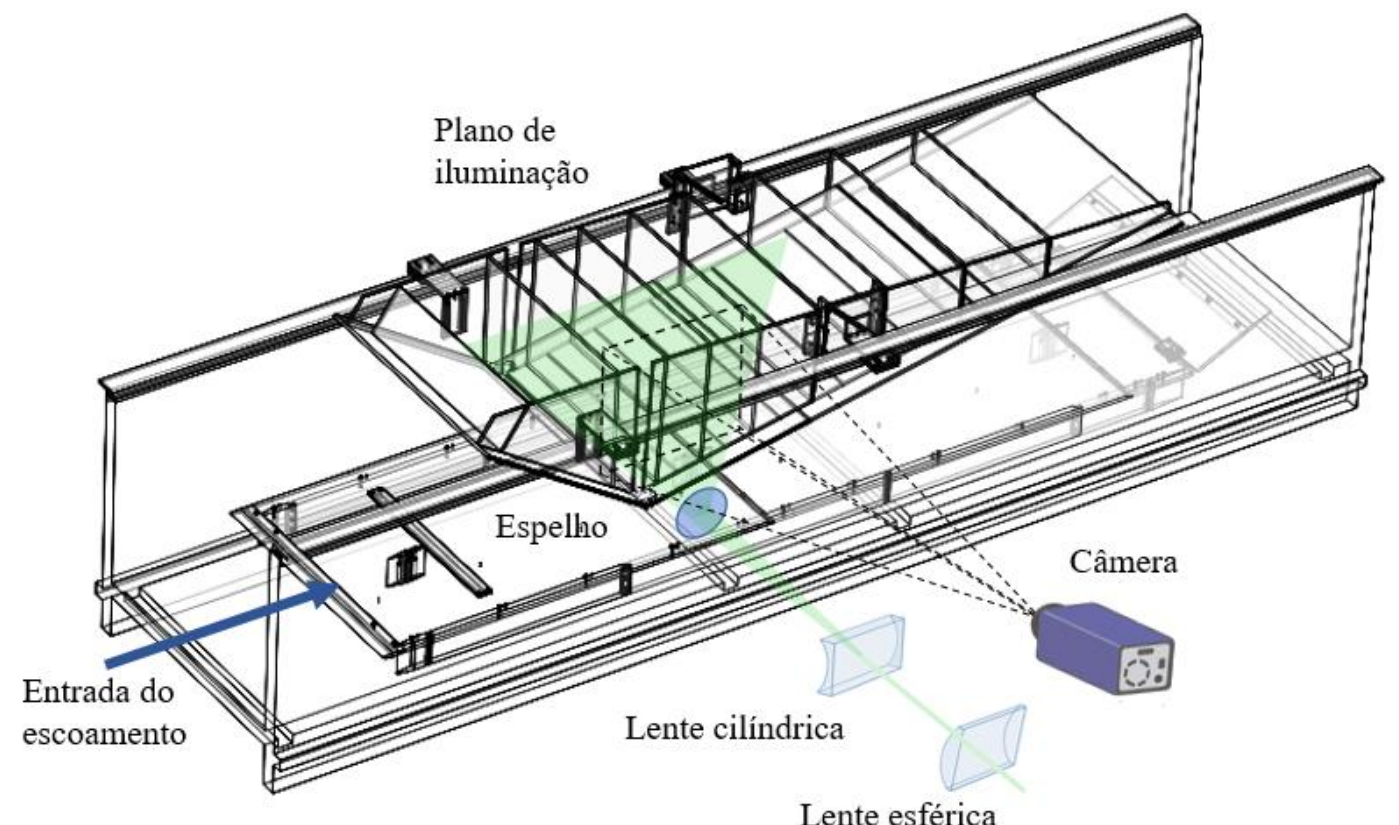

Figura 4.18 Arranjo experimental para a medição das bolhas de separação laminar implementado no laboratório de engenharia de fluidos da PUC-Rio.

$\mathrm{Na}$ parte inferior do canal de agua foi montado um sistema traverso que permite o deslocamento do caminho ótico tanto no sentido longitudinal quanto no sentido transversal. Isso permite o posicionamento do plano de iluminação em diferentes regiões de medição sem grandes ajustes no arranjo de lentes. As figuras 4.19 e 4.20 ilustram com detalhe o caminho ótico implementado, a disposição das lentes e a formação do plano de iluminação 


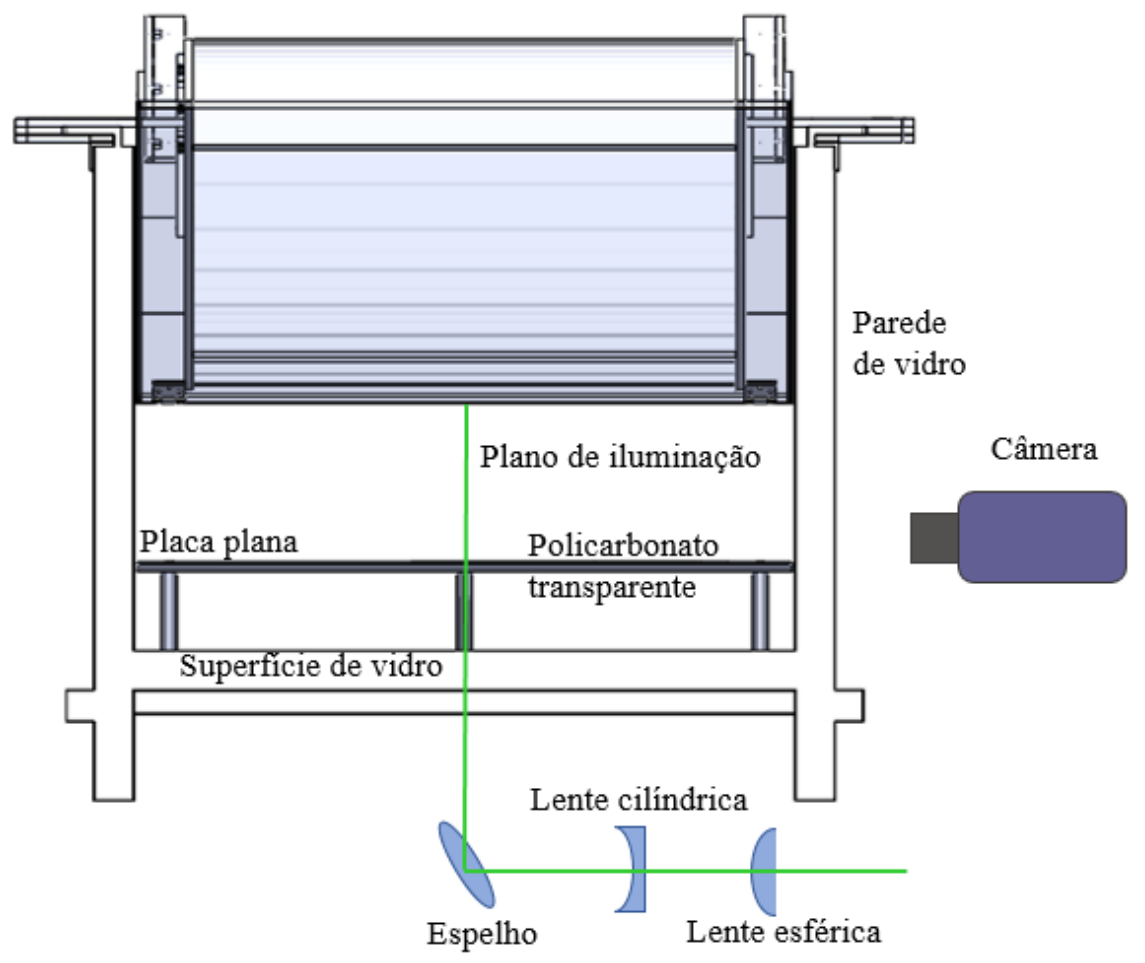

Figura 4.19 Vista lateral da região de medição, e visualização do caminho ótico localizado na parte inferior do canal de água.

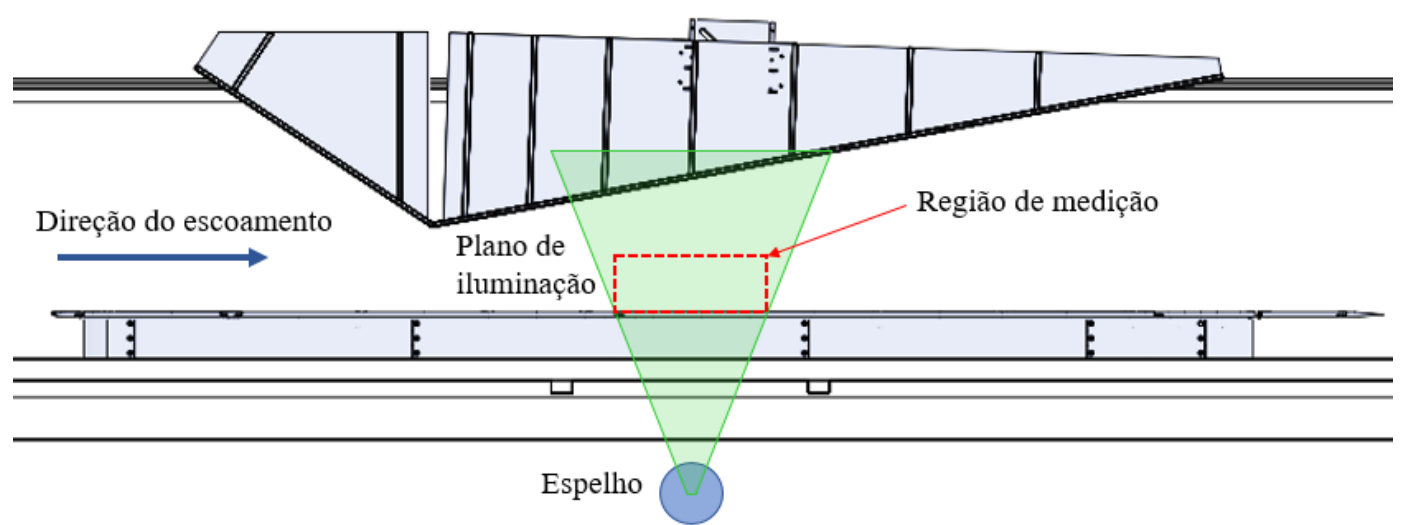

Figura 4.20 Vista frontal da região de medição.

\subsubsection{5}

\section{Medição das vazões de sucção}

Com base no projeto da placa divergente, descrito no capítulo 3, foram selecionadas as bombas para o sistema de sucção. Essas bombas foram colocadas em cada um dos compartimentos de sucção da placa divergente. Esses compartimentos são selados e somente há comunicação com o canal pela fenda de sucção. O fluido no interior das cavidades foi bombeado para fora dos compartimentos através de bombas centrífugas, do modelo Sarlo Better, que são 
utilizadas em aquários. Essas bombas ficam submersas e possuem alta vazão de bombeio. Foram utilizadas bombas independentes para cada compartimento, pois a vazão de sucção de cada ponto ao longo da placa divergente era diferente. A rotação das bombas foi ajustada com um potenciômetro.

Para medir a vazão de sucção efetiva de cada compartimento foram utilizados medidores de vazão YP30, trabalham na faixa de 0-30L/min. Esses medidores são do tipo turbina e possuem saída em frequência. Para uma maior confiabilidade das medições optou-se por realizar uma calibração do equipamento. A curva de calibração obtida experimentalmente neste trabalho é apresentada na Figura 4.21

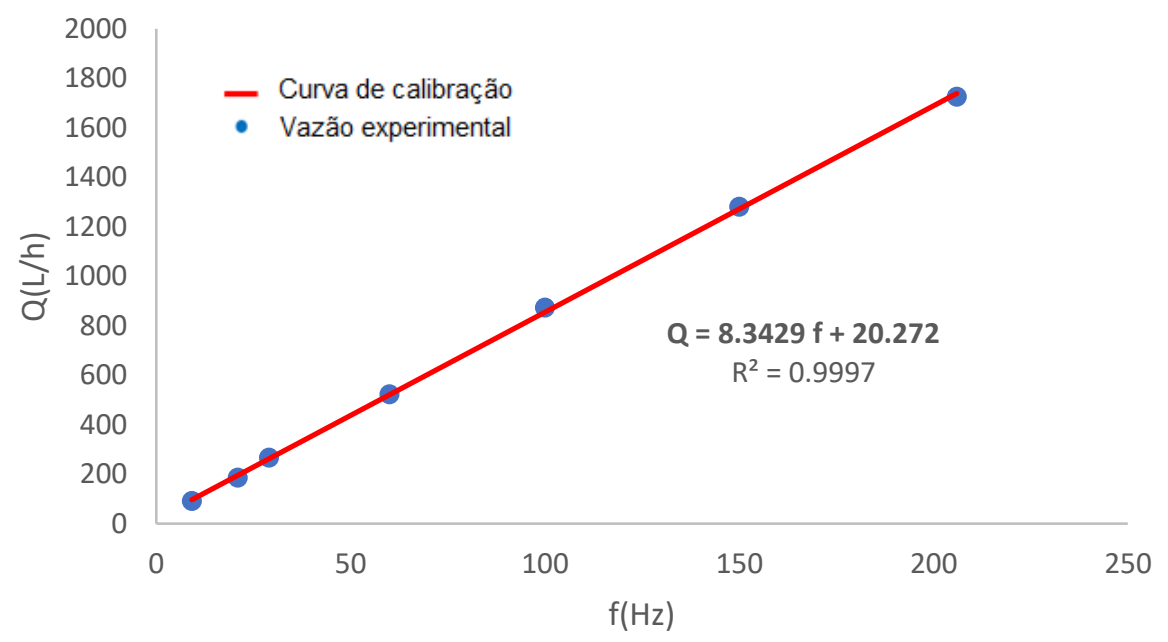

Figura 4.21 Curva de calibração do medidor de vazão tipo turbina

A medição da vazão de sucção foi feita em tempo real através de uma interface implementada em LabVIEW. Para isso utilizou-se uma placa de aquisição NI-PXIe-4300. A figura 4.22 (a) mostra a interface utilizada para monitorar a sucção e a Figura 4.22 (b) mostra a montagem do sistema de bombeio e das turbinas. A imagem da Figura 4.22 (b) corresponde a uma vista superior do aparato experimental. É importante ressaltar que foram utilizadas duas telas finas para garantir a uniformidade da sucção nas fendas. Essas telas foram coladas sobre as fendas, na parte inferior de cada um dos compartimentos. 


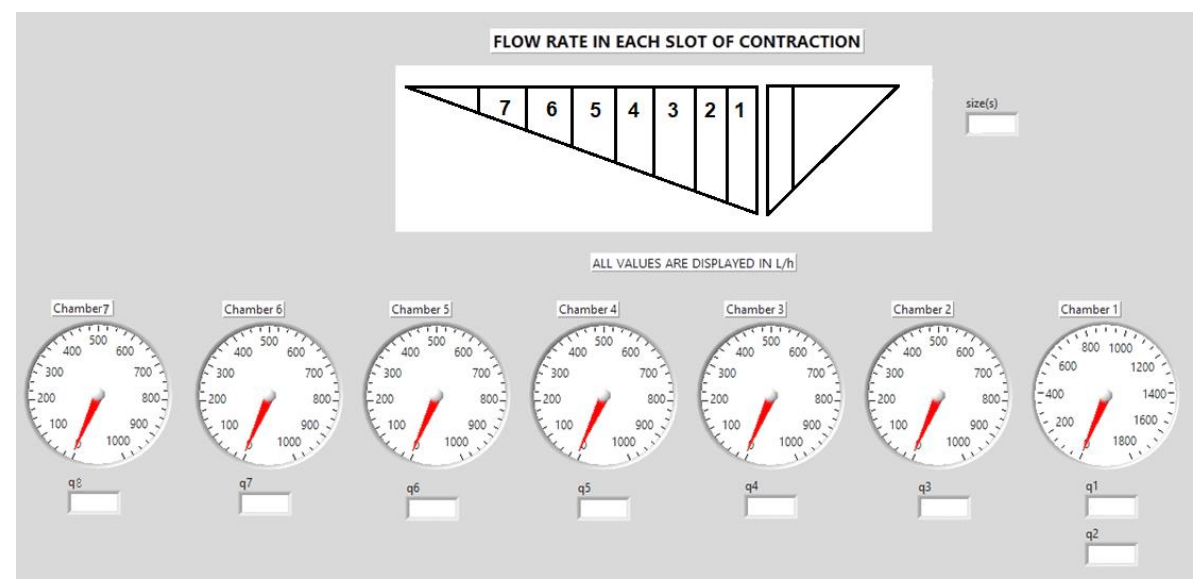

(a)

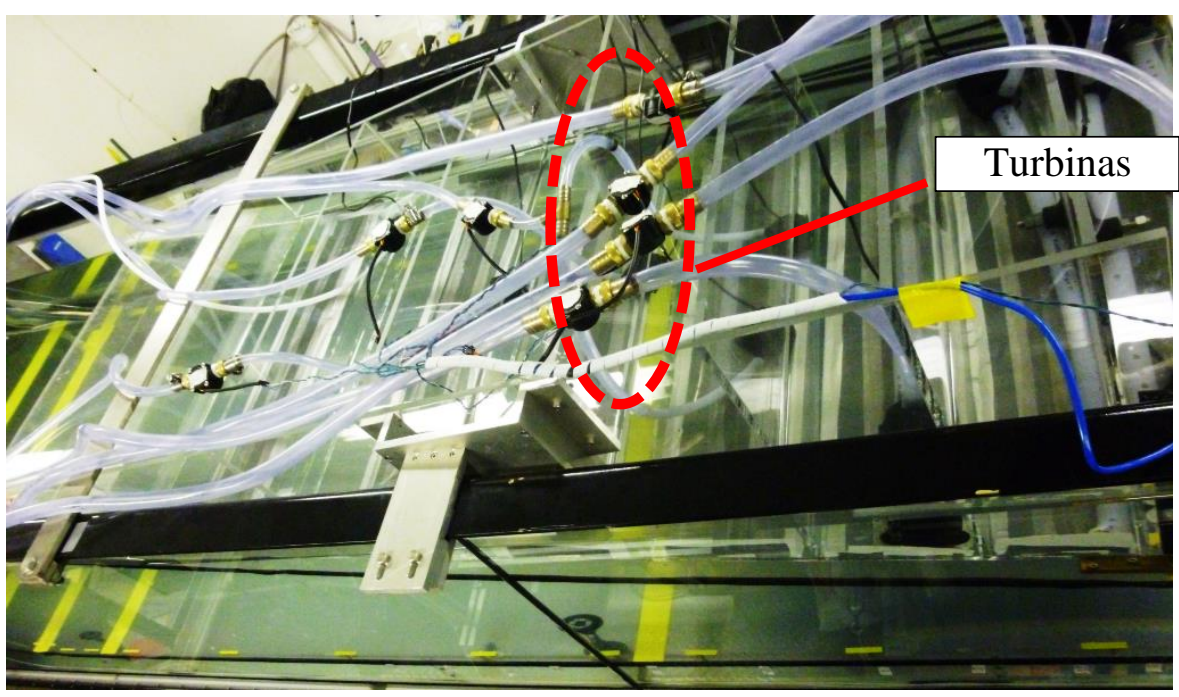

(b)

Figura 4.22 (a) sistema de monitoração das vazões de sucção, (b) montagem do sistema de bombeio

\subsubsection{6}

\section{Partículas traçadoras}

Foram utilizadas partículas de poliamida de $20 \mu \mathrm{m}$ e $50 \mu \mathrm{m}$, com uma densidade de $1.03 \mathrm{Kg} / \mathrm{m}^{3}$ e um índice refrativo de 1.5 da Dantec Dynamics. De acordo com a equação 4.13 o tempo de resposta de partículas de $50 \mu m$ em água é da ordem de $1.4 \mathrm{~ms}$, o que é bem mais baixo do que as frequências esperadas para as flutuações de velocidade do escoamento.

A massa de partículas inseridas no fluxo foi estimada usando a equação 4.14 para o qual se utilizaram os valores especificados na tabela 4.1. De acordo com a 
equação 4.13 para uma concentração de partículas por pixel, da ordem de 0.005 , seria necessária uma quantidade da ordem de $\mathrm{kg}$ de partículas para todo o volume do canal, que é da ordem de 10 000litros. Do ponto de vista prático isso é inviável. Sendo assim, construiu-se um injetor de partículas e um reservatório para que as partículas pudessem ser injetadas no escoamento somente na região próxima ao plano de medição. O injetor consiste em um tubo carenado com um perfil aerodinâmico para reduzir a perturbação do escoamento. O injetor foi localizado na entrada da câmara de testes do canal de agua. A vazão de injeção foi controlada com uma válvula agulha. No arranjo proposto considerou-se uma concentração de partículas $0.01 \mathrm{ppp}$ no reservatório. Assim, foram necessários somente $10 \mathrm{~g}$ de partículas para os $12 \mathrm{~L}$ do reservatório. Como a concentração reduz após a injeção no canal, foi necessário ajustar a concentração para 50\% a mais do valor previsto. Sendo então misturadas $15 \mathrm{~g}$ de partículas para cada $12 \mathrm{~L}$ do reservatório. Com isso, conseguiu-se uma concentração adequada de partículas na região de visualização sem a necessidade de inserir traçadores em todo o volume do canal de água.

Tabela 4.2 parâmetros envolvidos no cálculo da massa de partículas

\begin{tabular}{|l|r|}
\hline ppp & 0.01 \\
\hline$\Delta z(\mathrm{~mm})$ & 1.5 \\
\hline$V_{\text {sol }}\left(\mathrm{mm}^{3}\right)$ & $1.20 \mathrm{E}+07$ \\
\hline$\rho_{p}\left(\mathrm{~kg} / \mathrm{mm}^{3}\right)$ & $1.03 \mathrm{E}-06$ \\
\hline$d_{P}(\mathrm{~mm})$ & 0.05 \\
\hline $\mathrm{M}$ & 0.09 \\
\hline Dpixel & 0.0012 \\
\hline
\end{tabular}

\subsubsection{7 Calibração}

Um procedimento de calibração é necessário para se encontrar uma relação entre pixels da imagem e deslocamento no espaço (pixels $/ \mathrm{mm}$ ). Para isto se utiliza um alvo de calibração, que consiste em uma placa com marcações espaçadas e com distância entre marcações conhecida. Uma imagem do alvo utilizado é mostrada na Figura 4.23(a). Para a calibração das imagens esse alvo é colocado exatamente no plano de medição e deve coincidir com o plano de iluminação formado pelo laser. A câmera que registra as imagens deve estar perpendicular a este plano e 
cuidadosamente nivelada. $\mathrm{O}$ foco da câmera deve ser ajustado para a posição onde encontra-se o alvo. A Figura 4.23(b) mostra a montagem no interior do canal. Com as imagens do alvo é possível então relacionar a distância entre marcações com as distâncias em pixels. Nos ensaios de medição dos campos de velocidade com a sucção a relação pixels $/ \mathrm{mm}$ obtida foi de 7.5 , ou seja, cada 7.5 pixels de deslocamento na imagem, corresponde a um deslocamento de $1 \mathrm{~mm}$ no plano de medição. Já na medição das bolhas a relação foi de aproximadamente 13pixels/mm;

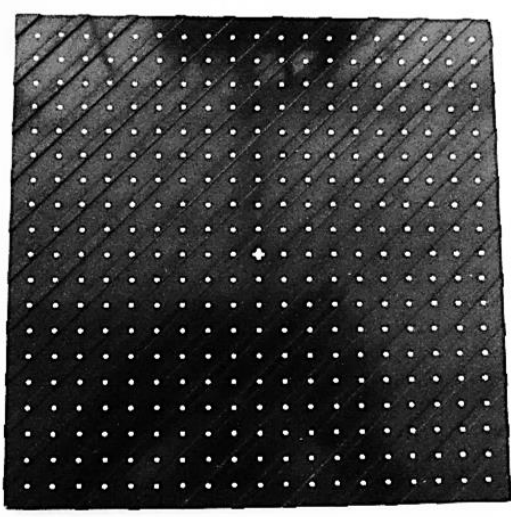

(a)

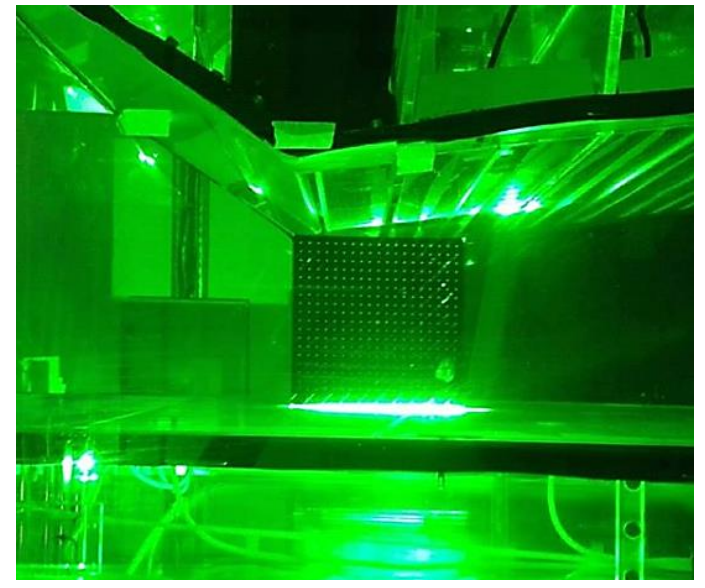

(b)

Figura 4.23 (a) alvo de calibração, (b) ajuste do alvo de calibração no plano de iluminação.

Para as medições feitas neste trabalho, foi realizado um procedimento de calibração para cada mudança de posição do plano de iluminação. Esse cuidado foi tomado para se obter uma boa fidelidade entre os dados coletados e o campo de velocidades. 


\section{5 \\ Resultados}

Neste capitulo são apresentados os resultados das medições que caracterizam e qualificam o aparato experimental.

Para facilitar a orientação em torno do volume de interesse, vamos definir um sistema de coordenadas conforme mostrado na figura 5.1, com o plano X-Z sobre a superfície da placa plana e o eixo Y normal à superfície da mesma. O deslocamento angular $\alpha$ do flap é medido em sentido anti-horário. Em adiante todos os valores das coordenadas estão referidos a este sistema.

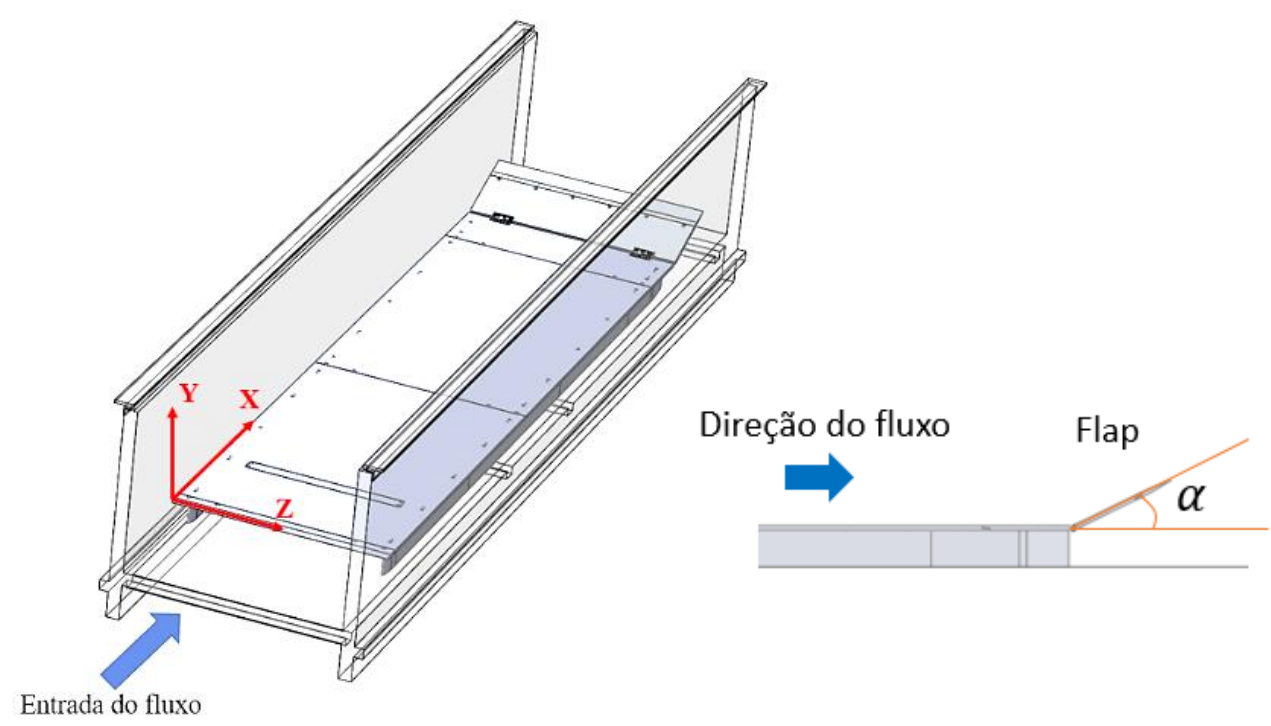

Figura 5.1 Sistema de coordenadas

\section{1}

\section{Verificação do Escoamento sobre a placa plana}

A caracterização do escoamento sobre a placa plana na condição de gradiente de pressão zero, foi realizada através da medição dos perfis de velocidade média da camada limite com a técnica de anemometria laser Doppler. Foram medidos perfis em diferentes posições ao longo da placa e também em algumas posições ao longo da direção transversal. O objetivo dessas medições foi verificar a qualidade do 
escoamento base sobre a placa plana. Como este é o primeiro trabalho que utiliza esse aparato, buscou-se qualificar o escoamento em relação a bidimensionalidade do fluxo e em relação ao nível de perturbações. A bidimensionalidade pôde ser avaliada diretamente através de medições ao longo da direção transversal. Já o nível de perturbações foi inferido de maneira qualitativa através da medição do comprimento da placa onde o escoamento ainda se mantinha como laminar. Cabe ressaltar que durante o curso do trabalho, buscou-se quantificar o nível de turbulência do escoamento com um anemômetro de filme quente. No entanto, os resultados não foram satisfatórios e o nível de ruído elétrico das medições era da mesma ordem das perturbações do escoamento.

Nos testes de caracterização do escoamento sobre a placa, utilizou-se uma velocidade do fluxo livre constante e igual a $0.15 \mathrm{~m} / \mathrm{s}$. Inicialmente foi avaliado o ajuste do flap localizado no bordo de fuga da placa plana. Nesse teste foram adicionadas partículas ao escoamento e visualizou-se o escoamento no bordo de ataque. Observou-se que para ângulos maiores que $10^{\circ}$ o escoamento não apresentava separação no bordo de ataque. Medições do perfil de velocidades indicaram que nessa condição o escoamento se apresentava como laminar sobre a placa plana. Com ângulos de ataque menores que $10^{\circ} \mathrm{o}$ escoamento já era turbulento próximo ao início da placa. Com base nas observações realizadas, fixou-se o ângulo do flap em $15^{\circ}$ durante os ensaios.

A figura 5.2 mostra alguns perfis da camada limite medidos sobre a placa plana para diferentes posições longitudinais. Os resultados experimentais foram comparados com o perfil de Blasius se encontrando uma excelente concordância. Em todos os perfis foi necessário fazer uma correção da posição do ponto experimental medido mais próximo à parede conforme já descrito no capítulo 4 . Os dados mostram que mesmo a $1725 \mathrm{~mm}$ do bordo de ataque o escoamento ainda se mantinha laminar. Nessa posição o número de Reynolds baseado na espessura de deslocamento $\left(\delta^{*}\right)$ é da ordem de 900 . Cabe ressaltar que durante os ensaios sem gradiente de pressão e sem introdução de perturbações controladas não se observou a transição do escoamento na região útil da placa. No entanto, não é possível afirmar que o escoamento era laminar em toda extensão da placa pois não foram realizadas 
medições em regiões mais próximas ao flap. Isso sugere que o nível de turbulência do canal de água não é elevado.
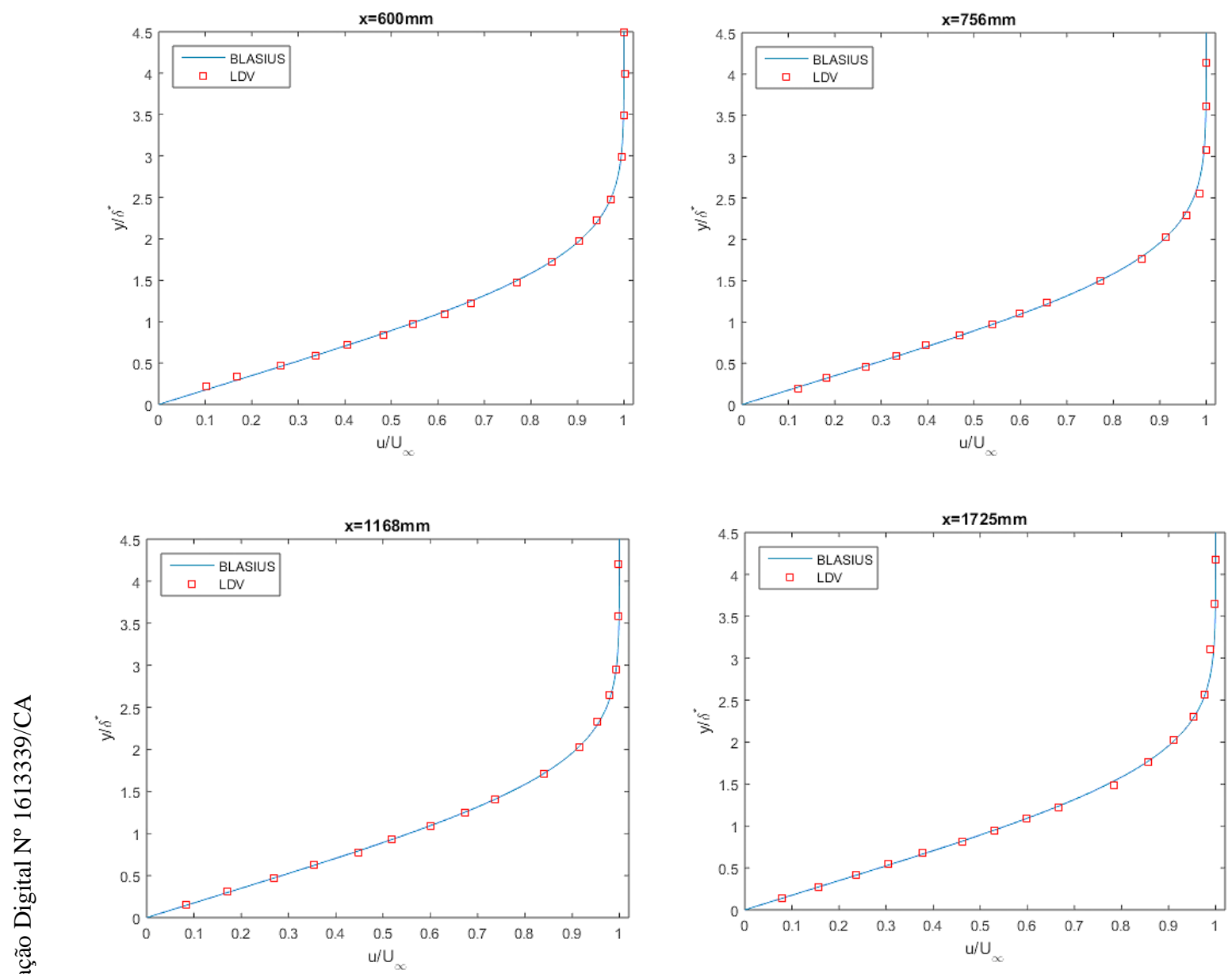

Figura 5.2 Correspondência entre os dados experimentais (LDV) e o perfil de Blasius para perfis medidos em diferentes posições longitudinais ao longo da placa.

O cálculo das integrais da espessura de deslocamento e a espessura de momentum foi realizada com o método do trapézio, a relação entre elas forneceu o valor do fator de forma para cada um dos perfis. Os resultados obtidos são apresentados no gráfico da Figura 5.3. 


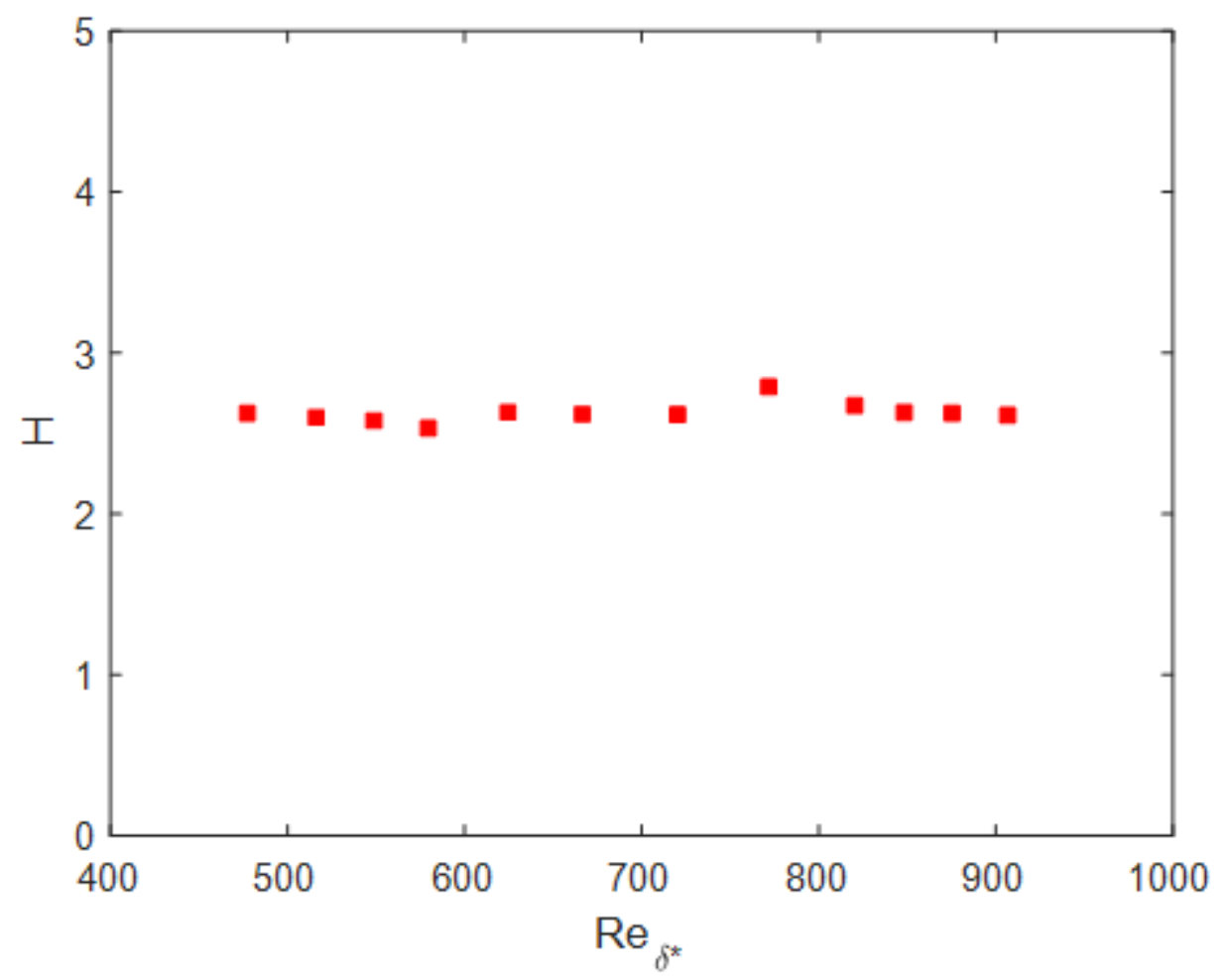

Figura 5.3 Fator de forma $H=\frac{\delta^{*}}{\theta}$ ao longo da placa plana

Segundo Blasius (ver Schlichting, H. 1979), camadas limites laminares sobre placas sem gradiente de pressão devem exibir um fator de forma em torno de 2.6. Diversos resultados experimentais comprovam a teoria de Blasius como por exemplo os realizados por Schubauer e Klebanoff, (1955). Isto indica que a camada limite desenvolvida sobre a placa plana consegue atravessar toda a região de medição sendo laminar. Também é importante ressaltar que de acordo com Schlichting, H. (1979), a partir de $R e_{\delta^{*}}$ igual a 520 o escoamento tende a se tornar instável para a instabilidade de ondas de Tollmien-Schlichting. Logo, pode-se inferir que o escoamento se mantém laminar mesmo em uma região onde o crescimento de ondas TS pode conduzir a transição. De acordo com a curva neutra mostrada na Figura 2.13, pode-se notar que nessa faixa de números de Reynolds o escoamento já ultrapassou o segundo ramo da curva neutra para algumas frequências de ondas TS. Isso reforça a ideia de que o nível das perturbações do escoamento livre é baixo e o canal de água pode ser considerado de baixa turbulência. 
$\mathrm{Na}$ posição longitudinal $\mathrm{x}=600 \mathrm{~mm}$ que equivale a um $R e_{\delta^{*}}$ de aproximadamente 500, foram medidos quinze perfis de velocidade ao longo da direção z. As medições foram realizadas com um espaçamento de $20 \mathrm{~mm}$ e foram amostrados 30 pontos por perfil de velocidade. Os perfis obtidos caracterizam um plano Z-Y transversal ao escoamento. As medições foram feitas na região central da placa, afastada cerca de $250 \mathrm{~mm}$ das paredes laterais do canal. O tempo total do experimento foi de aproximadamente 8 horas. A automação do processo de medição auxiliou na realização dos testes. Os resultados apresentados na Figura 5.4 comprovam a bidimensionalidade do escoamento e sugerem uma boa estabilidade do escoamento no canal. De fato, não se observa durante o dia variações grandes de temperatura no laboratório, devido ao mesmo estar localizado no subsolo do edifício.

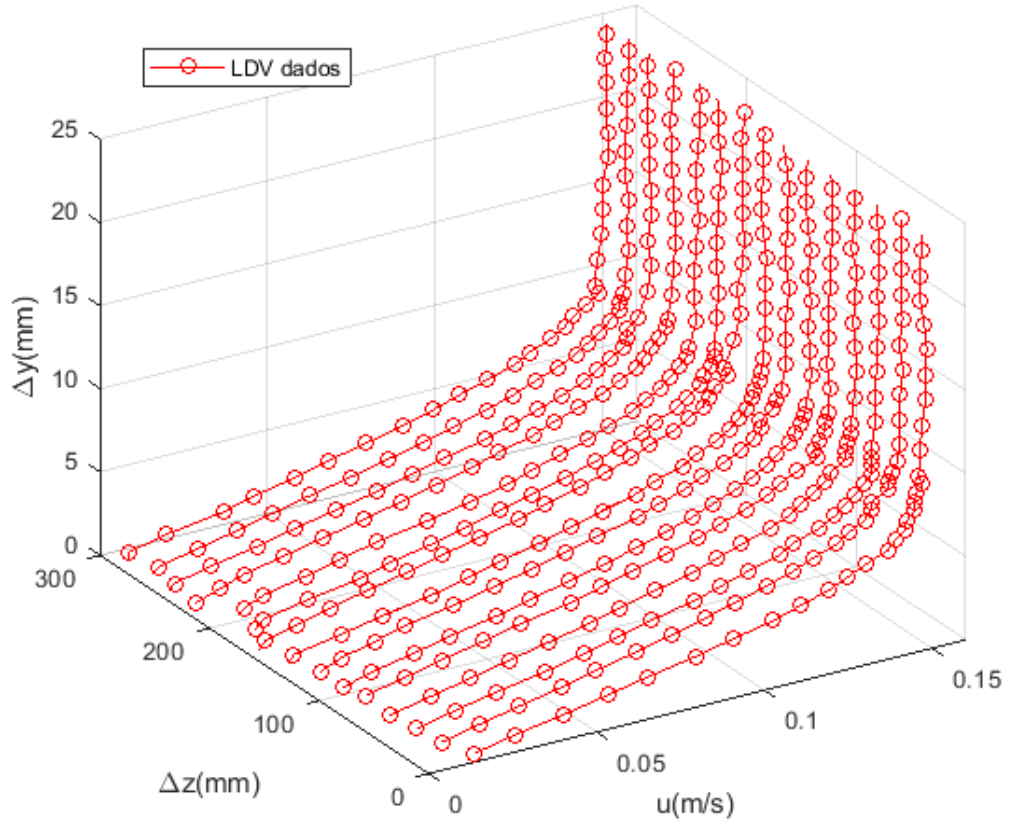

Figura 5.4 Perfis de velocidade média ao longo de uma secção transversal ao fluxo, para a posição $\mathrm{x}=600 \mathrm{~mm}$ desde o bordo de ataque

Com base nos testes iniciais pode-se concluir que de fato o escoamento sobre a placa plana é laminar em toda região de estudo e apresenta bidimensionalidade adequada. Isso é importante não só para o presente estudo, mas também qualifica o aparato para investigações futuras que envolvam estudo de fenômenos relacionados a transição de escoamentos laminares para turbulentos. 


\section{2}

\section{Avaliação da Sucção e Sopro Oscilatório}

Nos testes com sucção e sopro utilizou-se o mecanismo descrito no capítulo 3. Nesse teste a localização do jato de perturbação corresponde as coordenadas $x=400 \mathrm{~mm}, y=0, e \mathrm{z}=467 \mathrm{~mm}$. A frequência escolhida para excitação das perturbações foi de $0.30 \mathrm{~Hz}$. Isso corresponde a uma frequência adimensional de ondas TS de aproximadamente 70E-6, dita frequência é calculada do seguinte modo: $F=\left(2 \pi f v 10^{-6}\right) / U_{\infty}^{2}$, onde $f$ é a frequência dimensional, $v$ a viscosidade cinemática do fluido e $U_{\infty}$ a velocidade da corrente livre. De acordo com a curva neutra da figura 2.13, nessa faixa de frequência as ondas TS se tornam instáveis em um número de Reynolds de aproximadamente 720 . O processo de transição foi avaliado examinando o fator de forma dos perfis de velocidade. A evolução do fator de forma é mostrada na figura 5.5. Pode-se verificar que o fator de forma apresenta uma tendência de redução ao longo da direção do escoamento. De acordo com o que corresponde segundo Schubauer e Klebanoff (1955) camadas limites turbulentas exibem fator de forma de 1.4. Nota-se uma tendência dos valores em direção a esse valor.

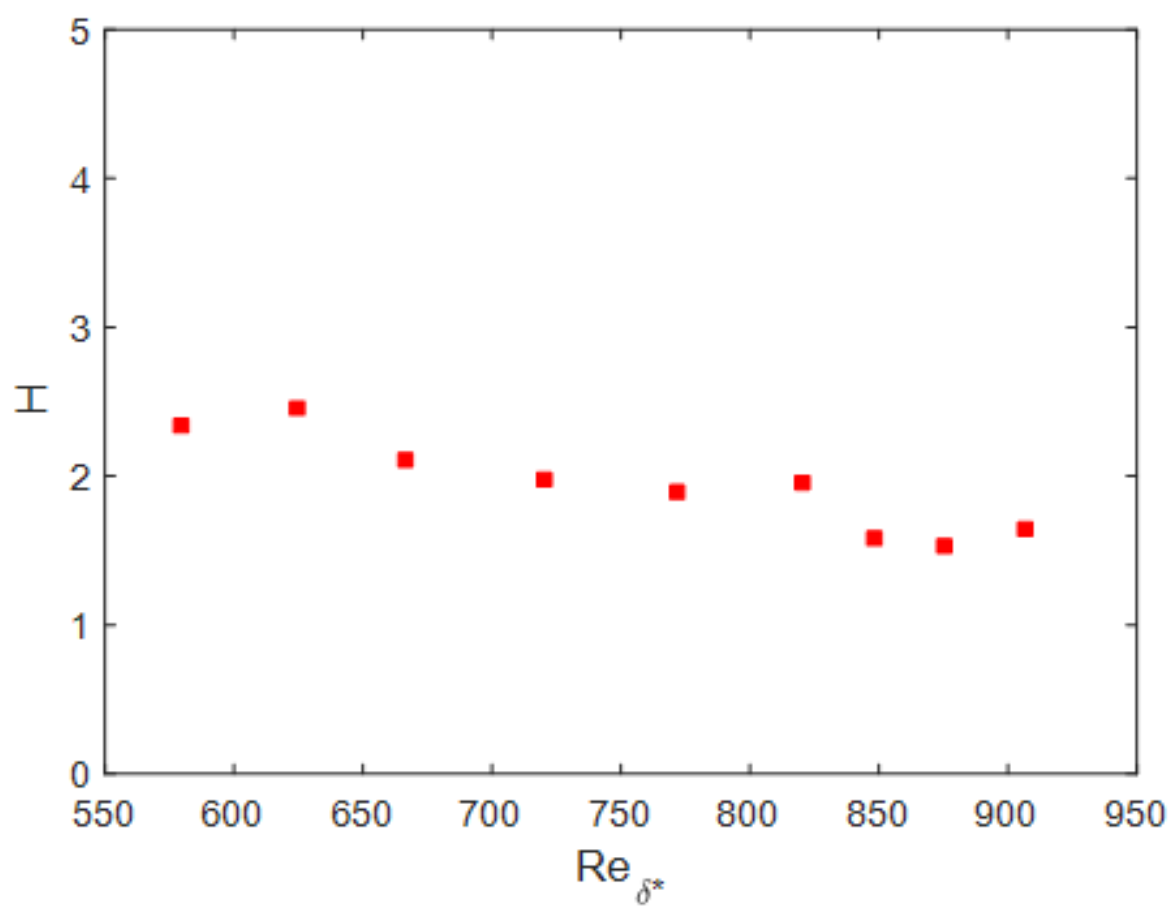

Figura 5.5 Evolução do fator de forma na camada limite submetida a sucção e sopro oscilatório 
Os resultados sugerem que o sistema de sopro e sucção permite introduzir de maneira controlada perturbações que conduzem à transição do escoamento.

Devido à baixa amplitude das perturbações geradas e a baixa taxa de amostragem obtidas com sistema LDV, não foi possível caracterizar as perturbações geradas para se comparar com ondas de Tollmien-Schlichting.

\section{3 Avaliação da sucção da camada limite}

Para a avaliação da sucção da camada limite foi empregada a técnica PIV bidimensional de dois componentes. O campo de visão das câmeras com as lentes selecionadas para os ensaios ficou limitado em uma área retangular de 160x80mm. Como a placa divergente se estende por uma região muito maior que essa área foi necessária deslocar a região de medição tanto na direção longitudinal como na direção vertical. O sistema traverso dos elementos ópticos, descrito no capítulo 4, foi utilizado para deslocamento do plano de luz longitudinalmente. O deslocamento na direção vertical só foi feito com a câmera pois o plano de laser ocupava toda a altura da seção do canal. $\mathrm{O}$ ajuste na vertical foi feito somente para compensar a mudança de altura da placa divergente.

De maneira similar à metodologia empregada nas simulações, buscou-se identificar nos experimentos às vazões de sucção mínimas para evitar o desprendimento de vórtices na placa divergente. As vazões de sucção estimadas no capitulo 3 que deram bons resultados para as simulações foram tomadas como valores de referência. $\mathrm{O}$ objetivo era evitar alterações no escoamento no interior do canal divergente.

Os resultados obtidos para a região mais crítica, isto é, o vértice entre as placas é apresentado na Figuras 5.6 a 5.11, as vazões mostradas em aquelas figuras correspondem à menor vazão de sucção sem separação. Em paralelo são mostradas medições realizadas sem sucção. 

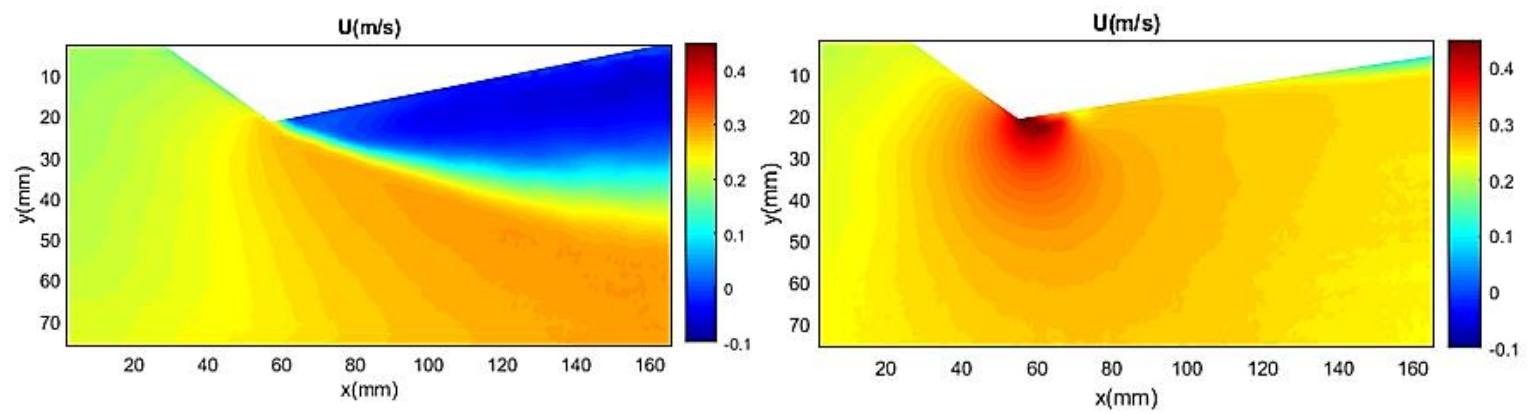

Figura 5.6 Contorno do componente "u" de velocidade para a região do vértice, Esquerda: sem sucção. Direita: $Q_{\text {sucção }}=1708 \mathrm{~L} / \mathrm{h}$

Na figura 5.6 podemos observar que depois de ativada a sucção a região de recirculação já não é formada, nem regiões com fluxo negativo. Isso indica que de fato, a sucção foi capaz de suprimir a separação no vértice do canal
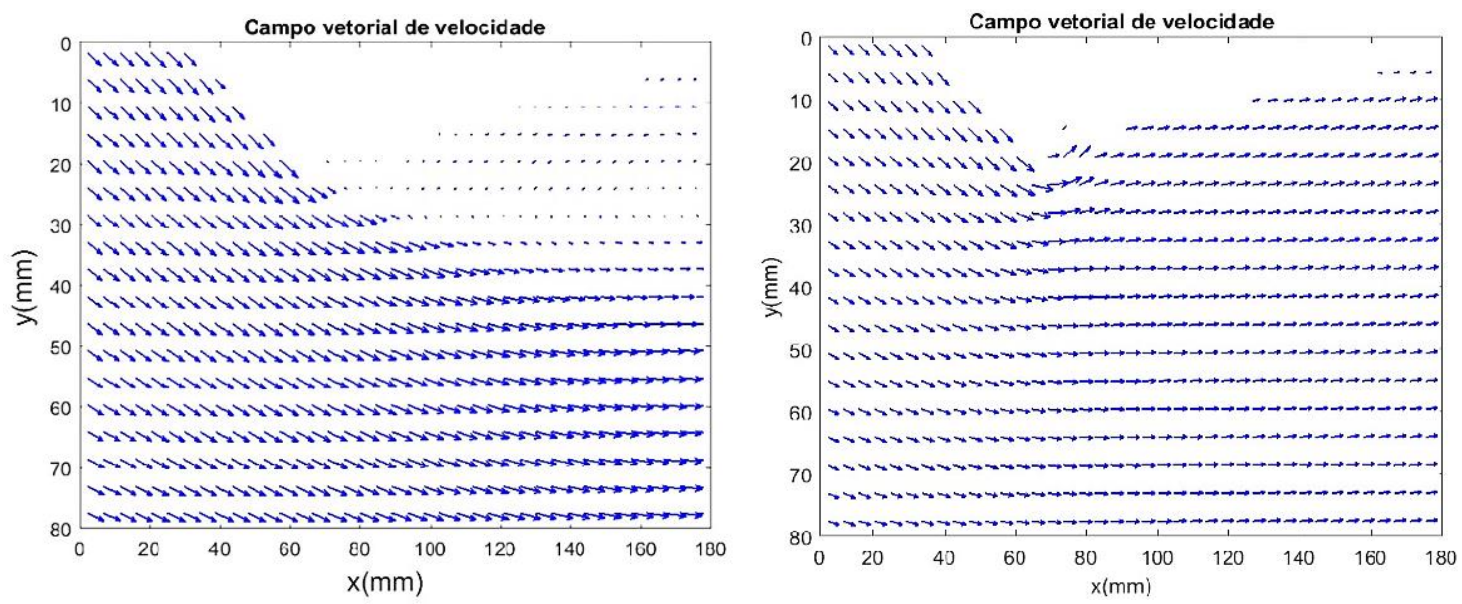

Figura 5.7 Campo vetorial de velocidade para a região do vértice, Esquerda: sem sucção. Direita: $Q_{\text {sucção }}=1708 \mathrm{~L} / \mathrm{h}$

A figura 5.7 mostra que uma vez ativada a sucção, o fluxo atravessa a região do vértice sem sofrer efeitos de sumidouro. 

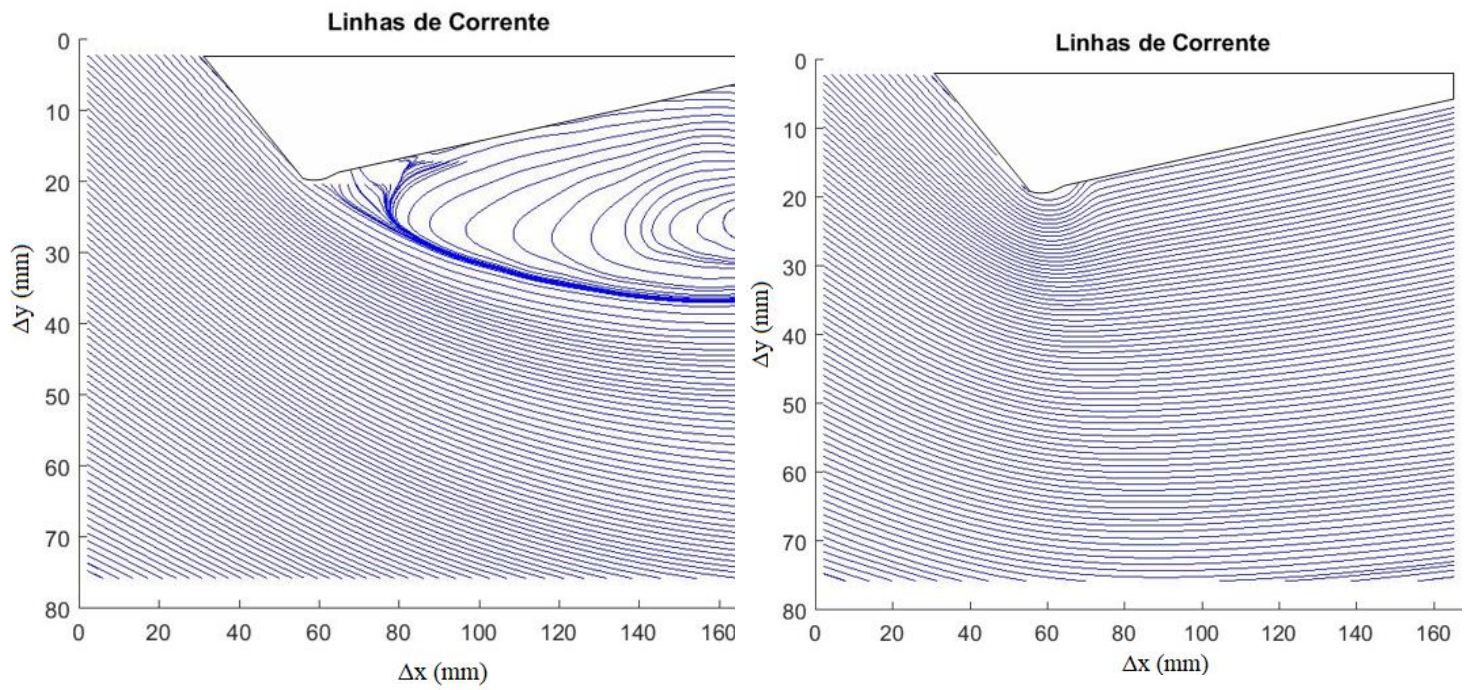

Figura 5.8 Linhas de corrente para a região do vértice, Esquerda: sem sucção.

Direita: $Q_{\text {sucção }}=1708 \mathrm{~L} / \mathrm{h}$

A figura 5.8 confirma o fato das linhas de corrente não sofrer efeitos de sumidouro perto da região do vértice, além disso pode-se observar que as linhas de corrente contornam a superfície divergente sem separação.
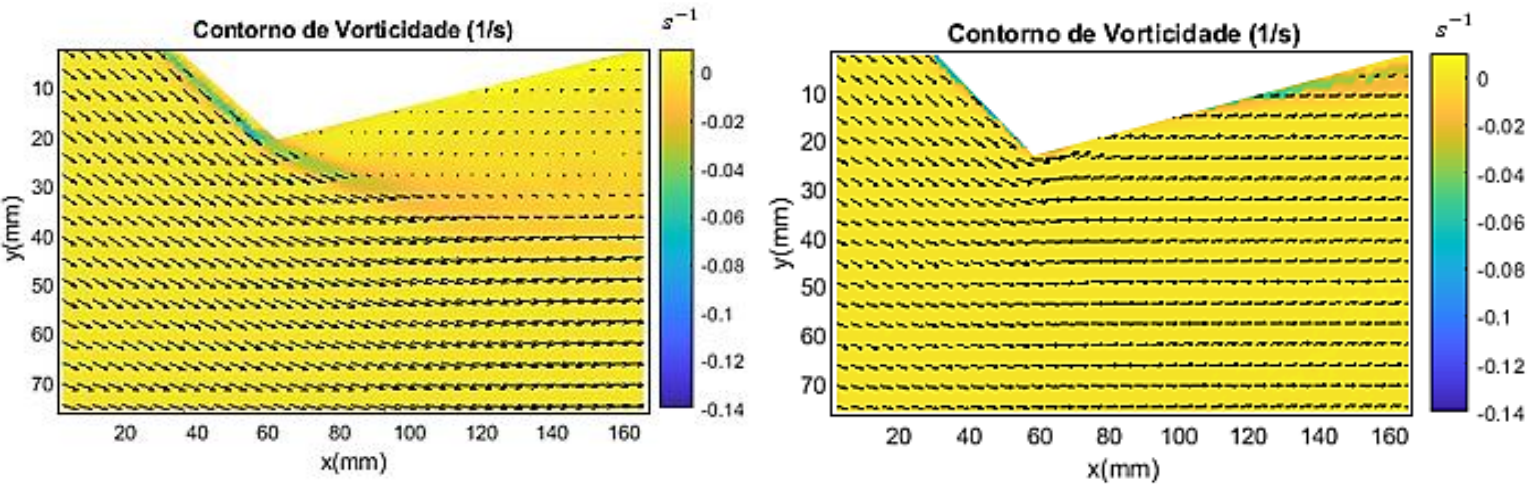

Figura 5.9 Contorno de vorticidade e campo de velocidade para a Janela 1, Esquerda: sem sucção. Direita: $Q_{\text {sucção }}=1708 \mathrm{~L} / \mathrm{h}$

A figura 5.9 mostra o contorno de vorticidade, pode-se ver claramente vórtices se desprendendo desde o vértice para o interior do escoamento para o caso sem sucção, enquanto que no caso com sucção ativada o desprendimento de vórtices é completamente omitido. 

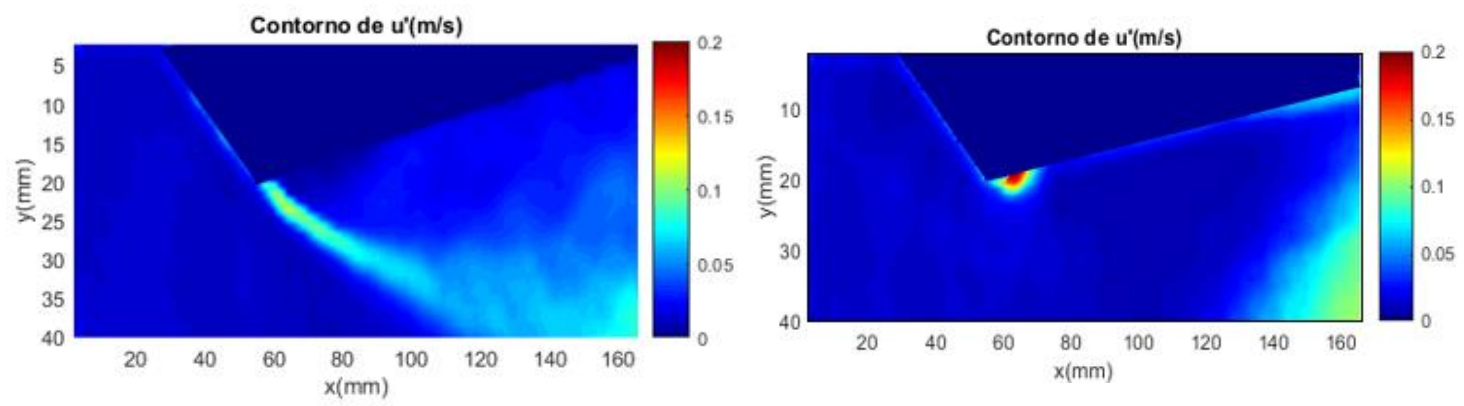

Figura 5.10 Flutuação da velocidade, componente $u^{\prime}$ para a região do vértice,

Esquerda: sem sucção. Direita: $Q_{\text {sucção }}=1708 \mathrm{~L} / \mathrm{h}$
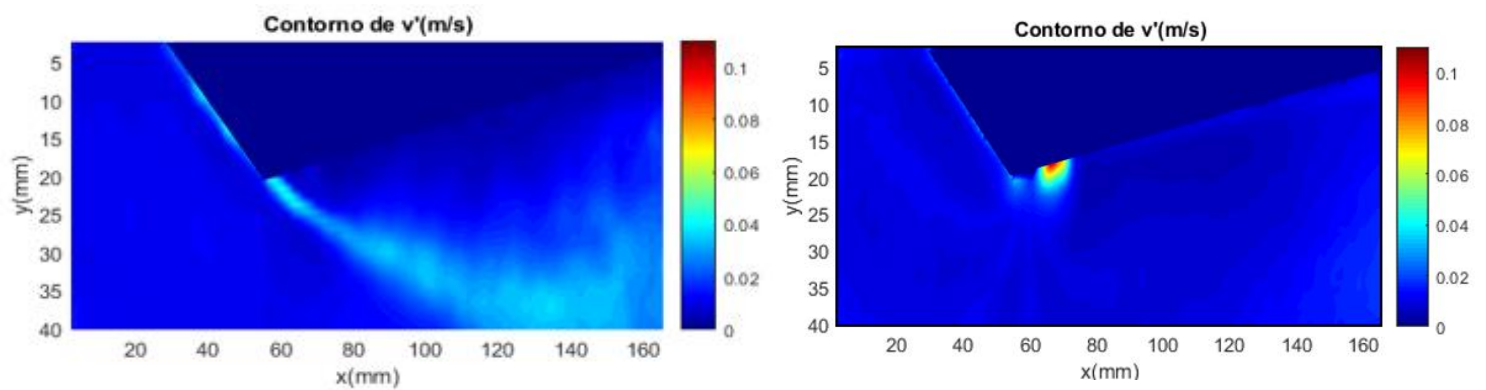

Figura 5.11 Flutuação da velocidade, componente $v^{\prime}$ para a região do vértice, Esquerda: sem sucção. Direita: $Q_{\text {sucção }}=1708 \mathrm{~L} / \mathrm{h}$

As figuras 5.10 e 5.11 mostram a diminuição dos valores das flutuações da velocidade geradas no vértice das placas após ativada a sucção.

Segundo o esquema mostrado na figura 5.12 a região do vértice corresponde à região de medição 1. A seguir, serão mostradas as gráficas das linhas de corrente com a sucção ativada correspondentes às regiões 2 até 5. As vazões mínimas para garantir a sucção sem desprendimento serão indicadas em cada gráfica.

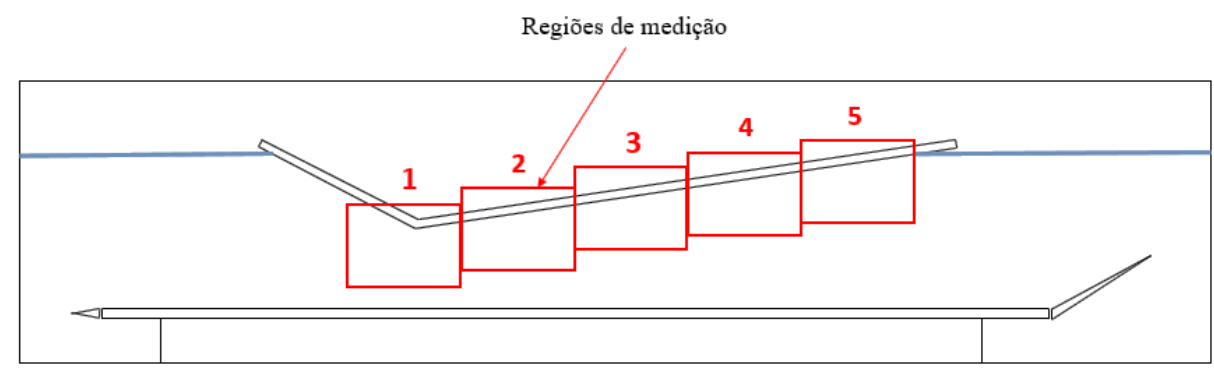

Figura 5.12 Regiões de medição para a verificação da sucção da camada limite. 


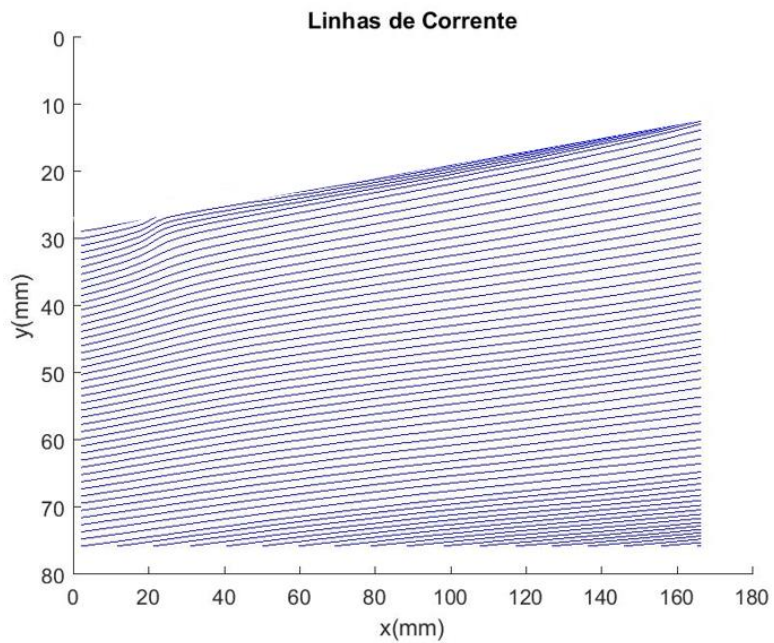

Figura 5.13 Linhas de corrente para a região de medição 2. $Q_{\text {sucção }}=835 \mathrm{~L} / \mathrm{h}$

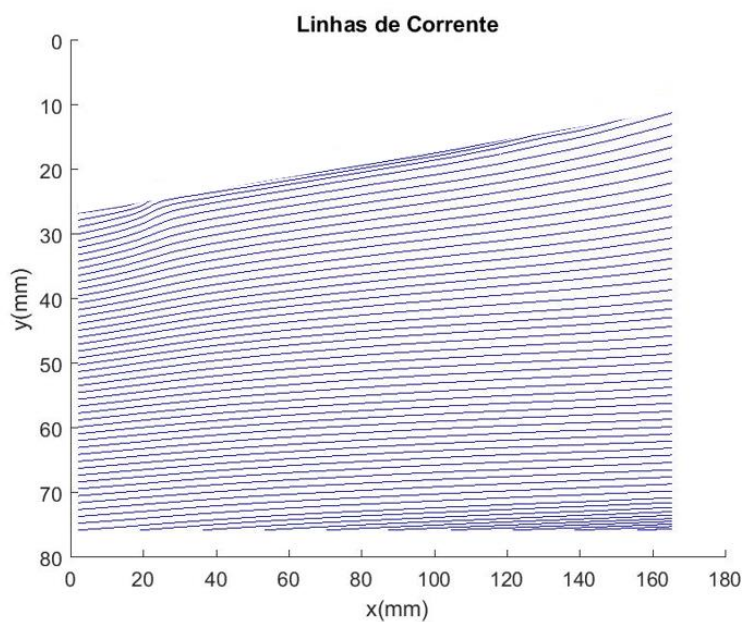

Figura 5.14 Linhas de corrente para a região de medição 3. $Q_{\text {sucção }}=833 \mathrm{~L} / \mathrm{h}$

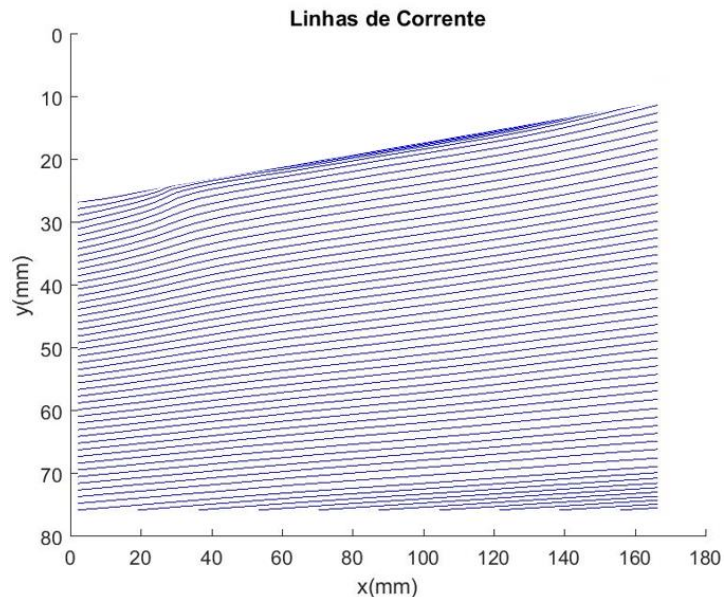

Figura 5.15 Linhas de corrente para a região de medição $4 . Q_{\text {sucção }}=400 \mathrm{~L} / \mathrm{h}$ 


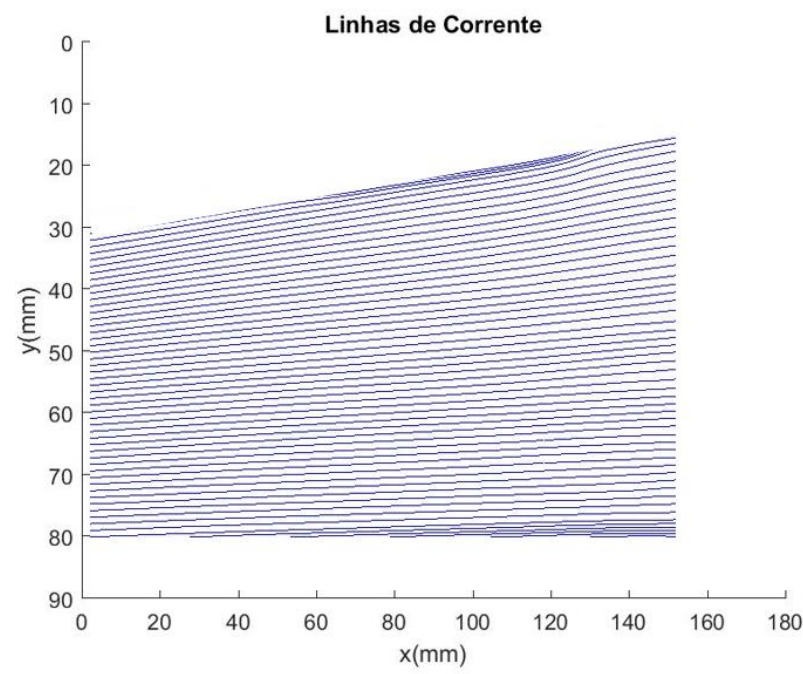

Figura 5.16 Linhas de corrente para a região de medição 5. $Q_{\text {sucção }}=217 \mathrm{~L} / \mathrm{h}$

As figuras 5.13 até 5.16 mostram a efetividade da sucção da camada limite ao longo de todo o comprimento da placa.

Em resumo, nesta seção demonstrou-se que o sistema de sucção foi capaz de suprimir a separação da camada limite na placa divergente. Os resultados experimentais validam qualitativamente as previsões feitas no estágio de projeto. No capítulo 3 foi sugerido para caso com ângulo de divergência de $7^{\circ}$ vazões de até $50 \%$ abaixo do que foi estimado como referência ainda poderiam ser capazes de evitar a separação. Para fins de comparação a vazão de referência para o vértice era de $3800 \mathrm{~L} / \mathrm{h}$ e a vazão utilizada nos ensaios experimentais foi de $1780 \mathrm{~L} / \mathrm{h}$. Abaixo disso a separação do escoamento era clara.

Com a qualificação do aparto, realizou-se um ensaio de caracterização da bolha de separação criada.

\section{4}

\section{Avaliação da Bolha de Separação laminar}

Nesta secção serão comparados os resultados obtidos neste trabalho com os resultados obtidos por outros autores. Além disso, fez-se uma caracterização do escoamento na região de separação. 


\section{4 .1 \\ Validação do fenômeno}

Através da técnica de visualização de fluxo por injeção de corante e utilizando uma fonte de iluminação LED foi verificada a formação do fenômeno. O corante utilizado foi leite integral com tinta de alimento, adicionou-se um pouco de etanol ao leite para reduzir a miscibilidade da mistura na água. O corante foi depositado sobre a superfície da placa plana com um tubo fino e uma seringa. Removeu-se o tubo e a seringa e o corante foi se desprendendo aos poucos da superfície da placa. Assim, o traçador continuava no escoamento, mas as perturbações criadas pela seringa e o tubo já não estavam mais presentes. Desta forma foi possível visualizar o escoamento sem a indução de turbulência pelo injetor de tinta. Uma câmera foi utilizada para filmar o escoamento. O resultado é apresentado na parte superior da Figura 5.17. Duas visualizações distintas foram incluídas para se ilustrar o comportamento da bolha. Para fins de referência, adicionou-se na Figura uma visualização de fumaça, extraída do trabalho de Braun e Kluwick (2005), de uma bolha formada sobre um perfil Eppler 387. As visualizações daquele trabalho foram feitas em túnel de vento para um número de Reynolds baseado no comprimento da corda da ordem de $10^{5}$. Neste trabalho o número de Reynolds baseado no comprimento da placa também é dessa ordem. De acordo com Gaster (1969) e Serna et. al. (2014), para comparações quantitativas o número de Reynolds baseado na espessura de momentum é mais indicado para relacionar diferentes estudos. No entanto, como as visualizações são apenas qualitativas o objetivo aqui foi identificar a estrutura geral de uma bolha de separação. Na figura da literatura, existem alguns estágios marcados como (1), (2), (3) e (4). Esses estágios correspondem ao ponto de separação, "bursting incipiente", formação de estruturas coerentes e desprendimento de vórtices, respetivamente. Estes estágios também foram qualitativamente observados na bolha formada neste projeto. Isso é um primeiro indicador de que o fenômeno de estouro de bolhas pode vir a ser estudado na bancada construída. No entanto, ainda são necessárias medições adicionais. Para isso, são analisados os resultados dos campos de velocidade do escoamento na região da bolha. 


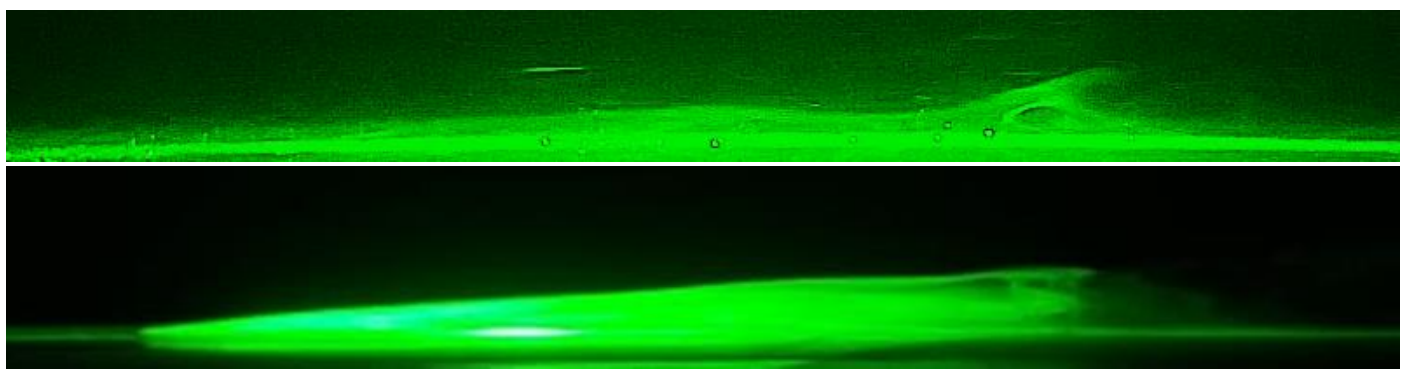

Direção do escoamento

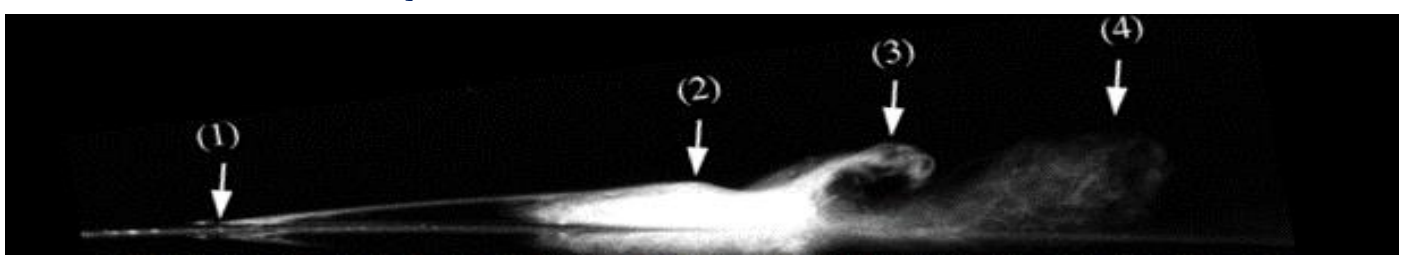

Figura 5.17 Comparação de resultados, imagens acima em verde: Visualização de uma BSL no canal de água da PUC-Rio. Imagem em preto e branco: Visualização de fumaça de uma BSL sobre um aerofólio Eppler 387. Retirado de Braun, S. \& Kluwick, A. (2005)

\section{4 .2}

\section{caracterização da Bolha de separação laminar}

Para se avaliar as características da bolha foram realizadas medições com a técnica PIV planar de alta resolução temporal. Como o comprimento da bolha era maior do que a região de visualização foi necessário deslocar o plano em duas posições. Em cada região foram coletadas 3000 imagens com uma taxa de amostragem de $200 \mathrm{~Hz}$ (enquanto que para a verificação da sucção foram coletadas 2000 imagens a uma taxa de $250 \mathrm{~Hz}$ ). Logo o tempo total de aquisição foi de 15 segundos.

Antes do processamento das imagens para o cálculo dos vetores de velocidade, realizou-se um pré-processamento para subtrair a imagem de fundo. Assim, removeu-se a influência da reflexão na parede nos resultados. Outro cuidado tomado foi a equalização das imagens. Algumas partículas apresentavam brilho mais intenso que outras e para garantir que todas as partículas tinham peso igual na correlação aplicou-se o algoritmo de equalização padrão sugerido no livro de Raffel et. al. (2007). 
No processamento das imagens utilizou-se $75 \%$ de sobreposição (overlap) das janelas de interrogação. Isso foi feito para se aumentar a resolução na região de escoamento separado. A descrição dos demais parâmetros de processamento é fornecida no capitulo 4. Os campos de velocidade média obtidos nas duas estações de medição são apresentados na Figura 5.18. Os campos referentes a cada posição foram identificados com cores diferentes. A linha tracejada representa o isocontorno de velocidade zero que delimita a região de fluxo reverso. Nota-se na figura 5.18 que próximo da parede existe uma região de baixa velocidade. Essa região no início da área de medição corresponde a camada limite (próximo de $\Delta \mathrm{X}=0$ ). Além disso se observa que a separação ocorre próximo a $\Delta \mathrm{X}=0.02 \mathrm{~m}$. $\mathrm{A}$ bolha cresce por aproximadamente $140 \mathrm{~mm}$ e depois recola rapidamente a superfície da placa próximo a $\Delta X=0.16 \mathrm{~m}$. A bolha atinge uma altura máxima de aproximadamente $5 \mathrm{~mm}$. O crescimento inicial da bolha segue uma tendência linear. Esse comportamento é bastante comum e reportado com frequência em diversos trabalhos (ver Gaster, 1969; Braun, \& Kluwick, (2005); Serna \& Lázaro (2014); dentre outros). Os campos de velocidade sugerem ainda que o escoamento longe da região da bolha é bem-comportado, o que reforça a ideia de que a separação é confinada a região próximo a superfície.

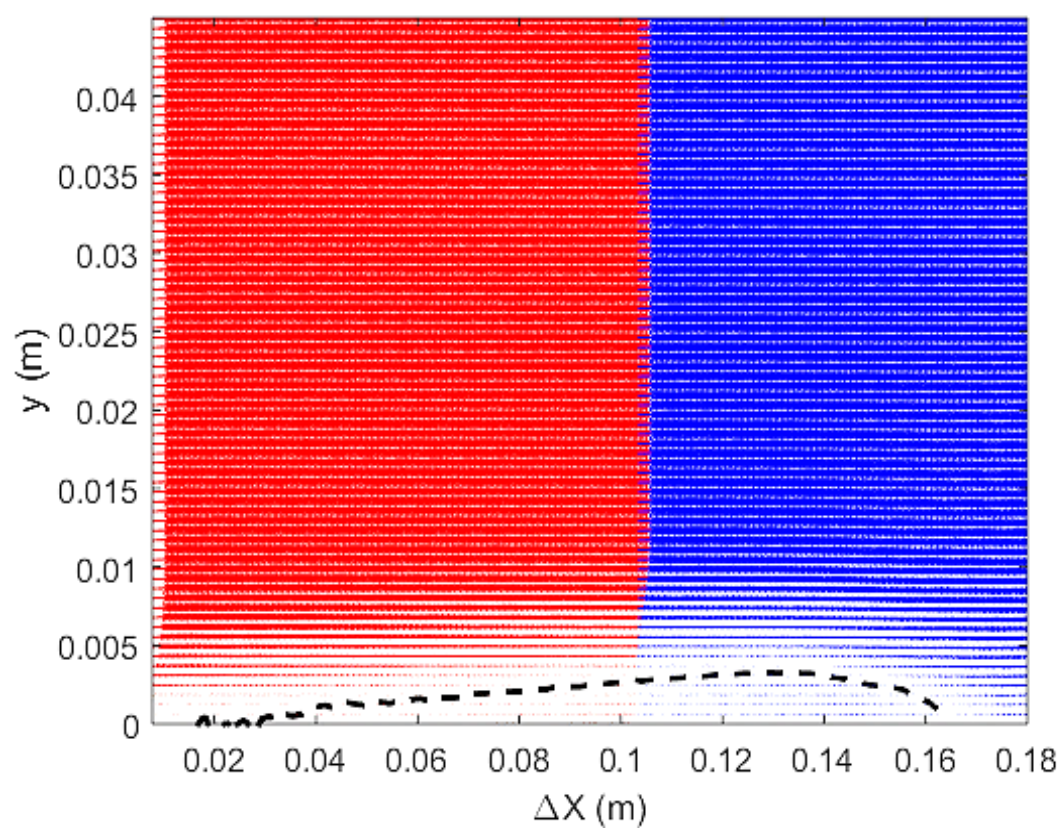

Figura 5.18 Reconstrução dos campos de velocidade média aquisitados

Para se ter uma ideia das velocidades do escoamento entorno a bolha apresenta-se na Figura 5.19 contornos da componente de velocidade média na 
direção do escoamento. Nota-se que fora da região da bolha a velocidade tem valores ao redor de $0.25 \mathrm{~m} / \mathrm{s}$. Próximo da contração os valores de velocidade chegam a $0.3 \mathrm{~m} / \mathrm{s}$. A Figura 5.20 mostra uma imagem ampliada da bolha. É interessante observar que a maior intensidade de escoamento reverso ocorre na região de recolamento da bolha bem próximo a parede.

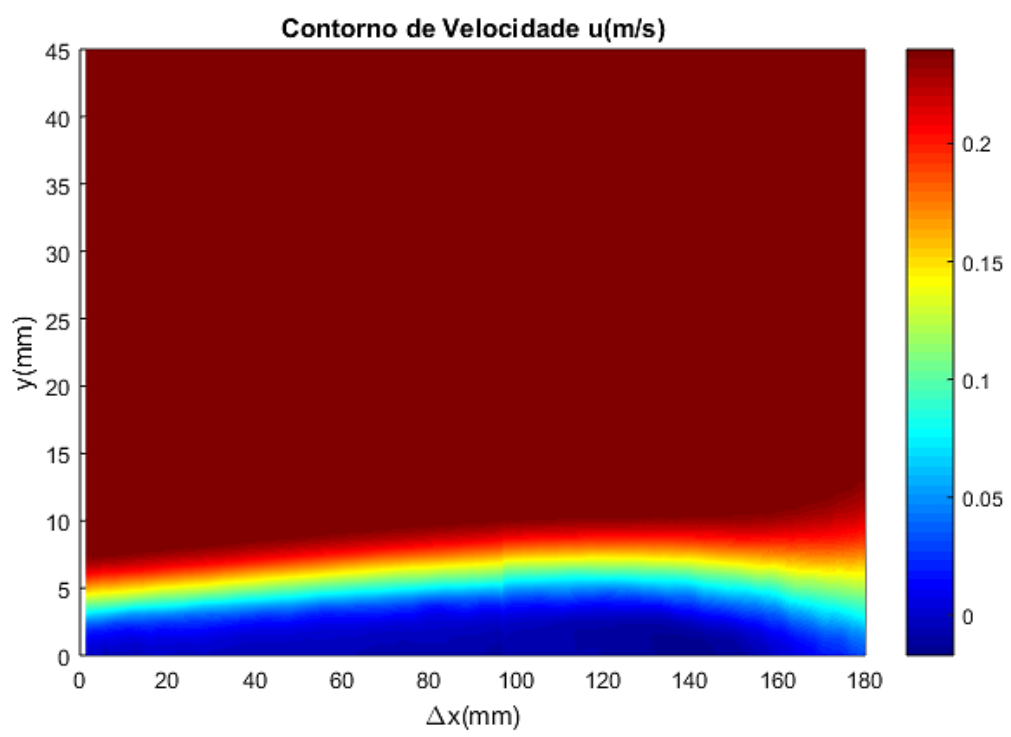

Figura 5.19 Contorno de velocidade média na bolha de separação laminar

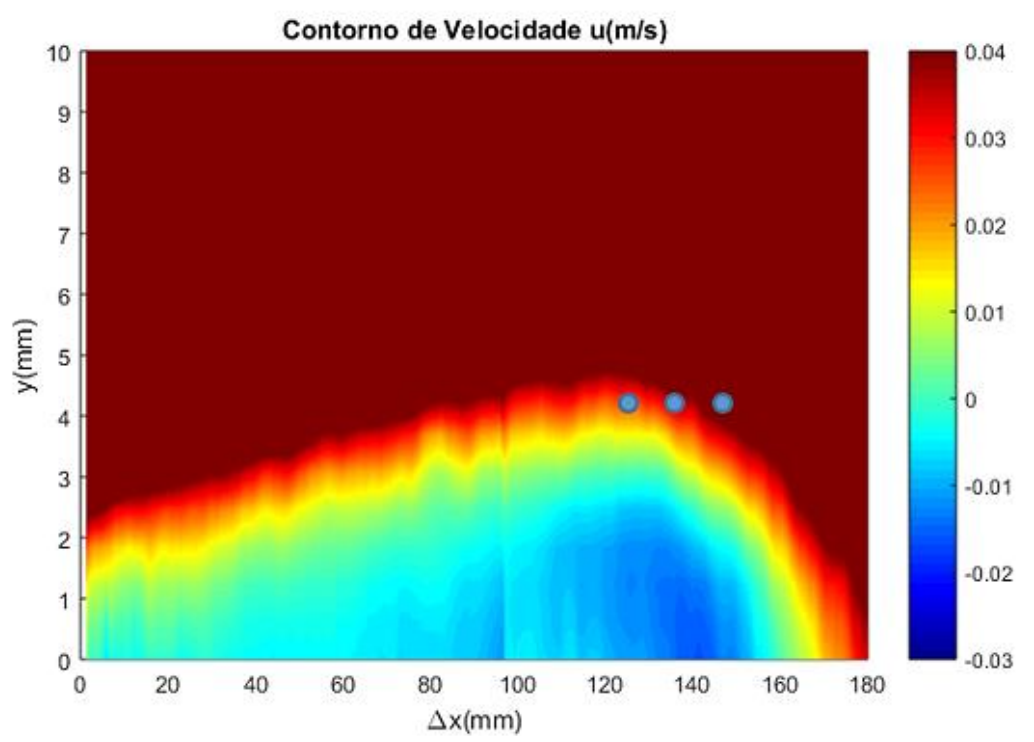

Figura 5.20 Imagem ampliada do contorno de velocidade média da bolha de separação laminar. Os três pontos marcados indicam as regiões onde serão extraídos dados para um analise espectral.

Observa-se na figura 5.20 que na região $\Delta X=40 \mathrm{~mm}$ que fica próximo do ponto de separação $(\Delta X=20 \mathrm{~mm}$, ver figura 5.18) a intensidade do escoamento reverso é quase nula. Mas ainda assim, o perfil de velocidades mostrado na figura 
5.21 exibe uma inflexão clara. Do ponto de vista da instabilidade espera-se que o escoamento nessa condição seja invíscidamente instável e perturbações sejam amplificadas rapidamente. No estudo teórico de bolhas de separação é comum aproximar o perfil de velocidades do escoamento na região separada por um perfil do tipo tangente hiperbólica, como o perfil utilizado nos trabalhos de Dovgal et al. (1994) e Serna, J. \& Lázaro B. J. (2015), dentre outros, definido pela seguinte equação:

$$
\frac{U(y)}{u_{e}}=\frac{\tanh \left(a\left(y-y_{i n}\right)\right)+\tanh \left(a y_{i n}\right)}{1+\tanh \left(a y_{i n}\right)}+b \sqrt{3}\left(\frac{y}{y_{i n}}\right) \exp \left[-1.5\left(\frac{y}{y_{i n}}\right)^{2}+0.5\right]
$$

Onde $y_{i n}$ é a altura do ponto de inflexão, $u_{e}$ é a velocidade do fluxo no bordo da camada limite, $b$ é a intensidade do fluxo reverso, $a$ é um parâmetro selecionado de forma a obter um valor unitário na espessura de momento $\theta$ da camada cisalhante.

Sendo assim, decidiu-se comparar os resultados obtidos na região de crescimento linear com um perfil deste tipo. A Figura 5.21 mostra que a intensidade do escoamento reverso aumenta a medida que a bolha cresce. No caso analisado essa intensidade ficou sempre abaixo de 10\%, mesmo nas regiões próximas ao recolamento, além disso nota-se uma excelente concordância entre os dados experimentais e a curva teórica, o que indica que o campo médio do escoamento no interior das bolhas foi de fato bem capturado.

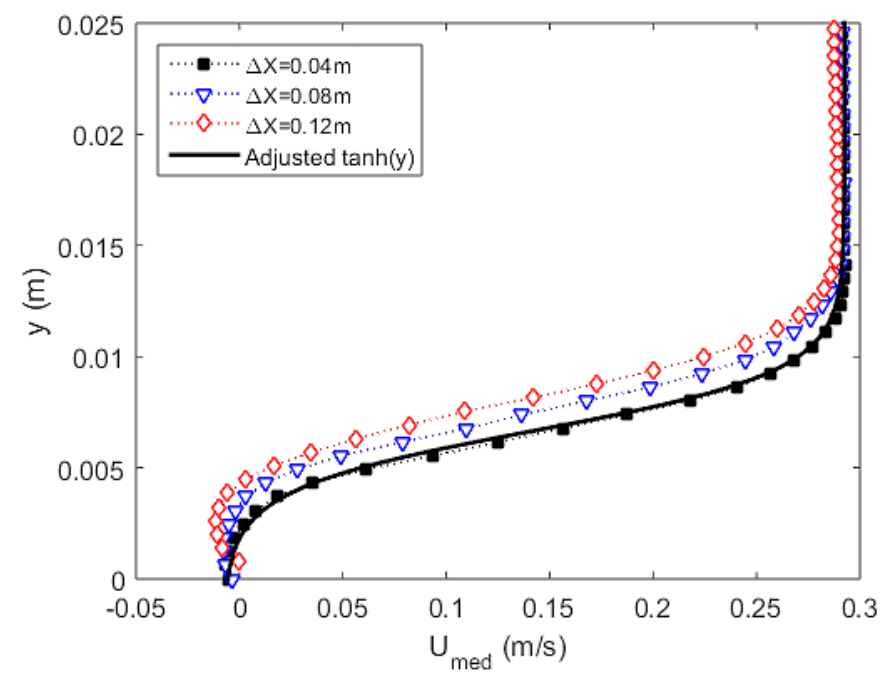

Figura 5.21 Perfis da componente de velocidade média U, em diferentes posições ao longo da bolha.

Para se avaliar a qualidade dos perfis de velocidade, comparou-se as derivadas dos perfis medidos com as derivadas do perfil tangente hiperbólica. Isso é importante caso se deseje utilizar os perfis medidos em simulações e análises de 
estabilidade. De acordo com a Figura 5.22(a), a primeira derivada do perfil se aproxima muito da curva teórica. Já a segunda derivada apresenta qualitativamente uma distribuição similar, mas diferenças significativas podem ser notadas. Ainda assim, julga-se que os perfis médios obtidos são de excelente qualidade, com exceção do primeiro ponto de medição do perfil na estação $\Delta \mathrm{X}=0.12 \mathrm{~m}$.

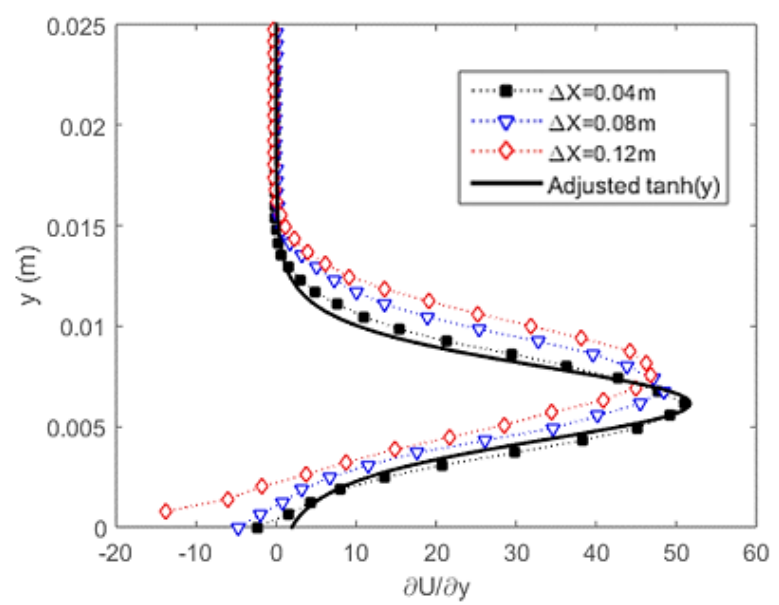

(a)

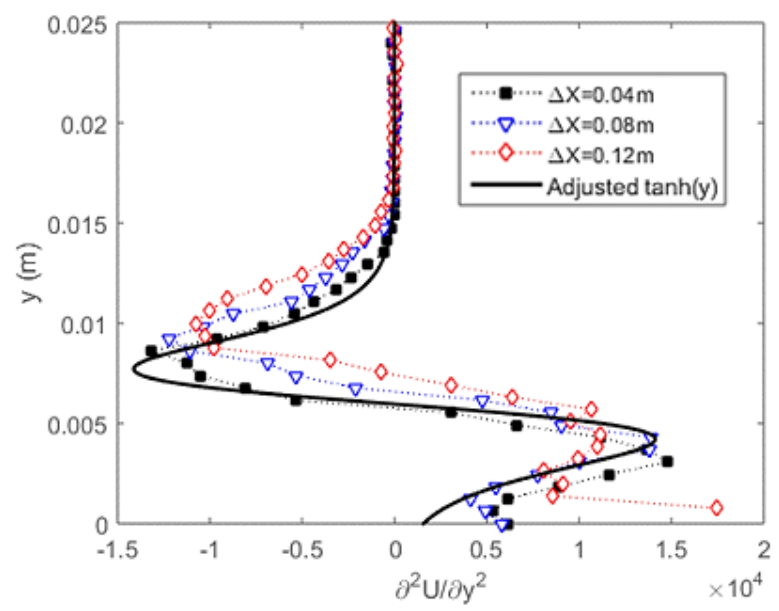

(b)

Figura 5.22 Derivada primeira (a) e segunda (b) do perfil de velocidade média U, em diferentes posições ao longo da bolha.

A densidade espectral de potência (PSD) das flutuações da velocidade extraídas nos pontos indicados anteriormente (ver figura 5.20) mostraram uma amplificação das perturbações numa faixa estreita de frequências. Como mostrado na figura 5.23. 


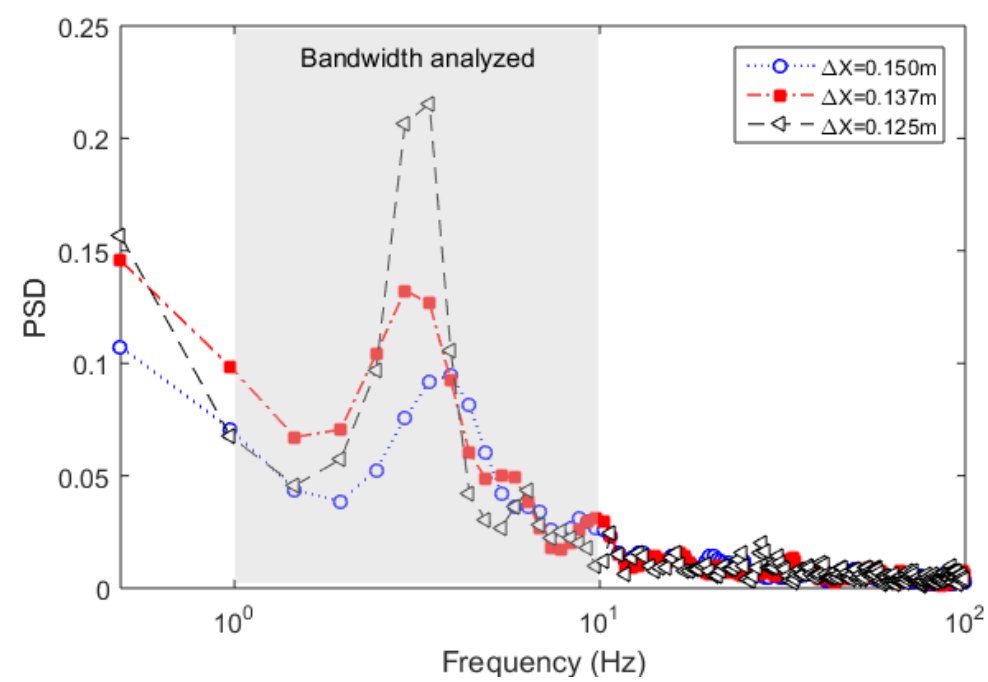

Figura 5.23 PSD das flutuações da velocidade em diferentes estações.

Para se analisar o comportamento dinâmico do escoamento na região de recolamento, utilizou-se a série temporal dos campos de velocidade. Uma técnica muito útil é conhecida como POD pelo termo em inglês Proper Orthogonal Decomposition. É uma ferramenta de correlação que decompõe uma série de realizações empíricas em uma base ortogonal ótima. O método é capaz de identificar padrões em uma série de dados. Uma revisão sobre a técnica é apresentada no trabalho de (Berkooz, et al., 1993).

A área cinza indicada na figura 5.23 mostra a faixa de frequências consideradas para a decomposição ortogonal própria. O analise POD mostrou que a energia contida em cada um dos dois primeiros modos apresentados na Figura 5.24 , é menor que $15 \%$ da energia total das flutuações, no entanto, representam a maior energia por modo.

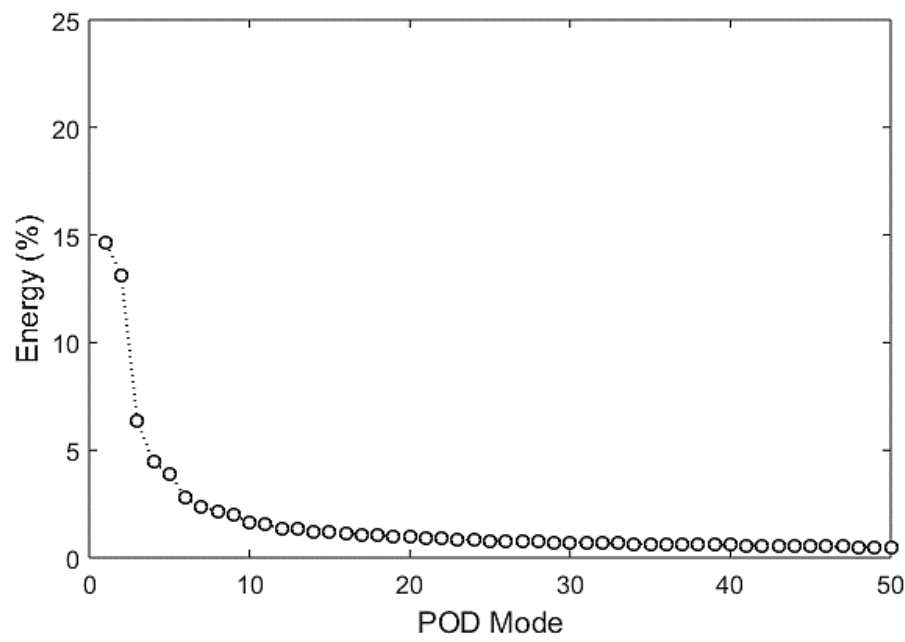

Figura 5.24 Distribuição de energia para diferentes modos 
Os modos POD da flutuação de velocidade na direção do escoamento e normal a parede são apresentados nas Figura 5.25. A análise é feita somente na região de recolamento da bolha. Os dois primeiros modos representam o mesmo tipo de estrutura e mostram um crescimento rápido de perturbações. Essas estruturas são frequentemente associadas com a instabilidade de Kelvin-Helmholtz (Lengani et al, 2014).
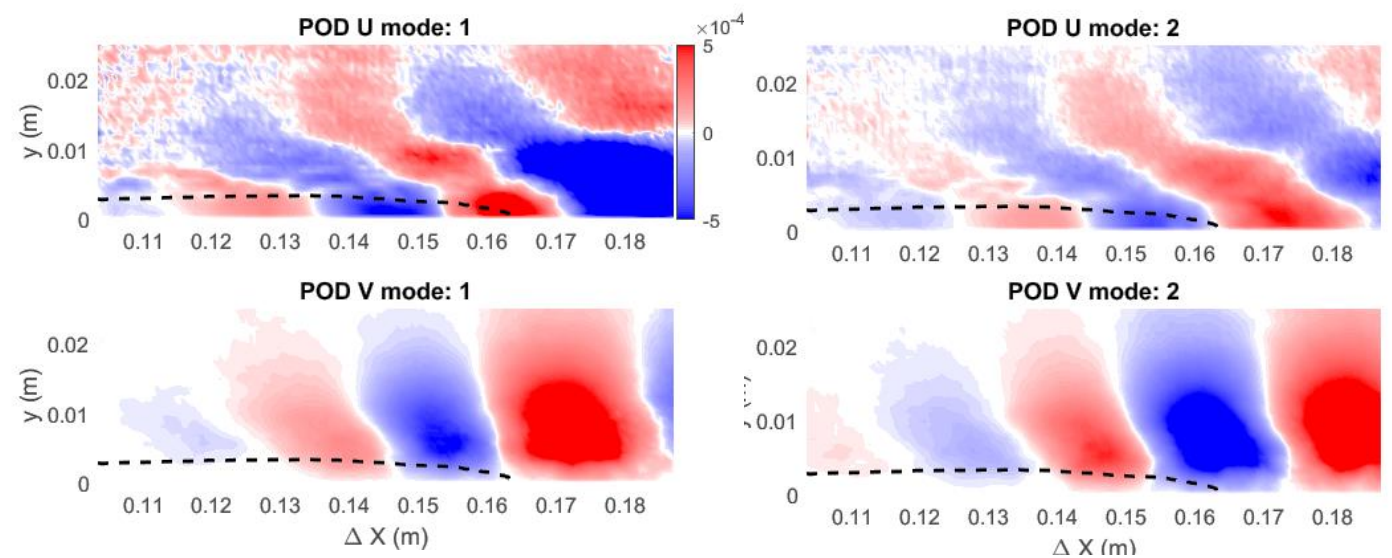

Figura 5.25 Modos POD do escoamento na região de recolamento da bolha

O comportamento de todos os modos do escoamento deve ser melhor analisado em investigações futuras. Neste trabalho buscou-se apenas avaliar se o comportamento da bolha gerada era compatível com o que se observa na literatura. Os resultados apresentados são satisfatórios e julga-se que o equipamento está pronto para estudos detalhados acerca da dinâmica de bolhas de separação. 


\section{6 \\ Conclusões e recomendações}

Este trabalho corresponde ao estágio inicial do projeto desenvolvido no laboratório de engenharia de fluidos da PUC-Rio que tem por objetivo geral o estudo do fenômeno de formação e evolução das bolhas de separação laminar.

Em particular este trabalho teve a responsabilidade de projetar, construir e avaliar os dispositivos e mecanismos necessários para a formação do fenômeno.

Inicialmente estes dispositivos foram projetados com ajuda de softwares comerciais de desenho e simulação numérica. Um parâmetro importante a ser avaliado através das simulações foram as vazões de sucção da camada limite na superfície divergente. A estimação inicial para os valores da sucção da camada limite foram baseados na compensação da queda de pressão ao longo da região de desaceleração do escoamento. As simulações sugeriram que as taxas de sucção eram superestimadas para alguns casos e que menores vazões do que aquelas inicialmente previstas poderiam ser utilizadas nos ensaios experimentais. Adicionalmente, foi desenhado um dispositivo gerador de perturbações para a excitação de perturbações na camada limite. $\mathrm{O}$ objetivo era criar uma ferramenta para disparar a transição do escoamento de maneira controlada.

Um segundo estágio do projeto, foi a construção e montagem de cada um dos dispositivos anteriormente mencionados, alguns deles foram construídos nas instalações da universidade e outros fora. Nesse estágio teve-se extremo cuidado com o acabamento das superfícies em contato com o escoamento para minimizar qualquer perturbação que pudesse antecipar a transição do escoamento.

O estágio final, foi o estágio de avaliação e qualificação dos dispositivos e equipamentos construídos. O trabalho nesse estágio foi subdividido em três partes. Na primeira, realizou-se a caracterização do escoamento sobre a placa plana. Para isto se utilizou a técnica LDV. Foram medidos perfis da componente média da velocidade na direção do escoamento. Esses perfis foram aquisitados em diferentes estações ao longo da placa. Mediu-se também o escoamento em um plano transversal a seção do canal. O objetivo nesse último era a avaliação da 
uniformidade do escoamento na direção transversal. A análise dos resultados mostrou que, no caso do escoamento não perturbado a camada limite se mantem laminar ao longo de todas as estações de medição. Os perfis medidos apresentaram excelente concordância com o perfil de Blasius. Esse comportamento também foi observado ao longo da direção transversal da placa, indicando que o escoamento era bidimensional. Os resultados obtidos com o gerador de perturbações ligado indicam que a medida que se desloca ao longo da placa, o perfil de velocidades tende aquele esperado para um escoamento turbulento.

A segunda parte foi a verificação do funcionamento do arranjo projetado para a sucção da camada limite na placa divergente. Os resultados das medições com a técnica PIV corroboram as previsões de projeto e validam a metodologia empregada.

Finalmente, utilizando a técnica PIV foi verificada a formação da bolha sobre a superfície da placa plana. Mediu-se o campo de velocidades na região da bolha, e foi possível identificar que uma bolha de aproximadamente $140 \mathrm{~mm}$ de comprimento e $5 \mathrm{~mm}$ de altura foi formada sobre a placa. Os perfis de velocidade no interior da bolha foram medidos e comparados com um perfil do tipo tangente hiperbólica. Essa função é muito empregada para modelar o escoamento base na região da bolha. Os resultados sugerem que o escoamento no interior da bolha foi bem capturado. A análise das estruturas do escoamento na região de recolamento da bolha também se mostraram compatíveis com que é reportado na literatura. Logo, pode-se concluir que o projeto do aparato para o estudo de bolhas de separação laminar foi concluído com êxito.

Para trabalhos futuros sugere-se a análise mais detalhada do escoamento na região da bolha. Para isso técnicas de PIV planar e estereoscópica podem ser empregadas. Sugere-se também um estudo comparativo com simulações numéricas e ferramentas de análise de instabilidade. É interessante também o estudo do comportamento transiente das bolhas, em casos onde a intensidade de turbulência do escoamento na camada limite varia periodicamente. 


\section{7 Referências bibliográficas}

Abrantes, J. K., de Paula, I. B., \& Azevedo, L. F. A. (2012). Medição de escoamentos turbulentos utilizando velocimetria por imagem de partículas. Capítulo, 5, 133-209.

Abu-Ghannam, B. J., \& Shaw, R. (1980). Natural transition of boundary layers the effects of turbulence, pressure gradient, and flow history. Journal of Mechanical Engineering Science, 22(5), 213-228.

Airbus, Global Market Forecast "Future Journeys 2013-2014" (2013)

Amitay, M., Smith, D. R., Kibens, V., Parekh, D. E., \& Glezer, A. (2001). Aerodynamic flow control over an unconventional airfoil using synthetic jet actuators. AIAA journal, 39(3), 361-370.

Andreas Eder, Bodo Durst, Martin Jordan. (2001). Optical Measurements techniques and Applications. Second edition. Cap. 8. Laser-Doppler Velocimetryprinciple and Application to Turbulence Measurements.

Arena, A. V., \& Mueller, T. J. (1980). Laminar separation, transition, and turbulent reattachment near the leading edge of airfoils. AIAA journal, 18(7), 747-753.

Arndt, R. E. A., \& Weitendorf, E. A. (1990). Hydromechanical Considerations in the Design of the New Cavitation Research Facility at the Hamburg Ship Model Basin. Schiffstechnik Bd, 37.

Berkooz, G., Holmes, P., \& Lumley, J. L. (1993). The proper orthogonal decomposition in the analysis of turbulent flows. Annual review of fluid mechanics, 25(1), 539-575.

Boiko, A. V., Dovgal, A. V., Kozlov, V. V., Simonov, O. A. \& Scherbakov, V. A. (1988). Laminar flow separation at 2D bumps in a boundary layer (Preprint No. $7-$ 88). Novosibirsk:RAS. Sib. Branch. Inst. Theoret. Applied Mech. (In Russian)

Boiko, A. V., Grek, G. R., Dovgal, A. V., Kozlov, V. V., \& Dowling, D. R. (2003). Origin of Turbulence in Near-Wall Flows. Applied Mechanics Reviews, 56, B13.

Braun, S., \& Kluwick, A. (2005). Blow-up and control of marginally separated boundary layers. Philosophical Transactions of the Royal Society of London A: Mathematical, Physical and Engineering Sciences, 363(1830), 1057-1067.

Brendel, M., \& Mueller, T. J. (1988). Boundary-layer measurements on an airfoil at low Reynolds numbers. Journal of aircraft, 25(7), 612-617.

Brossard, C., Monnier, J. C., Barricau, P., Vandernoot, F. X., Le Sant, Y., Champagnat, F., \& Le Besnerais, G. (2009). Principles and applications of particle image velocimetry. AerospaceLab, (1), p-1.

Carmichael, B. H. (1981). Low Reynolds number airfoil survey, volume 1. 
Chen, L. W. (2015). Application of PIV measurement techniques to study the characteristics of flame-acoustic wave interactions. Flow Measurement and Instrumentation, 45, 308-317.

Curtis, E. M., Hodson, H. P., Banieghbal, M. R., Denton, J. D., Howell, R. J., \& Harvey, N. W. (1997). Development of blade profiles for low-pressure turbine applications. Journal of Turbomachinery, 119(3), 531-538.

De Paula, I. B. (2006). Influência de uma rugosidade tridimensional isolada na transição de uma camada limite sem gradiente de pressão. Tese (Doutorado) Escola de Engenharia de São Carlos, Universidade de São Paulo, São Carlos.

Dovgal, A. V., Kozlov, V. V., \& Michalke, A. (1994). Laminar boundary layer separation: instability and associated phenomena. Progress in Aerospace Sciences, 30(1), 61-94.

Dovgal, A.V. and Kozlov, V.V. (1983b). Instability of flow separating from a wall with an inflexion. Dokl. Akad. Nauk: $270(6), 1356-1358$

Fernandes, L. S. (2017). Medição do Campo de Velocidade do Líquido no Escoamento Bifásico, Intermitente, em Duto Horizontal, Utilizando Velocimetria Estereoscópica (Master dissertation, PUC-Rio).

Fernández, U., Réthoré, P. E., Sørensen, N. N., Velte, C. M., Zahle, F., \& Egusquiza, E. (2012). Comparison of four different models of vortex generators. Proceedings of EWEA, 39.

Gaster, M. (1969). The structure and behaviour of laminar separation bubbles (pp. 1-32). HM Stationery Office.

GB Schubauer. (1947). Laminar boundary-layer oscillations and stability of laminar flow. Journal of the Aeronautical Sciences, 14(2), 69-78.

Hak M. Gad-el. Flow Control: Passive, Active, and Reactive Flow Management, Cambridge University Press, The Edinburgh Building, 421pp. ISBN 0-52177006-8.

Hatman, A., \& Wang, T. (1999). A prediction model for separated-flow transition. Journal of Turbomachinery, 121(3), 594-602.

He, W., Gioria, R., Pérez, J., \& Theofilis, V. (2017). Linear instability of low Reynolds number massively separated flow around three NACA airfoils. Journal of Fluid Mechanics, 811, 701-741. doi:10.1017/jfm.2016.778

Horton, H. P. (1969). A semi-empirical theory for the growth and bursting of laminar separation bubbles. HM Stationery Office.

Hourmouziadis, J. (1989). Aerodynamic design of low pressure turbines. AGARD, Blading Design for Axial Turbomachines 40 p(SEE N 89-27661 22-07).

Huerre, P., \& Monkewitz, P. A. (1985). Absolute and convective instabilities in free shear layers. Journal of Fluid Mechanics, 159, 151-168.

Jahanmiri, M. (2011). Aircraft Drag Reduction: An Overview. Chalmers University of Technology.

Jahanmiri, M. (2011). Particle image velocimetry: Fundamentals and its applications. Chalmers University of Technology. 
Joslin, R. D. (1998). Aircraft laminar flow control. Annual review of fluid mechanics, 30(1), 1-29

Kerho, M., Hutcherson, S., Blackwelder, R. F., \& Liebeck, R. H. (1993). Vortex generators used to control laminar separation bubbles. Journal of aircraft, 30(3), 315-319.

Kozlov, V. V. (1983). Influence of acoustic perturbations on the flow structure in a boundary layer with adverse pressure gradient. Fluid Dynamics, 18(2), 205-209.

Langtry, R.B., Menter, F.R., Likki, S.R., Suzen, Y.B., Huang, P.G., and Völker, S., "A Correlation based Transition Model using Local Variables Part 2 - Test Cases and Industrial Applications", ASME-GT2004-53454, ASME TURBO EXPO 2004, Vienna, Austria.

Lengani, D., Simoni, D., Ubaldi, M., \& Zunino, P. (2014). POD analysis of the unsteady behavior of a laminar separation bubble. Experimental Thermal and Fluid Science, 58, 70-79.

Lin, J. C., Robinson, S. K., McGhee, R. J., \& Valarezo, W. O. (1994). Separation control on high-lift airfoils via micro-vortex generators. Journal of aircraft, 31(6), $1317-1323$.

Lin, N., Reed, H. L., \& Saric, W. S. (1992). Effect of leading-edge geometry on boundary-layer receptivity to freestream sound. In Instability, Transition, and Turbulence (pp. 421-440). Springer, New York, NY.

Lissaman, P. B. S. (1983). Low-Reynolds-number airfoils. Annual Review of Fluid Mechanics, 15(1), 223-239.

Lou, W., \& Hourmouziadis, J. (2000, May). Separation bubbles under steady and periodic-unsteady main flow conditions. In ASME Turbo Expo 2000: Power for Land, Sea, and Air (pp. V003T01A075-V003T01A075). American Society of Mechanical Engineers.

Mack L. (1985). Boundary-Layer stability theory, special course on stability and transition of laminar flow, technical Report 709, AGARD

Maldonado, V., Boucher, M., Ostman, R., \& Amitay, M. (2009). Active Vibration Control of a Wind Turbine Blade Using Synthetic Jets. International Journal of Flow Control, 1(4).

Malkiel, E., \& Mayle, R. E. (1995, June). Transition in a separation bubble. In ASME 1995 International Gas Turbine and Aeroengine Congress and Exposition (pp. V001T01A003-V001T01A003). American Society of Mechanical Engineers.

Martinstetter, M., Niehuis, R., \& Franke, M. (2010, October). Passive boundary layer control on a highly loaded low pressure turbine cascade. In ASME Turbo Expo 2010: Power for Land, Sea, and Air (pp. 1315-1326). American Society of Mechanical Engineers.

Mayle, R. E. (1991). The 1991 igti scholar lecture: The role of laminar-turbulent transition in gas turbine engines. Journal of Turbomachinery, 113(4), 509-536.

McAuliffe, B. R., \& Yaras, M. I. (2005, January). Separation-bubble-transition measurements on a low-Re airfoil using particle image velocimetry. In ASME 
Turbo Expo 2005: Power for Land, Sea, and Air (pp. 1029-1038). American Society of Mechanical Engineers.

McCormick, D. (2000, January). Boundary layer separation control with directed synthetic jets. In 38th Aerospace Sciences Meeting and Exhibit (p. 519).

Menter, F.R., Langtry, R.B., Likki, S.R., Suzen, Y.B., Huang, P.G., and Völker, S., "A Correlation based Transition Model using Local Variables Part 1- Model Formulation", ASME-GT2004-53452, ASME TURBO EXPO 2004, Vienna, Austria.

Milanovic, I. M., \& Zaman, K. B. (2005). Synthetic jets in cross-flow. AIAA journal, 43(5), 929-940.

Mittal, R., Rampunggoon, P., \& Udaykumar, H. (2001). Interaction of a synthetic jet with a flat plate boundary layer. In 15th AIAA Computational Fluid Dynamics Conference (p. 2773)

Morkovin, M. V. (1969). On the many faces of transition. In Viscous, drag reduction (pp. 1-31). Springer, Boston, MA.

Pauley, L. L., Moin, P., \& Reynolds, W. C. (1990). The structure of twodimensional separation. Journal of Fluid Mechanics, 220, 397-411.

Raffel, M., Willert, C. E., \& Kompenhans, J. (2007). Particle image velocimetry: a practical guide. Springer Science \& Business Media.

Reed, H. L., \& Saric, W. S. (1989). Stability of three-dimensional boundary layers. Annual Review of Fluid Mechanics, 21(1), 235-284.

Rodríguez, D., Gennaro, E., \& Juniper, M. (2013). The two classes of primary modal instability in laminar separation bubbles. Journal of Fluid Mechanics, 734, R4. doi:10.1017/jfm.2013.504

Russell, J. M. (1979). Length and bursting of separation bubbles: A physical interpretation.[of pressure distribution]. In NASA. Langley Res Science and technology of low speed and motorless flight, Pt. 1, p 177-202 (SEE N79-23889 15-01)

Sandham, N. D. (2008). Transitional separation bubbles and unsteady aspects of aerofoil stall. The Aeronautical Journal, 112(1133), 395-404.

Schaeffler, N. W., \& Jenkins, L. N. (2006). Isolated synthetic jet in crossflow: experimental protocols for a validation dataset. AIAA journal, 44(12), 2846-2856.

Schlichting, H. 1979 Boundary Layer Theory, 7th edn. McGraw Hill

Schubauer, G. B., \& Klebanoff, P. S. (1955). Contributions on the mechanics of boundary-layer transition.

Serna, J., \& Lázaro, B. J. (2014). The final stages of transition and the reattachment region in transitional separation bubbles. Experiments in fluids, 55(4), 1695.

Serna, J., \& Lázaro, B. J. (2015). On the laminar region and the initial stages of transition in transitional separation bubbles. European Journal of MechanicsB/Fluids, 49, 171-183.

Sharma, O. (1998, June). Impact of Reynolds number on LP turbine performance. In Proc. of 1997 Minnowbrook II Workshop on Boundary Layer Transition in Turbomachines. 
Smith, B. L., \& Glezer, A. (2005). Vectoring of adjacent synthetic jets. AIAA journal, 43(10), 2117-2124.

Squire, H. B. (1933). On the stability for three-dimensional disturbances of viscous fluid flow between parallel walls. Proceedings of the Royal Society of London. Series A, Mathematical and Physical Sciences, 142(847), 621-628.

Stalnov, O., Kribus, A., \& Seifert, A. (2010). Evaluation of active flow control applied to wind turbine blade section. Journal of Renewable and Sustainable Energy, 2(6), 063101.

Stratford, B. S., \& Gadd, G. E. (1954). Flow in the laminar boundary layer near separation (Doctoral dissertation, Department of Aerodynamics (Potential Flow \& Boundary Layers), Imperial College London).

T. van der Hoeven, Slot suction in the turbulent boundary layer, Master's thesis, TU Delft, Delft University of Technology, Delft (2013).

Tani, I. (1964). Low speed flows involving separation bubbles. Progress in Aeronautical Sciences, 5(2), 70-103.

Tornblom, O. (2004). Introduction course in particle image velocimetry. Course Introductory Material: STEM Project, KTH, Department of Mechanics, Stockholm Sweden.

Tuck, A., \& Soria, J. (2004, December). Active flow control over a NACA 0015 airfoil using a ZNMF jet. In 15th Australasian fluid mechanics conference (pp. 13-17).

Volino, R. J. (2003, January). Passive flow control on low-pressure turbine airfoils. In ASME Turbo Expo 2003, collocated with the 2003 International Joint Power Generation Conference (pp. 833-844). American Society of Mechanical Engineers.

Wakelam, C. T., Hoeger, M., \& Niehuis, R. (2013). A comparison of three low pressure turbine designs. Journal of Turbomachinery, 135(5), 051026. 